\title{
Capillary Electrophoresis Analysis of Proteins using Phospholipid Based Materials
}

\author{
Cassandra L. Crihfield \\ West Virginia University, clcrihfield@mix.wvu.edu
}

Follow this and additional works at: https://researchrepository.wvu.edu/etd

Part of the Analytical Chemistry Commons

\section{Recommended Citation}

Crihfield, Cassandra L., "Capillary Electrophoresis Analysis of Proteins using Phospholipid Based Materials" (2020). Graduate Theses, Dissertations, and Problem Reports. 7833.

https://researchrepository.wvu.edu/etd/7833

This Dissertation is protected by copyright and/or related rights. It has been brought to you by the The Research Repository @ WVU with permission from the rights-holder(s). You are free to use this Dissertation in any way that is permitted by the copyright and related rights legislation that applies to your use. For other uses you must obtain permission from the rights-holder(s) directly, unless additional rights are indicated by a Creative Commons license in the record and/ or on the work itself. This Dissertation has been accepted for inclusion in WVU Graduate Theses, Dissertations, and Problem Reports collection by an authorized administrator of The Research Repository @ WVU.

For more information, please contact researchrepository@mail.wvu.edu. 
Capillary Electrophoresis Analysis of Proteins using Novel

Phospholipid Based Materials

Cassandra Crihfield

Dissertation submitted to the Eberly College of Arts and Sciences at West Virginia University in partial fulfillment of the requirements for the degree of

\author{
Doctor of Philosophy \\ in \\ Chemistry
}

\author{
Lisa A. Holland, Ph.D., Committee Chair \\ Harry O. Finklea, Ph.D. \\ Stephen J. Valentine, Ph.D. \\ Peng Li, Ph.D. \\ Jeremy Dawson, Ph.D. \\ Jennifer E. Gallagher, Ph.D.
}

Chemistry Department

Morgantown, West Virginia

2020

Keywords: Capillary Electrophoresis, Proteins, Phospholipid, DMPC, DHPC Copyright 2020 Crihfield 


\section{Abstract \\ Capillary Electrophoresis Analysis of Proteins using Novel}

Phospholipid Based Materials

\section{Cassandra Crihfield}

Capillary electrophoresis has many advantages that make it a powerful technique for the analysis of proteins, which is challenging due to the natural heterogeneity of proteins. The small sample volume required for each analysis (nano- and pico-liter), fast separation times ( $<30 \mathrm{~min}$ ), and ability to couple the separation to mass spectrometry are all factors that make capillary electrophoresis an ideal technology for protein separations. Capillary zone electrophoresis and capillary gel electrophoresis are the two most commonly employed modes for protein analysis and allow for rapid, high resolution separations that can be automated. This makes capillary electrophoresis ideal for meeting the needs of protein analyses in the biopharmaceutical and clinical fields. Still, methods are continually improving in order to address the challenges of analyzing these samples with capillary electrophoresis, such as adsorption to the capillary wall, heterogeneity due to multiple isoforms, and maintaining native structure through analysis. The work presented utilized a coating and/or sieving matrix composed of the phospholipids 1,2-dimyristoyl-snglycero-3-phosphocholine (DMPC) and 1,2-dihexanoyl-sn-glycero-3-phosphocholine (DHPC) to confront these needs. The phospholipids lead to reduced adsorption and enhanced resolution that can be tuned with temperature. Furthermore, the phospholipids have been shown to support and enhance protein function and lifetime in-capillary, which makes the material promising for native analyses of proteins in the future.

The phospholipids were the basis of a hybrid coating using cetyltrimethylammonium bromide (CTAB) that enabled simultaneous separation of acidic and basic proteins. The semi-permanent coating cost less than $\$ 0.10$ to apply to a traditional silica capillary, and unlike previously published work, the ability to analyze both basic and acidic proteins using the phospholipid-cetyltrimethylammonium bromide (CTAB coating) without requiring the use of low $\mathrm{pH}$ buffers that lead to denaturing proteins. The phospholipid coating reduced protein adsorption compared to bare fused silica; however, it also suppressed and reversed the electroosmotic flow. This led to acidic proteins being analyzed in one polarity while basic proteins were analyzed in another polarity. Incorporating the cetyltrimethylammonium bromide (CTAB) into the phospholipid coat generated sufficient electroosmotic flow for simultaneous analysis of both acidic and basic proteins. The coating was stable through extensive flushing and exhibited no protein adsorption through six consecutive analyses with no flushing in between. The coating was applied to the analysis of abundant proteins in human serum and the accurate quantification further demonstrates the lack of interaction between the surface and the proteins.

For the first time, the phospholipid nanogel was utilized to add a size-based component to separation mechanism of proteins. The phospholipid nanogel cost $\$ 0.14$ per $5 \mu \mathrm{L}$, which is less than commercial matrices currently available, and when used in-capillary as described in this paper, the matrix utilized for one sample is only $\$ 0.04$. Furthermore, the thermally-responsive viscosity of the nanogel makes it a more user-friendly material than 
traditional gels since it can be inserted into the capillary similarly to buffers at temperatures below $24^{\circ} \mathrm{C}$ without the requirement of high pressures or chemical measures for cross-linking in-capillary that can lead to non-uniform matrices. The temperature is then raised to create a gel-like matrix for the separation. As demonstrated in prior work with DNA, the concentration of the nanogel can be utilized to tune the resolution to the size range of the analytes of interest, so the concentration used is determined by the mass range relevant to the analyte. Because the application of this material for the separation of proteins is novel, the separation mechanism is investigated with focus being placed on the impact of phospholipid concentration. A size-based component is superimposed on the preexisting charge-to-size ratio mechanism using the phospholipid. This leads to enhanced the resolution of proteins in human serum and allows for the accurate quantification of the proteins using external standards. 


\section{Dedication}

In honor of my dad Jack L. Crihfield and stepmom Carol A. Price, who always urged me to be the best version of myself possible, to strive for high achievements, to always move forward, and to find happiness. Their love and support of me is never ending, despite the sacrifices they often made to ensure I chased the opportunities presented. I can never express how grateful I was to have them as parents, as they helped make everything I have achieved possible.

I also dedicate this dissertation to my brothers and sisters, Jason, Brian, Jack, Judy, April, and Tina, to their families, to my aunts and uncles, and to my friends. My family has been an immense source of inspiration, support, love, and motivation throughout my entire life, especially over the last year. This, as well as my family's commitment to keeping my mom's memory alive for me, has greatly aided in forming who I am. I have been blessed with many people in my life, guidance counsellors, teachers, professors, friends, etc., who saw my potential before I could and pushed me in the right direction, especially Nancy Cumberledge, who was always cheering me forward. Finally, pushing through this year may never have happened without the support of James Edwards, who helped me laugh when the only other option was crying, made me work on this dissertation when my anxiety felt unbearable, and reminded me it is okay to enjoy life when it was time to put down work. 


\section{Acknowledgements}

I want to recognize my research advisor Dr. Lisa Holland for her continuous support from my time in her lab as a summer undergraduate researcher through the entire duration of my Ph.D. research. I am sincerely grateful for the opportunities she made possible, as well as the challenges that aided in my professional development. Her belief in my ability to succeed and encouragement to always aim for better has benefited me greatly both as a researcher and a person. Her ability to work alongside us into late nights and her dedication to ensuring every student had a chance to succeed despite her incredible schedule was a constant inspiration.

I would like to thank the rest of my graduate committee: Dr. Harry O. Finklea, Dr. Stephen J. Valentine, Dr. Peng Li, Dr. Jeremy Dawson, and Dr. Jennifer Gallagher for their investment in my graduate career, either through classes, examinations, and seminars or through interdisciplinary research team meetings and IGERT meetings. I also want to extend my sincere appreciation for their time, patience, and insight into my dissertation.

My sincere gratitude goes to Dr. Kim Quedado for her constant aid in my professional training and for the enthusiasm she showed for the success of all the IGERT fellows with whom she worked. Her willingness to listen and her advice on getting through the hard times to achieve goals will not be forgotten.

Finally, for all the advice about the graduate program, for all the nights worked in lab, for the late night phone calls about data and experiments, for being team members that made hard things just a little easier, I thank my fellow labmates (past and present): Lloyd Bwanali, Courtney Kristoff, Lindsay Veltri, William Penny, Gayatri Gautam, Grace Lu, Srikanth Gattu, Tyler Davis, Brandon Durney, Patrick Russo, Ebenezer Newton, Marriah Ellington, and Vincent Nyakubaya. 


\section{Table of Contents}

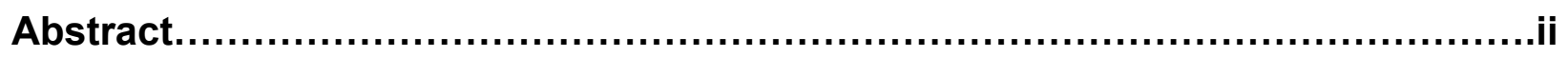

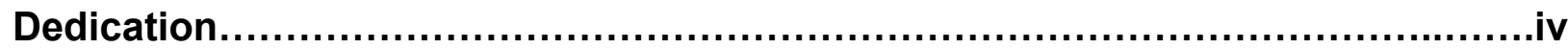

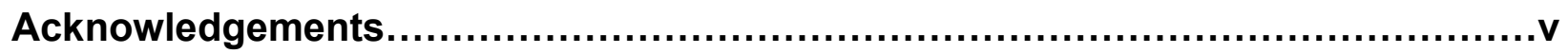

Table of Contents................................................................................

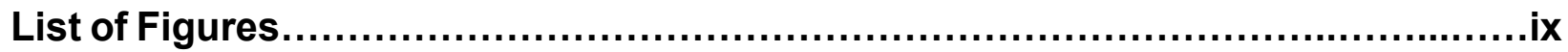

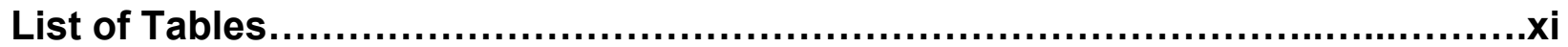

List of Nomenclature and Abbreviations..............................................xii

Chapter 1: Introduction to capillary electrophoresis separations of proteins..........1

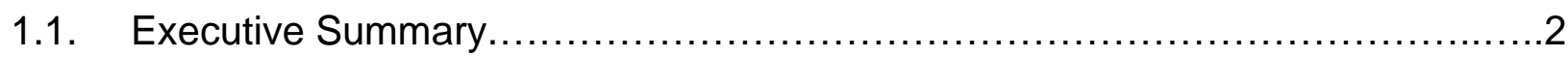

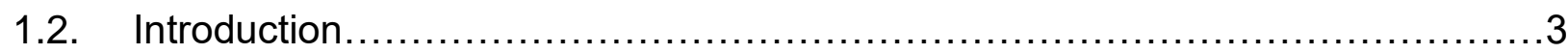

1.3. Capillary Zone Electrophoresis..................................................

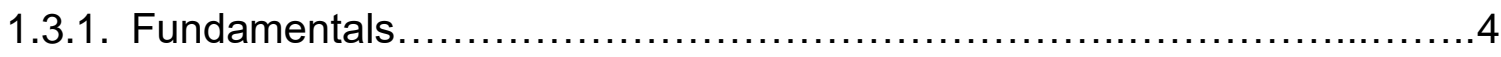

1.3.2. Capillary coatings for capillary zone electrophoresis ......................10

1.3.3. Permanent coatings for capillary electrophoresis......................... 10

1.3.4. Dynamic coatings for capillary electrophoresis........................... 12

1.3.5. Semi-permanent coatings for capillary electrophoresis....................12

1.4. Capillary gel electrophoresis ...................................................... 14

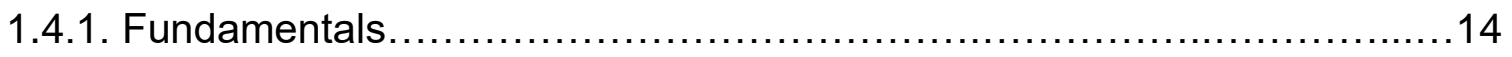

1.4.2. Capillary gel electrophoresis materials ..................................14

1.5. Prior use of phospholipids as separation materials ................................... 15

1.6. Novel phospholipid-CTAB hybrid coating for protein separations.....................18

1.7. Phospholipid nanogel for protein separations..................................... 19

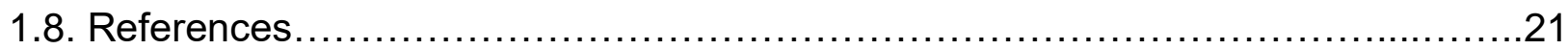

Chapter 2: Semi-permanent cationic coating for protein separations.................26

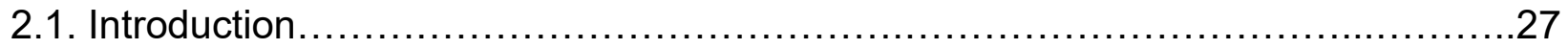

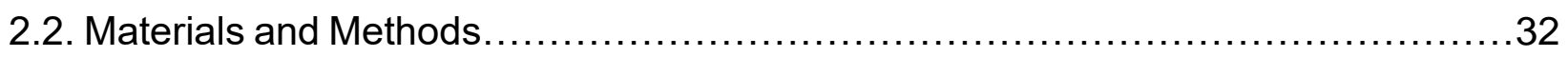

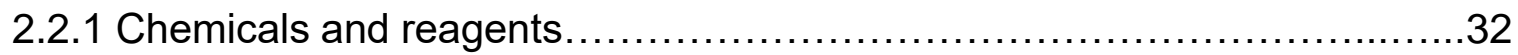


2.2.2 Preparation of Phospholipid and CTAB solutions..........................32

2.2.3 Capillary Electrophoresis................................................

2.2.4 Preparation of bare fused silica capillaries.................................34

2.2.5 Preparation of the phospholipid coated capillaries..........................34

2.2.6 Preparation of the phospholipid-CTAB coated capillaries...................35

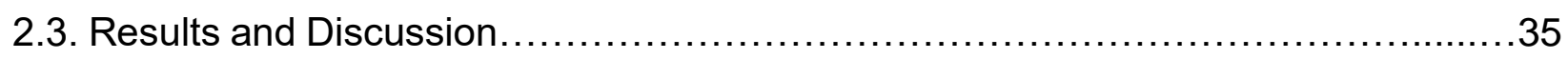

2.3.1 Bare fused silica analyses ...................................................

2.3.2 Phospholipid coated analyses........................................ 37

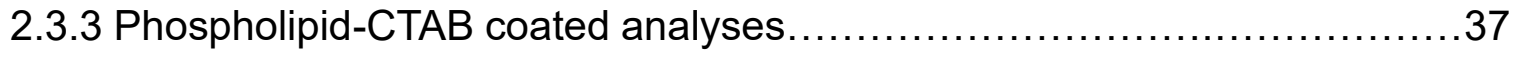

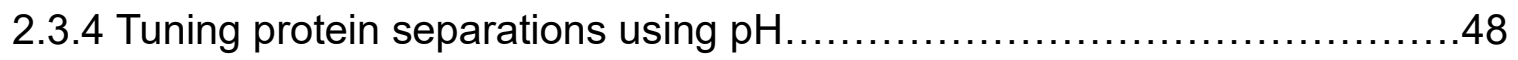

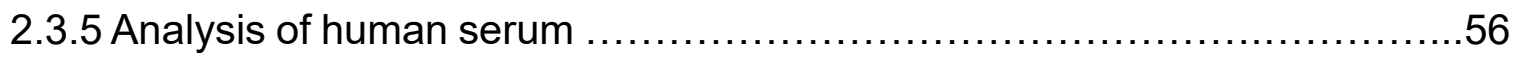

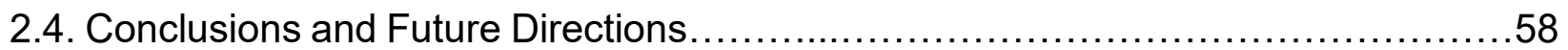

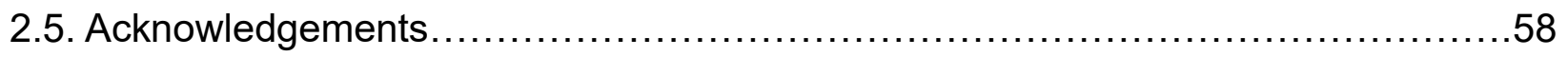

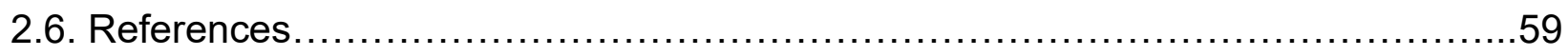

Chapter 3: Size-based capillary electrophoresis separations of proteins using

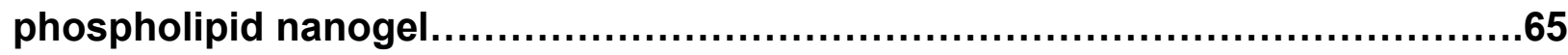

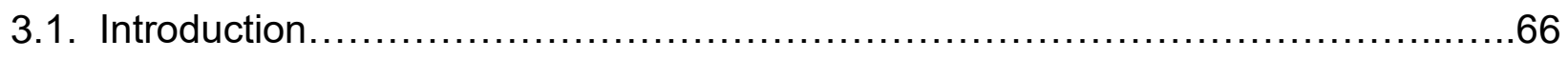

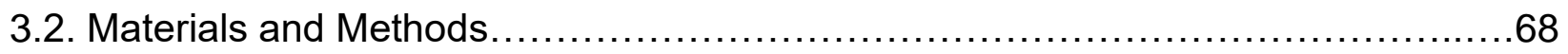

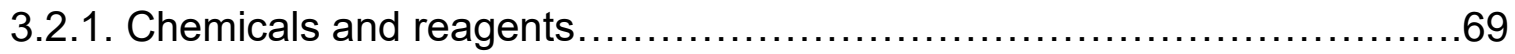

3.2.2. Preparations of buffers and phospholipids.................................69

3.2.3 Preparation of standards and samples.................................69

3.2.4. Capillary electrophoresis methods.....................................69

3.2.5. Electroosmotic flow measurements.......................................70

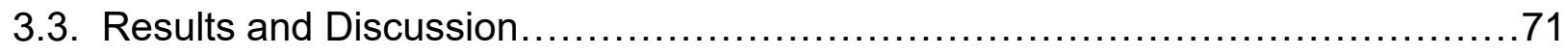

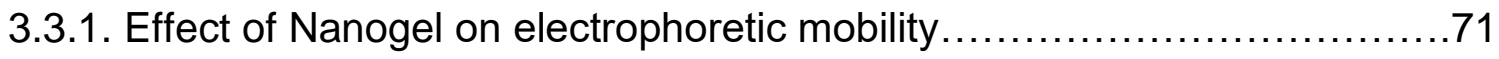

3.3.2. Separation figure of merit obtained for sieving ...........................75

3.3.3. Effect of nanogel concentration on protein sieving .........................79 
3.3.4. Quantification of human serum proteins using nanogel.................... 85

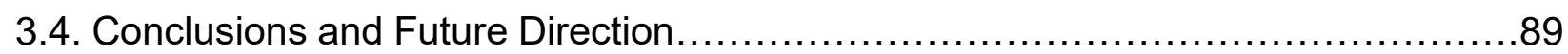

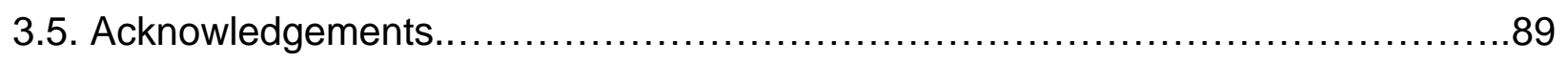

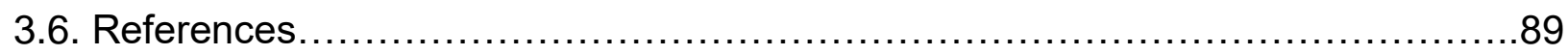

Chapter 4: Future Directions.........................................................93

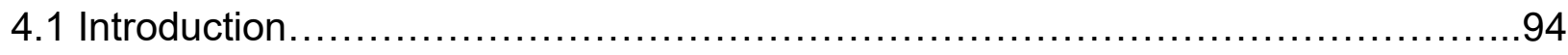

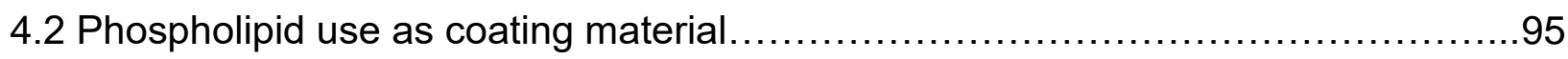

4.3 Phospholipid use as a protein separation matrix....................................96

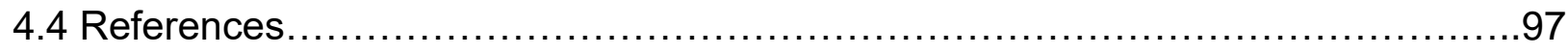

Appendix 1 Supporting Experiments for Chapters 2 and 3.........................99

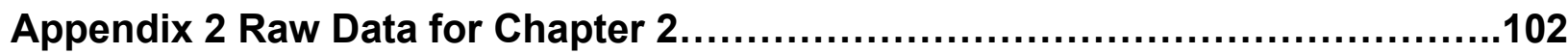

Appendix 3 Raw Data for Chapter 3 ....................................................114

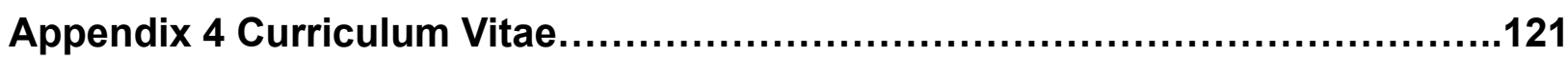




\section{List of Figures}

Figure 1-1. Depiction of analyte migration in a capillary electrophoresis separation utilizing unmodified bare fused silica.

Figure 1-2. Depiction of analyte migration in a capillary electrophoresis separation utilizing a neutral coated capillary.

Figure 1-3. Depiction of analyte migration in a capillary electrophoresis separation utilizing a cationic coated capillary. .11

Figure 1-4. Structure of 1,2-dimyristoyl-sn-glycero-3-phosphocholine (DMPC) (A) and 1,2-dihexanoyl-sn-glycero-3-phosphocholine (DHPC) (B). 17

Figure 2-1. Bare fused silica and phospholipid coated separations of proteins. 36

Figure 2-2 Electroosmotic flow and ribonuclease $A$ mobility measurements in phospholipid coated capillary 38

Figure 2-3. The electroosmotic flow for a phospholipid coated capillary (A) for phospholipid capillary coated with the tetramethyl ammonium bromide head group ( $\mathrm{HG})$ of CTAB (B) and for phospholipid capillary coated with CTAB ........................40 Figure 2-4. Phospholipid-CTAB coated surface and separation .........................46 Figure 2-5. Consecutive analyses of $\alpha-1$-antitrypsin, neutral marker (DMF), and lysozyme on phospholipid-CTAB coated capillary.

Figure 2-6. Compatibility of the phospholipid-CTAB coated capillary with background electrolyte buffered to a $\mathrm{pH}$ ranging from 4 to 8 . .52

Figure 2-7. Analysis of human serum using the phospholipid-CTAB coated capillary....55 Figure 2-8. An electropherogram of a 6 protein mixture obtained using a phospholipidCTAB coated fused silica capillary and ammonium acetate. .57

Figure 3-1. Separation of trypsin inhibitor and alpha-1-antitrypsin across $\mathrm{pH}$ values.....73 Figure $3-2$. Identification of proteins using $25 \%$ nanogel............................. 74

Figure 3-3. Comparison of non-sieving and sieving separations.......................77

Figure 3-4. Ferguson plot for proteins analyzed using phospholipid nanogel............82

Figure 3-5. Plot of the retardation versus molecular size $-20-30 \%$ nanogel.............83

Figure 3-6. Plot of the retardation versus molecular size - $0-20 \%$ nanogel...........84

Figure 3-7. Separation of human serum using the free solution capillary electrophoresis (A) or sieving (B) .86 
Figure 3-8. External calibration curves used for quantifying alpha-1-acid glycoprotein (AGP), alpha-1-antitrypsin (AAT), and transferrin in human serum.....................87 


\section{List of Tables}

Table 1-1. Attributes of techniques commonly used for protein separations ..............5

Table 1-2. Commercially available coated capillaries and the cost......................13

Table 2-1. Semi-permanent coatings developed for protein separations..............29

Table 2-2. Impact of capillary surface on efficiency....................................... 39

Table 2-3. Impact of CTAB concentration on electroosmotic flow.......................42

Table 2-4. Impact of buffer flush time on electroosmotic flow...........................43

Table 2-5. Impact of $\mathrm{pH}$ on electroosmotic flow......................................... 44

Table 2-6. Effect of $\mathrm{pH}$ on mobility ................................................... 49

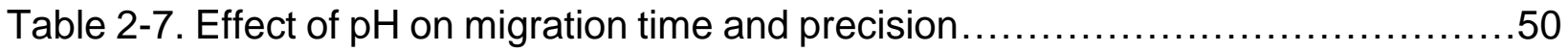

Table 2-8. Impact of capillary length on plates/meter..................................51

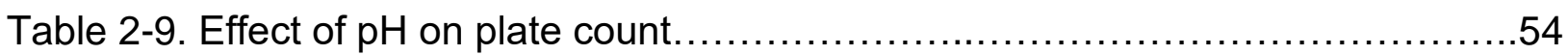

Table 3-1. Analyte characteristics and mobilities in buffer and nanogel buffer.............78

Table 3-2. Effect of percent nanogel on protein mobility ............................... 80

Table 3-3. Linear regression figures for mobilities across nanogel concentrations.........81 


\section{List of Nomenclature and Abbreviations}

$\begin{array}{ll}\text { CE } & \text { Capillary Electrophoresis } \\ \text { EOF } & \text { Electroosmotic Flow } \\ \text { Eph } & \text { Electrophoretic } \\ \mu_{a p p} & \text { Apparent mobility } \\ \mu_{\text {eph }} & \text { Electrophoretic Mobility } \\ q & \text { Charge of the ion } \\ \eta & \text { Viscosity } \\ r & \text { Radius of the ion } \\ \text { UV } & \text { Ultraviolet } \\ \text { DMPC } & 1,2 \text {-dimyristoyl-sn-glycero-3-phosphocholine } \\ \text { DHPC } & 1,2 \text {-dihexanoyl-sn-glycero-3-phosphocholine } \\ \text { CTAB } & \text { Cetyltrimethylammonium bromide } \\ \text { MS } & \text { Mass spectrometry } \\ \text { SDS } & \text { Sodium dodecyl sulfate } \\ \text { AAT; A } & \text { Alpha-1-antitrypsin } \\ \text { Tf; T } & \text { Transferrin } \\ \text { Enol; E } & \text { Enolase } \\ \text { RNAse; R } & \text { Ribonuclease A } \\ \text { Chymo; } & \text { Alpha-1-chymotrypsinogen } \\ \text { Lys; } L & \text { Lysozyme } \\ \text { DMF } & \text { Dimethylformamide } \\ \text { HG } & \text { Head group } \\ \text { TI } & \text { Trypsin inhibitor } \\ \text { AGP } & \text { Alpha-1-acid glycoprotein } \\ \text { IgG } & \text { Immunoglobulin G } \\ \end{array}$




\section{Chapter 1: Introduction to capillary electrophoresis separations of proteins Specific Aims:}

1. Develop a semi-permanent coating for capillary electrophoresis separations of proteins.

a. Simultaneous separation of acidic and basic proteins

b. Easy, self assembling modification process

c. Low cost (\$0.05 per coat)

d. Reduce protein adsorption

e. Generate EOF across $\mathrm{pH}$ values

f. Accurate analysis of human serum proteins with standard addition

2. Capillary gel electrophoresis protein separations using phospholipid nanogels

a. Size-based separations of proteins using phospholipid nanogels

b. Thermally-dependent viscosity for easy introduction in-capillary

c. Low cost ( $\$ 0.14$ per $5 \mu \mathrm{L} ; \$ 0.04$ per analysis)

d. Determination of the transition of the separation into a sieving mechanism

e. Accurate quantification of human serum proteins with external calibration 


\subsection{Executive Summary}

The research described in this dissertation was centered on the development of new analytical techniques for analyzing proteins using two commonly employed modes of capillary electrophoresis: capillary zone electrophoresis and capillary gel electrophoresis. The fundamentals of these two modes of capillary electrophoresis, as well as current materials used for these modes are described in chapter one. The first aim of the research, which is discussed fully in chapter 2 , was to address the need for a coating that reduces protein adsorption to the capillary surface while still allowing simultaneous detection of basic (cationic at $\mathrm{pH}$ 7) and acidic (anionic at $\mathrm{pH}$ 7) proteins. The second aim of the research, detailed in chapter 3 , was to present a new, cost-effective material for protein sieving that addresses many of the limitations of currently employed matrix materials, such as requirements of high pressure systems for introduction, non-uniform pore sizes, and limited useful lifetime.

Aim 1 created a coating through the interaction of the phospholipid with the surfactant cetyltrimethylammonium bromide $(\mathrm{CTAB})$ to enable low protein adsorption while still maintaining electroosmotic flow. The main benefits are low adsorption, stable electroosmotic flow regardless of $\mathrm{pH}$, ease of application, and cost effectiveness. The phospholipid-CTAB coating improved peak asymmetry and decreased interactions of the proteins, especially cations, with the surface when compared to traditional bare-fused silica surfaces. Lack of protein adsorption was further demonstrated through consistent migration times $(<1 \% \mathrm{RSD})$ when proteins were analyzed without flushing between analyses. The electroosmotic flow was stable regardless of harsh flushing (2 hours) using a buffer void of the modification reagent and was stable across a range of $\mathrm{pH}$ values. The application of this coating is user-friendly as it does not require covalent chemistry and instead harnesses the self-assembly of the phospholipid on the capillary surface followed by the hydrophobic interaction between the surfactant and the phospholipid. Additionally, the materials are inexpensive and cost less than $\$ 0.10$ to apply to a silica capillary. The coating was utilized for the analysis of proteins in a human serum sample and allowed for accurate quantification of abundant proteins using standard addition. 
Aim 2 presents phospholipid nanogels as a material for separating proteins in-capillary based on size. As a sieving matrix, this material poses advantages such as thermallyresponsive viscosity and low cost. Traditional gels require the use of high pressure systems for the introduction and removal from capillaries, and while some gels can be introduced at lower pressures, these matrices often require chemistry in-capillary that can lead to pores that are either difficult to reproduce or non-uniform. The thermallyresponsive viscosity enables phospholipid nanogel to be easily introduced and removed from the capillary at the same pressures as aqueous buffers at $19^{\circ} \mathrm{C}$, while selfassembling to form an ideal sieving matrix at $27^{\circ} \mathrm{C}$. Furthermore, the material is costeffective, requiring only $\$ 0.04$ worth of material per run. Aim 2 research assesses the qualities of the phospholipid nanogel by first demonstrating the transition of the separation from strictly charge-to-size ratio to size-based in relation to the concentration of the nanogel. The enhanced resolution resulting from the nanogel sieving is harnessed to quantify proteins in human serum using external calibration curves.

\subsection{Introduction}

Protein analysis is paramount to medical diagnostics, pharmaceutical fields, and fundamental research. Proteins are involved in many physiological functions in the body including nutrient transport, enzymatic catalysis, immune response, etc. Therefore when disease sets in, protein function [1], structure [2,3], and concentration [4, 5] may be altered either as a cause or a result of the disease. This has led to several proteins becoming biomarkers approved by the food and drug administration for use in the clinics, such as fibrinogen, albumin, and $\beta$-2-microglobulin [6], and many more remain under investigation $[7,8]$. The biopharmaceutical industry, which contributed $\$ 1.3$ trillion to the United States economic output in 2015 [9], is heavily dependent on the analysis of proteins to ensure products are pure and have the same efficacy lot-to-lot. Proteins essential to the biopharmaceutical industry include but are not limited to antibodies and fusion proteins and have been utilized in applications such as cancer therapies [10,11] and vaccines [12]. As these fields develop, more biomarkers are discovered, and essential drugs 
become more complex, analytical methods capable of rapid, accurate analysis easily tailored to the proteins of interest become more critical.

Capillary electrophoresis is a powerful tool for protein analysis. Table 1-1 summarizes the attributes of some of the most frequently employed techniques for protein separations, including capillary electrophoresis (CE), polyacrylamide gel electrophoresis (PAGE), reverse phase liquid chromatography (RPLC), size exclusion chromatography (SEC), and ion exchange mobility. As indicated by the table, capillary electrophoresis utilizes minimal amount of sample per analysis while still allowing for coupling to mass spectrometry, maintaining protein structure, and separating positive and negative species simultaneously. In addition to these qualities, capillary electrophoresis also boasts high resolution, automation capability, and the potential to run multiple capillaries at the same time. Capillary electrophoresis methods are predominantly capillary zone electrophoresis (only aqueous running buffer in the capillary) or capillary gel electrophoresis, which incorporates a gel for separations. Capillary gel electrophoresis improves on the gel electrophoresis separations traditionally performed in slab gels [13] and slab gel electrophoresis demands more sample when compared to similar techniques using capillary electrophoresis. Furthermore, capillary electrophoresis separations can achieve higher resolution than traditional gel electrophoresis because the small inner diameter of the capillary enables higher voltages to be utilized without joule heating that diminishes resolution [18]. This enhanced resolution has been harnessed for the analysis of peptides and proteins since the late 1980s [13] and has seen widespread adaptation, especially in the pharmaceutical field [19-24].

\subsection{Capillary Zone Electrophoresis}

1.2.1. Fundamentals. Capillary zone electrophoresis is the most fundamental form of the technique. The separation is based on the charge-to-size ratio of the analytes. The apparent mobility ( $\left.\mu_{\text {app}}\right)$ of the analytes is impacted by the electroosmotic flow (EOF) and electrophoretic mobility ( $\mu$ eph). A diagram depicting the magnitude of these forces and the migration order is shown in Figure 1-1. 
Table 1-1. Attributes of techniques commonly used for protein separations

\begin{tabular}{|c|c|c|c|c|}
\hline Technique & $\begin{array}{l}\text { Sample size } \\
\text { per run }\end{array}$ & $\begin{array}{l}\text { Online coupling } \\
\text { to MS }\end{array}$ & $\begin{array}{l}\text { Native analysis } \\
\text { possible }\end{array}$ & $\begin{array}{l}\text { Simultaneous } \\
\text { separation of } \\
\text { basic and } \\
\text { acidic } \\
\text { proteins }\end{array}$ \\
\hline
\end{tabular}

$\begin{array}{lcccc}\text { CE } & \begin{array}{c}1.4 \mathrm{ng} \\ (0.5 \mathrm{~nL})^{\mathrm{a}}\end{array} & \mathrm{Y} & \mathrm{Y} & \mathrm{Y} \\ \text { PAGE }^{\mathbf{b}} & \begin{array}{c}5 \mu \mathrm{g} \\ (40 \mu \mathrm{L})\end{array} & \mathrm{N} & \mathrm{Y}^{\mathrm{c}} & \mathrm{Y}^{\mathrm{c}} \\ & 1-10 \mu \mathrm{g} & \mathrm{Y} & \mathrm{N} & \mathrm{Y} \\ \text { RPLC }^{\text {d }} & (10 \mu \mathrm{L}) & & \mathrm{Y} & \mathrm{Y} \\ & 1-10 \mu \mathrm{g} & \mathrm{Y} & & \mathrm{N} \\ \text { SEC }^{d} & (10 \mu \mathrm{L}) & & \mathrm{Y} & \mathrm{N} \\ & 1-10 \mu \mathrm{g} & \mathrm{N} & & \end{array}$

a. Sample size is based on conditions used for injections of alpha-1-antitrypsin in chapter 2 , which were $3.4 \mathrm{kPa}(0.5 \mathrm{psi})$ for $5 \mathrm{~s}$ of a $50 \mu \mathrm{M}$ sample using UV-Vis detection at 200 $\mathrm{nm}$.

b. Based on vendor specifications [14]

c. Native analysis is possible when non-denaturing conditions and no SDS are utilized.

d. Based on vendor specifications [15]

e. Traditional techniques are not mass spectrometry friendly due to high salts and denaturants; however, some techniques to circumvent this have been developed and applied to therapeutic proteins $[16,17]$. 


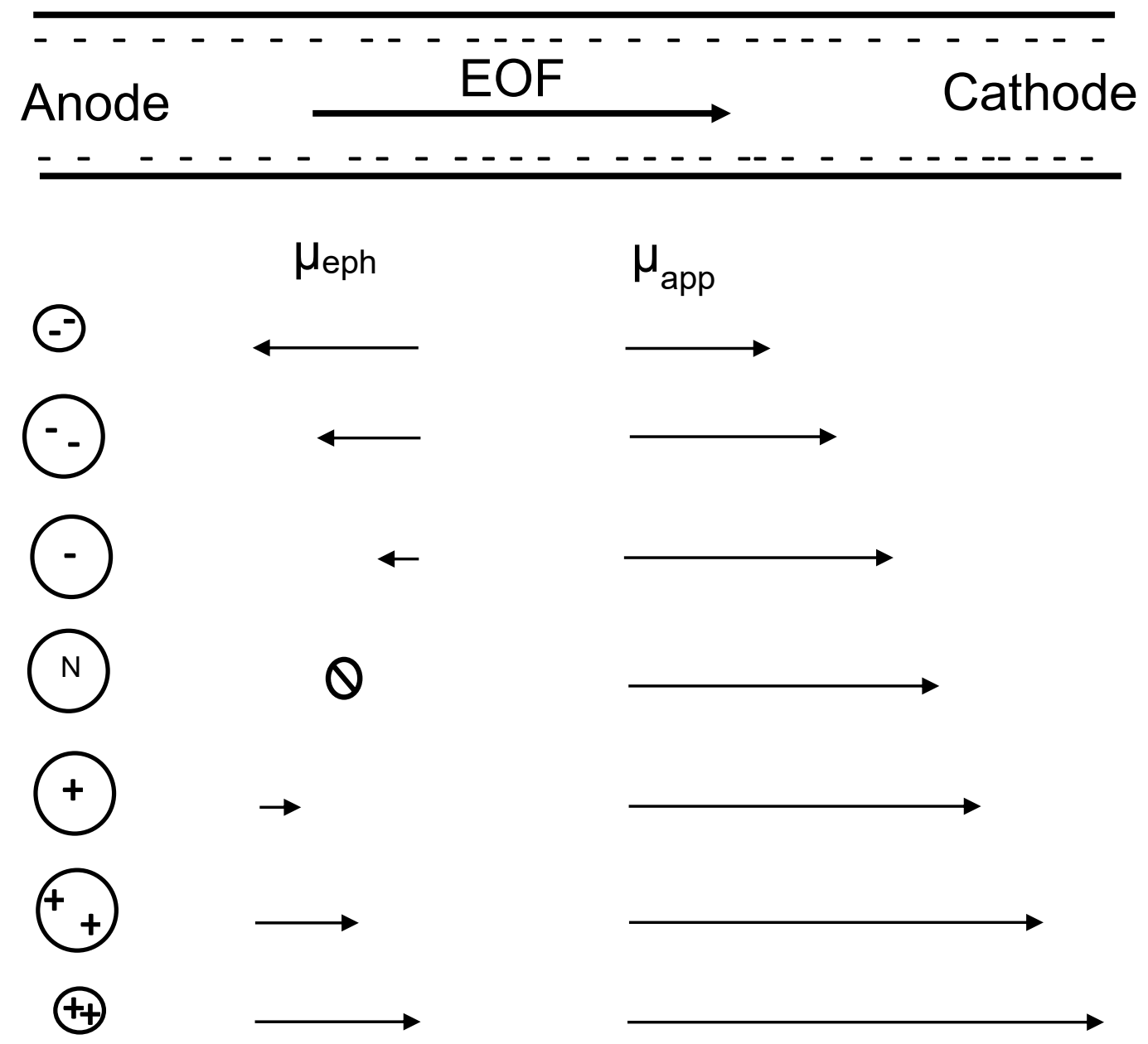

Figure 1-1. Depiction of analyte migration in a capillary electrophoresis separation utilizing unmodified bare fused silica at $\mathrm{pH}$ values above 4 . The negative charges are those associated with the wall. The magnitude and direction of the mobilities are indicated by the vectors for electroosmotic flow (EOF), electrophoretic mobility ( $\mu$ eph), and apparent mobility ( $\mu$ app). 
The electroosmotic flow is the bulk flow of fluid through the capillary, which is based on the charge of the capillary wall. In traditional capillary zone electrophoresis separations, the capillary is silica with a pKa of approximately 4 . Therefore, at $\mathrm{pH}$ values above 4 the capillary surface is negative. Cations from the background electrolyte are attracted to the negative surface and line up on it, and anions are in turn attracted to the positive layer of charge. When a voltage is applied across the capillary, the layer of cations migrates toward the cathode pulling the other layers with it. This bulk flow results in a universal flow in the capillary regardless of the charge of the analytes.

The electrophoretic mobility is based on the charge of the analytes. Electrophoretic mobility can be calculated using the equation [25]

$$
\mu \mathrm{eph}=\frac{q}{6 \pi \eta r}
$$

where $q$ is the charge of the ion, $\eta$ is the viscosity of the buffer, and $r$ is the radius of the ion. Cations migrate toward the cathode and anions migrate toward the anode. Neutral analytes in the capillary have no movement based on electrophoretic mobility. The size and charge density of the analyte also plays a role as radius is factored into the equation and larger ions will have greater frictional drag than smaller ions. Therefore, small, highly charged analytes migrate faster than large, less charged analytes.

As seen in Figure 1-1, the electroosmotic flow and the electrophoretic mobility make up the net migration of analytes, which ultimately leads to resolution by charge-to-size ratio. The electroosmotic flow typically has a larger magnitude than the electrophoretic mobility at $\mathrm{pH}$ values above 4 . This is especially true in the case of proteins where physiological $\mathrm{pH}$ values are usually investigated or utilized to maintain structure and function. Therefore, positive, neutral, and negative proteins can be analyzed simultaneously. The order of migration for a capillary zone electrophoresis separation using a bare fused silica capillary is cationic proteins first, followed by neutral proteins, and finally anionic proteins, as depicted in Figure 1-1. 
While capillary zone electrophoresis possesses many advantages for the separation of proteins, protein adsorption remains an issue that often must be addressed in order to achieve the highest performance. The traditional silica wall possesses a high density of negative charges, which results in the attraction of the positive amine groups in proteins to the wall. This has been documented in the literature [26-28], especially in the case of lysozyme which is a very basic protein and adheres to the capillary surface making it problematic to detect. The protein adsorption not only makes the analysis of basic proteins challenging but also deteriorates separation resolution and reproducibility. With each analysis, the protein adsorbed on the wall increases and eventually impacts the charge on the wall of the capillary because the protein carries a charge opposite that of the surface. This results in the electroosmotic flow gradually changing, which is evident by a shift over time in the apparent mobility of the analytes over time. This poses a barrier for any technique where reproducibility is key to analysis, such as routine analyses for quality control in the pharmaceutical field [29]. As discussed in literature [30], the most frequently utilized methods of alleviating this barrier are extremely acidic $\mathrm{pH}$ values and coatings. Acidic $\mathrm{pH}$ values are effective because they protonate the surface and remove the negative charge; however, this also removes the electroosmotic flow resulting in flow rates not compatible with mass spectrometry and the harsh $\mathrm{pH}$ means most proteins cannot be analyzed in the native state. For these reasons, capillary coatings are a more practical solution.

Protein adsorption is commonly circumvented by utilizing capillary coatings to mask or alter the charge on the surface. The coatings are often used to make the surface neutral or cationic. This impacts the migration of the analytes by altering the electroosmotic flow. For neutral coatings, electroosmotic flow is suppressed as shown in Figure 1-2, resulting in the apparent mobility being based on the electrophoretic mobility. This results in separations that only allow for the analysis of positive or negative proteins depending on whether the separation voltage is positive or negative. On the other hand, cationic coatings maintain electroosmotic flow but reverse the direction toward the anode rather 


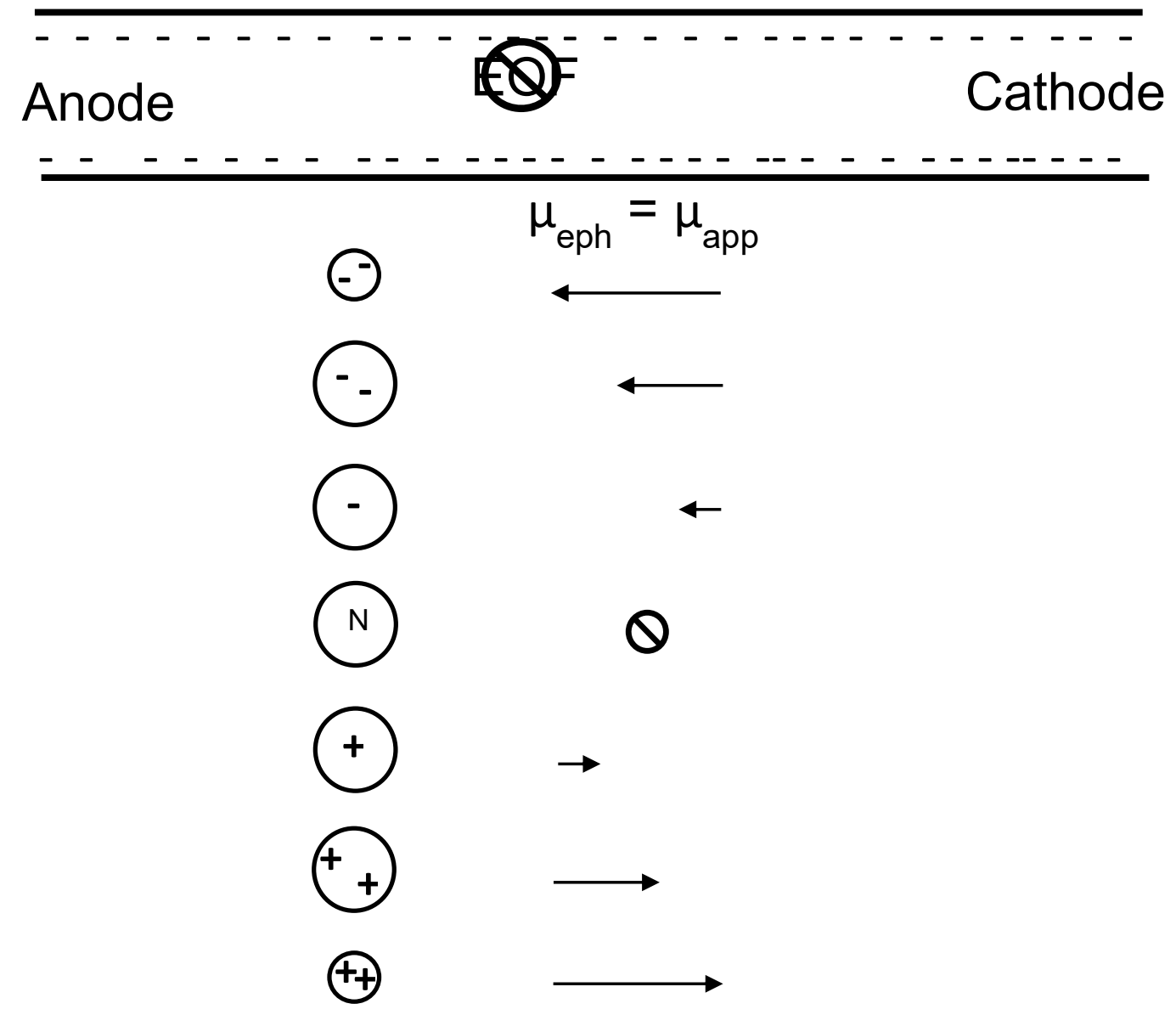

Figure 1-2. Depiction of analyte migration in a capillary electrophoresis separation utilizing a neutral coated capillary. The magnitude and direction of the mobilities are indicated by the vectors for electroosmotic flow (EOF), electrophoretic mobility ( $\left.\mu_{\mathrm{eph}}\right)$, and apparent mobility ( $\mu$ app). 
than the cathode since the anions will now be the first layer of buffer ions to line up on the surface of the capillary. This reverses the order of analyte migration compared to the negative surface, as shown in Figure 1-3.

1.2.2. Capillary coatings for capillary zone electrophoresis. Capillary coatings are usually categorized into three classes with each having a unique set of advantages and disadvantages that must be considered for compatibility with the application. Permanent, semi-permanent, and dynamic modifications are the three major types of coatings [31, 32]. Still, coatings developed to address basic protein adsorption to the capillary wall only analyzed basic proteins [27, 33-35] and did not demonstrate application to acidic proteins, let alone simultaneous separation. One exception used an acidic $\mathrm{pH}$ to make all the proteins cationic [36].

1.2.3. Permanent coatings for capillary electrophoresis. Permanent coatings are formed through covalent modifications of the capillary wall. Covalent modification requires the use of silanol chemistry to form bonds to the surface [37]. A triethoxy coupling agent with the desired functional group undergoes hydrolysis and hydrogen bonding to form a network in solution prior to forming a polymerized coat on the surface [37]. Permanent coatings do not require the modification agent to be flushed through the capillary once modification is complete, which is important to the use of coatings with mass spectrometry $[38,39]$ as reagents commonly used can suppress the ionization efficiency. However, these processes are time consuming, require harsh chemicals, and cannot be restored to optimum once the surface is fouled, so the lifetime and number of times the capillary can be reused is limited. Permanently modified capillaries are commercially available $[15,40]$ but are predominantly only manufactured in inner diameters of $50 \mu \mathrm{m}$ and larger, which are more susceptible to joule heating than smaller diameter capillaries (like the 25 $\mu \mathrm{m}$ inner diameter capillary used in these studies) and overall more expensive than purchasing a silica capillary and modifying it. To demonstrate the difference in cost, a table with an abbreviated list of commercial capillaries for protein separations and the 


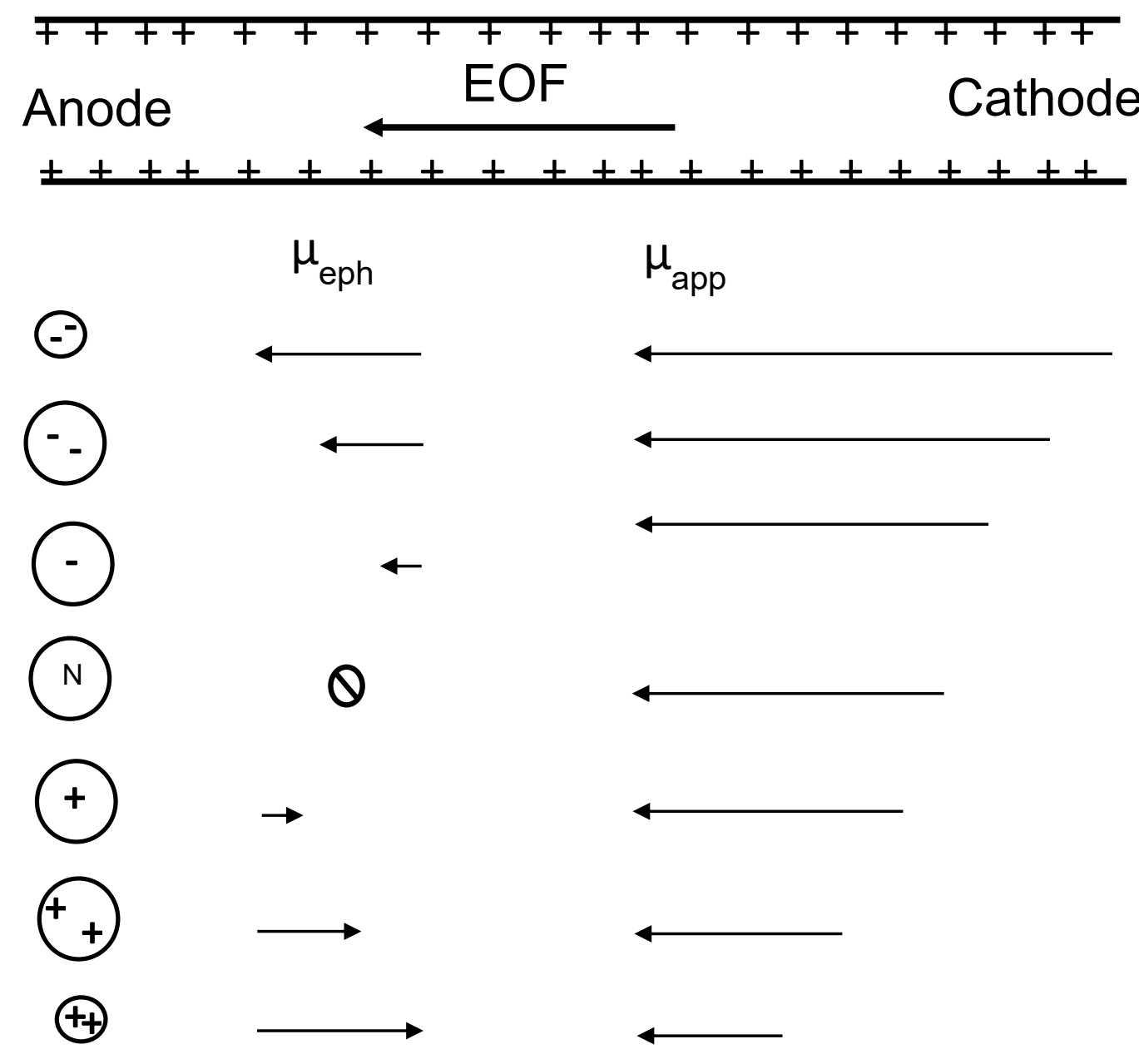

Figure 1-3. Depiction of analyte migration in a capillary electrophoresis separation utilizing a cationic coated capillary. The positive charges are those associated with the wall. The magnitude and direction of the mobilities are indicated by the vectors for electroosmotic flow (EOF), electrophoretic mobility ( $\left.\mu_{\text {eph}}\right)$, and apparent mobility ( $\mu_{\text {app }}$ ). 
cost is shown in Table 1-2. It should be emphasized that while the commercially available capillaries lifetime is limited due to fouling or coat deterioration, the coating developed in this research can be regenerated, which greatly extends the capillary lifetime.

1.2.4 Dynamic coatings for capillary electrophoresis. Dynamic coatings have positive attributes, but due to the potential to interfere with detection were not the route chosen for this research. Dynamic coatings are formed through weak to moderate adsorption of the modification agent to the surface. The coating agent is typically flushed through the capillary to form the initial coat and then placed in the background electrolyte in order to maintain the equilibrium of agent at the surface and in solution. Dynamic coatings are easily applied and regenerated during the analyses; however, the inclusion of the analyses; however, the inclusion of the modification agent in the background electrolyte can be problematic. Modification reagents are typically not compatible with mass spectrometry due to the ability to suppress ionization [38] and must be chosen to limit interaction with the analyte that may diminish resolution.

1.2.5. Semi-permanent coatings for capillary electrophoresis. Semi-permanent coatings offer a compromise between permanent and dynamic coatings that makes this class of coatings more cost effective and practical for most protein applications; therefore, this class of coatings was utilized for the work in this dissertation. Semi-permanent coatings are formed through physical adsorption due to electrostatic or hydrophobic forces or hydrogen bonding [44] similarly to dynamic coatings, but the interactions tend to be stronger which allows the modification reagent to be excluded from the background electrolyte. These coatings are generally created by simply flushing the modification reagent through the capillary prior to analyses, which makes this technique easy to employ with reproducible results. Furthermore, when the coating begins to deteriorate, the coat can be regenerated using small flushes of the modification reagent between analyses. 


\begin{tabular}{|c|c|c|c|}
\hline Capillary & Vendor & $\begin{array}{l}\text { Inner diameter } \\
(\mu \mathrm{m})\end{array}$ & Cost $/ \mathrm{cm}$ \\
\hline Bare-fused ${ }^{a}$ & Molex & 25 & $\$ 0.13$ \\
\hline eCAP amine coated ${ }^{b}$ & Sciex & 50 & $\$ 3.96$ \\
\hline Neutral coated ${ }^{b}$ & Sciex & 50 & $\$ 5.69$ \\
\hline $\mathrm{N}-\mathrm{CHO}$ Coated $^{\mathrm{b}}$ & Sciex & 50 & $\$ 4.81$ \\
\hline $\mathrm{PVA}^{\mathrm{C}}$ & Agilent & 50 & $\$ 5.39$ \\
\hline$\mu$ Sil Wax (polyethylene oxide) ${ }^{c}$ & Agilent & 50 & $\$ 2.37$ \\
\hline
\end{tabular}
a. Based on [41]
b. Based on [42]
c. Based on [43] 


\subsection{Capillary gel electrophoresis}

1.3.1 Fundamentals. Capillary gel electrophoresis is one of the most frequently employed forms of capillary electrophoresis for the analysis of proteins [13, 19-22]. Because proteins were traditionally analyzed using slab gel electrophoresis, translating the technique to a capillary format that produces results similar to those achieved with the gel makes interpreting new data and comparing to data collected with the older format more straightforward. As such, several commercial instruments have been manufactured specifically to meet the needs for capillary gel electrophoresis and more specialized versions of the technique [45]. While these instruments make capillary gel electrophoresis analysis more straightforward than method development on a more general capillary electrophoresis instrument, it also demands a commitment to the cartridges, capillaries, and reagents provided by the manufacturer, which comes at a higher price than unmodified capillaries and reagents available at a range various vendors.

Capillary gel electrophoresis is generally utilized for proteins when a size-based component is desired for the separation. The gel creates a matrix of pores in the capillary through which the proteins must navigate. Proteins of smaller size will have less collisions with the matrix than proteins of larger size since the smaller sized proteins will fit through more pores than the larger sized proteins. In many cases, sodium dodecyl sulfate (SDS), or other surfactants $[19,46,47]$, is incorporated in the matrix as a way to normalize the charge on the proteins. The hydrophobic portion of the surfactant interacts with hydrophobic patches on the protein and the charged head group of the surfactant presents itself to the surface. This interaction generally leads to all the proteins possessing the same charge-to-size ratio, and with this normalization, the separation mechanism is based on size. When the surfactant is left out of the matrix, the mechanism is based both of charge-to-size ratio and size.

1.3.2. Capillary gel electrophoresis materials. A wide range of materials have been investigated to implement size-based separations in capillary electrophoresis. The most critical factors to judge the potential for a material to be used with capillary gel 
electrophoresis are development of uniform pore size and low adsorption of the analyte to the material. Uniform pore size impacts reproducibility and efficiency in capillary gel electrophoresis similarly to high performance liquid chromatography. Irregular pore sizes leads to analytes having the option of multiple paths with varying lengths, which leads to eddy diffusion and therefore band broadening in accordance with the Van Deemter equation [48]. Other important considerations are compatibility with detection, robustness, and ease of use.

Polymers such as polyacrylamide, linear polyacrylamide, and borate cross-linked dextran are the most common media employed for size-based separations. Polyacrylamide [13], which is employed in many slab gel electrophoresis separations, is often polymerized incapillary to form a permanent matrix due to the high viscosity, which meant that bubble formation or clogging required a new capillary with the polymerization process performed again to continue analyses [49]. As a result, linear polyacrylamide was developed to possess a lower viscosity, which allowed it to be replaced between analyses [50]. This gel demands a coating to be used on the capillary first in order to control EOF and reduce adsorption. Alternatively, borate-crosslinked dextran is one of the most frequently used materials for capillary gel electrophoresis $[21,24,51]$ due to the commercial availability and ease of use.

Colloidal silica is a less traditional media that has been successfully implemented for sizebased separations in capillary electrophoresis. The size of the colloidal silica can be altered in order to adapt the material to the size range of the proteins of interest. This has been harnessed for the analysis of antibody aggregation [52], and protein complexes in the megadalton molecular weight range [53]. Colloidal silica has also been adaptable for microfluidic [54] formats.

\subsection{Prior use of phospholipids as separation materials}

Phospholipids are a smart material, meaning the morphology changes with separation conditions, that have already been harnessed to improve capillary electrophoresis separations in prior works. While phospholipids of different varieties have been used as 
a coating in many groups [55-61], the Holland lab has extensively demonstrated the advantages of the phospholipids 1,2-dimyristoyl-sn-glycero-3-phosphocholine (DMPC) and 1,2-dihexanoyl-sn-glycero-3-phosphocholine (DHPC) as coating [62, 63], separation matrix [64-72], and microfluidic steering [73] materials. The structure of each phospholipid is depicted in Figure 1-4. A mixture of these phospholipids self-assemble to form bilayers and micelles depending on the temperature and compositions of the mixtures, which is what allows this material to be adaptable to so many applications.

At a DMPC:DHPC ratio of $q=0.5$, the phospholipids form bilayers which are fused together using calcium to form a coat on the capillary surface. This coating has been applied to the separation of small molecule pharmaceuticals [62] and carbohydrates [62, 63]. The phospholipid material was demonstrated to provide an inert surface capable of higher efficiencies and lower sample interaction with the wall than bare fused silica and a polyacrylamide coating [62]. Furthermore, the coating was shown to be compatible with capillary electrophoresis electrospray ionization mass spectrometry (CE-ESI-MS) operated in negative mode as suppression of ionization was not observed [63].

The phospholipids form an effective nanogel matrix for improving capillary electrophoresis separations at DMPC:DHPC ratios of $q=2.5$ [64, 66-70]. Morphology, and therefore viscosity, of the phospholipid nanogel is dependent on temperature. At temperatures below the transition temperature of $24^{\circ} \mathrm{C}$, the phospholipid mixture has a water-like viscosity, while temperatures above the transition temperature can be utilized to form a gel-like viscosity [75]. This makes it possible to easily refresh the nanogel matrix at $19^{\circ} \mathrm{C}$ between analyses. The phospholipid nanogel enables the separation of glycans that vary only by an isomeric linkage by exploiting the differences in frictional drag $[64,68]$. The matrix is biocompatible and supports enzyme and lectin processing of glycan monomers and linkages [66, 68-70]. Additionally, the phospholipid nanogel extends the lifetime of enzyme preparations and improves the activity, especially at low concentrations [68]. 


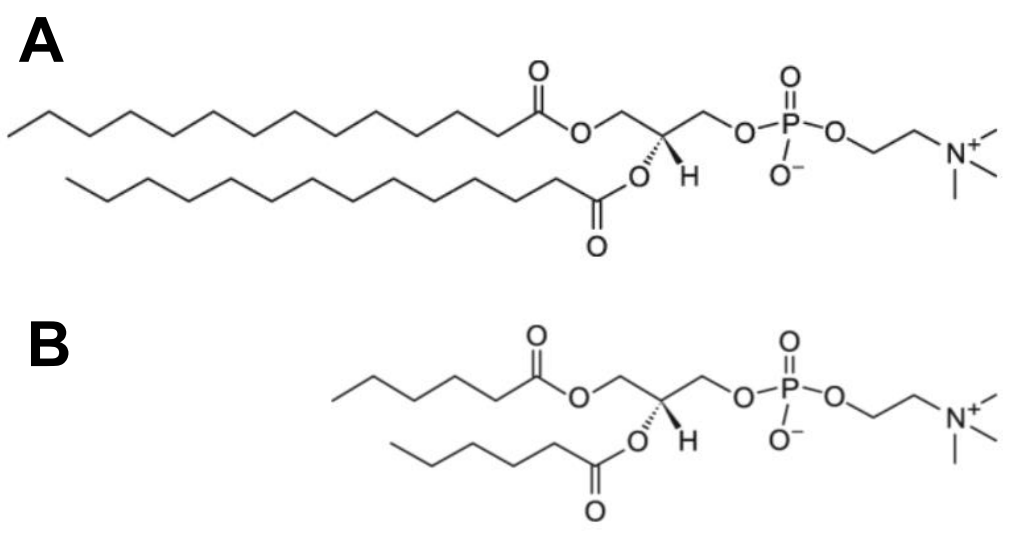

Figure 1-4. Structure of the long and short chain phospholipids 1,2-dimyristoyl-snglycero-3-phosphocholine (DMPC) (A) and 1,2-dihexanoyl-sn-glycero-3-phosphocholine (DHPC) (B) used for the formation of coating materials and nanogels. Figure is adapted from the vendor website[74]. 
As a result of the thermally responsive viscosity, the phospholipid nanogel serves as an excellent material for DNA sieving [71, 72]. Separations of a range of DNA sizes approximated the pore size of a particular composition of the nanogel at $31 \mathrm{~nm}$, which allowed for DNA below 500 bp to be separated via Ogston sieving [71]. Temperature can be utilized to tailor the separation the size of DNA being analyzed. Moreover, stacking zones were made possible by patterning a higher percent composition of the nanogel in the capillary prior to the separation zone in order to exploit the differences in viscosity [72].

The demonstrated advantages make this phospholipid material an attractive basis for expanding on capillary electrophoresis of proteins. The inert surface allows for reducing protein interaction with the wall; thereby reducing peak broadening. The biocompatibility leaves the potential for native analyses of proteins, and the ability to tune the separation resolution in the nanogel makes it adaptable to specific applications. Furthermore, the ease with which the coating is applied and the matrix is introduced into the capillary makes these techniques user friendly. This was the basis for utilizing the phospholipid material in the research that follows.

\subsection{Novel phospholipid-CTAB hybrid coating for protein separations}

The studies presented in chapter two $[28,76]$ developed a hybrid coating from the phospholipids DMPC and DHPC and the surfactant cetyltrimethylammonium bromide (CTAB) to allow for high efficiency separations of both acidic and basic proteins in a single run without significant protein adsorption. The coating developed in this research requires no covalent modification, which makes it easy to reproducibly form and regenerate. The coating is cost effective at $\$ 0.05$ per coat. Additionally, a stable electroosmotic flow can be generated across $\mathrm{pH}$ values, which makes it a potential material for coupling capillary electrophoresis to mass spectrometry in the future at both native and non-native conditions for protein analysis. The electroosmotic flow is also important for allowing the simultaneous separation of basic and acidic proteins. 
The limitations of bare fused silica separations are demonstrated. While the phospholipid coating when used alone is capable of alleviating protein adsorption to the capillary wall, it does not allow for simultaneous detection of the cationic and anionic proteins due to the suppressed electroosmotic flow. Incorporation of CTAB generates an electroosmotic flow toward the anode due to the positive charge it places on the capillary surface. The hybrid phospholipid-CTAB surface enables high efficiency separations of cationic and anionic proteins simultaneously through the generation of an electroosmotic flow of 3.14 $\times 10^{-4} \mathrm{~cm}^{2} \mathrm{~V}^{-1} \mathrm{~s}^{-1}(\mathrm{n}=10)$ from the cathode to the anode at a $\mathrm{pH}$ of 7 . The coating is stable even after 2 hours of flushing with background electrolyte lacking CTAB and six consecutive protein injections with no flush sequence between runs. Three basic proteins, lysozyme, ribonuclease $A$, and $\alpha$-chymotrypsinogen $A$, and three acidic proteins, $\alpha-1$ antitrypsin, transferrin, and enolase, served as models for evaluating the coating performance in terms of protein interaction, stability across $\mathrm{pH}$ values, and ability to resolve proteins of similar isoelectric points and with isoforms. Finally, the coating is applied for the accurate quantification of proteins in human serum using standard addition.

\subsection{Phospholipid nanogel for sieving proteins}

The study in chapter three [77] utilized the phospholipid nanogel for the first time as a way to introduce a size-based mechanism to capillary electrophoresis separations of proteins. Despite the advances to which current sieving materials have led, the high viscosity makes the materials less than ideal given that high pressures are required to introduce the viscous gels in capillary or permanent crosslinking the gel makes capillary lifetimes shorter. Phospholipid nanogels composed of dimyristoyl-sn-glycero-2phosphocholine (DMPC) and 1,2-dihexanoyl-sn-glycero-3-phosphocholine (DHPC) have the advantage of a thermally-responsive viscosity for easy introduction at $19^{\circ} \mathrm{C}$ and the formation of a sieving matrix at $27^{\circ} \mathrm{C}$. This work circumvents performing cross-linking chemistry in the capillary, which sometimes results in the matrix misforming and becoming irregular due to bubble formation or gel shrinking. Additionally, the nanogel can be introduced at the same pressures required for aqueous solutions, which makes 
methods developed using the nanogel more easily adaptable to other systems than traditional gels since a high pressure system is not required. This also extends the lifetime of the capillary since the nanogel is easily repatterned for a fresh matrix for each new run. Again, the phospholipid nanogel is an affordable matrix and costs only $\$ 0.04$ per analysis.

All of the above advantages made phospholipid nanogels a promising material for sieving proteins in the presented research. The mechanism of protein separation in nanogel is shown to be a combination of charge-to-size ratio and size at higher percent phospholipid concentrations. Using a Ferguson plot for the model proteins, the concentration of the phospholipid to shift the mechanism to sieving is determined. The superior resolution achieved in the sieving separations compared to the non-sieving separations enables quantification of proteins in human serum using external standards. Additionally, due to the size discrepancy between the proteins of interest and the immunoglobulin $A$ which normally overlaps with the proteins, immunoglobulin $A$ is shifted out of the separation. 


\subsection{References}

1. Walsh, D. M.; Klyubin, I.; Fadeeva, J. V.; Cullen, W. K.; Anwyl, R.; Wolfe, M. S.; Rowan, M. J.; Selkoe, D. J., Naturally secreted oligomers of amyloid beta protein potently inhibit hippocampal long-term potentiation in vivo. Nature 2002, 416 (6880), 535-539.

2. Chiti, F.; Dobson, C. M., Protein misfolding, functional amyloid, and human disease. Annu. Rev. Biochem 2006, 75, 333-366.

3. Hugot, J. P.; Chamaillard, M.; Zouali, H.; Lesage, S.; Cezard, J. P.; Belaiche, J.; Almer, S.; Tysk, C.; O'Morain, C. A.; Gassull, M.; Binder, V.; Finkel, Y.; Cortot, A.; Modigliani, R.; Laurent-Puig, P.; Gower-Rousseau, C.; Macry, J.; Colombel, J. F.; Sahbatou, M.; Thomas, G., Association of NOD2 leucine-rich repeat variants with susceptibility to Crohn's disease. Nature 2001, 411 (6837), 599-603.

4. Haass, C.; Selkoe, D. J., Soluble protein oligomers in neurodegeneration: lessons from the Alzheimer's amyloid beta-peptide. Nat. Rev. Mol. Cell Biol. 2007, 8 (2), 101112.

5. Bedard, K.; Krause, K. H., The NOX family of ROS-generating NADPH oxidases: Physiology and pathophysiology. Physiol. Rev. 2007, 87 (1), 245-313.

6. Administration, F. a. D. List of Qualified Biomarkers. https://www.fda.gov/drugs/cderbiomarker-qualification-program/list-qualified-biomarkers (accessed June 22).

7. Packard, R. R. S.; Libby, P., Inflammation in atherosclerosis: From vascular biology to biomarker discovery and risk prediction. Clinical Chemistry 2008, 54 (1), 24-38.

8. Aravalli, R. N.; Steer, C. J.; Cressman, E. N. K., Molecular Mechanisms of Hepatocellular Carcinoma. Hepatology 2008, 48 (6), 2047-2063.

9. USA, S. Biopharmaceutical Spotlight. https://www.selectusa.gov/pharmaceuticaland-biotech-industries-united-states (accessed June 22).

10. Slamon, D. J.; Leyland-Jones, B.; Shak, S.; Fuchs, H.; Paton, V.; Bajamonde, A.; Fleming, T.; Eiermann, W.; Wolter, J.; Pegram, M.; Baselga, J.; Norton, L., Use of chemotherapy plus a monoclonal antibody against HER2 for metastatic breast cancer that overexpresses HER2. N. Engl. J. Med. 2001, 344 (11), 783-792.

11. Piccart-Gebhart, M. J.; Procter, M.; Leyland-Jones, B.; Goldhirsch, A.; Untch, M.; Smith, I.; Gianni, L.; Baselga, J.; Bell, R.; Jackisch, C.; Cameron, D.; Dowsett, M.; Barrios, C. H.; Steger, G.; Huang, C. S.; Andersson, M.; Inbar, M.; Lichinitser, M.; Lang, I.; Nitz, U.; Iwata, H.; Thomssen, C.; Lohrisch, C.; Suter, T. M.; Ruschoff, J.; Suto, T.; Greatorex, V.; Ward, C.; Straehle, C.; McFadden, E.; Dolci, M. S.; Gelber, R. D.; Team, H. T. S., Trastuzumab after adjuvant chemotherapy in HER2-positive breast cancer. N. Engl. J. Med. 2005, 353 (16), 1659-1672.

12. Tripathi, N. K.; Shrivastava, A., Recent Developments in Recombinant ProteinBased Dengue Vaccines. Frontiers in Immunology 2018, 9.

13. Cohen, A. S.; Paulus, A.; Karger, B. L., High-performance capillary electropohresis using open tubes and gels. Chromatographia 1987, 24, 15-24.

14. Thermofisher https://assets.thermofisher.com/TFS-Assets/BID/Handbooks/proteingel-electrophoresis-technical-handbook.pdf (accessed July 15).

15. Agilent

https://www.agilent.com/cs/library/eseminars/Public/Column\%20Choices\%20for\%2 Oproteins_037214.pdf (accessed July15). 
16. Shi, R. L.; Xiao, G.; Dillon, T. M.; Ricci, M. S.; Bondarenko, P. V., Characterization of therapeutic proteins by cation exchange chromatography-mass spectrometry and top-down analysis. MAbs 2020, 12 (1).

17. Muneeruddin, K.; Nazzaro, M.; Kaltashov, I. A., Characterization of Intact Protein Conjugates and Biopharmaceuticals Using Ion-Exchange Chromatography with Online Detection by Native Electrospray Ionization Mass Spectrometry and TopDown Tandem Mass Spectrometry. Anal. Chem. 2015, 87 (19), 10138-10145.

18. Jorgenson, J. W.; Lukacs, K. D., Zone electrophoresis in open-tubular glasscapillaries. Anal. Chem. 1981, 53 (8), 1298-1302.

19. Beckman, J.; Song, Y. L.; Gu, Y.; Voronov, S.; Chennamsetty, N.; Krystek, S.; Mussa, N.; Li, Z. J., Purity Determination by Capillary Electrophoresis Sodium Hexadecyl Sulfate (CE-SHS): A Novel Application For Therapeutic Protein Characterization. Anal. Chem. 2018, 90 (4), 2542-2547.

20. Sanger-van de Griend, C. E., CE-SDS method development, validation, and best practice-An overview. Electrophoresis 2019, 40 (18-19), 2361-2374.

21. Filep, C.; Guttman, A., The Effect of Temperature in Sodium Dodecyl Sulfate Capillary Gel Electrophoresis of Protein Therapeutics. Anal. Chem. 2020, 92 (5), 4023-4028.

22. Rustandi, R. R.; Hamm, M., Development of an ADP-ribosylation assay for residual toxicity in C. difficile binary toxin CDTa using automated capillary western blot. J. Pharm. Biomed. Anal. 2020, 182.

23. Loughney, J. W.; Ha, S.; Rustandi, R. R., Quantitation of CRM197 using imaged capillary isoelectric focusing with fluorescence detection and capillary Western. Anal. Biochem. 2017, 534, 19-23.

24. Lacher, N. A.; Wang, O.; Roberts, R. K.; Holovics, H. J.; Aykent, S.; Schlittler, M. R.; Thompson, M. R.; Demarest, C. W., Development of a capillary gel electrophoresis method for monitoring disulfide isomer heterogeneity in IgG2 antibodies. Electrophoresis 2010, 31 (3), 448-458.

25. Landers, J., Handbook of Microchip and Capillary Electrophoresis and Associated Microtechniques. Third ed.; CRC Press: Boca Raton, FL, 2008.

26. Bushey, M. M.; Jorgenson, J. W., Capillary electrophoresis of proteins in buffers containing high-concentrations of zwiterionic salts. J. Chromatogr. 1989, 480, 301310.

27. Yeung, K. K. C.; Lucy, C. A., Suppression of electroosmotic flow and prevention of wall adsorption in capillary zone electrophoresis using zwitterionic surfactants. Anal. Chem. 1997, 69 (17), 3435-3441.

28. Crihfield, C. L.; Kristoff, C. J.; Veltri, L. M.; Penny, W. M.; Holland, L. A., Semipermanent cationic coating for protein separations. J Chromatogr A 2019, 1607, 460397.

29. Guttman, A.; Varoglu, M.; Khandurina, J., Multidimensional separations in the pharmaceutical arena. Drug Discov. Today 2004, 9 (3), 136-144.

30. Kristoff, C. J.; Bwanali, L.; Veltri, L. M.; Gautam, G. P.; Rutto, P. K.; Newton, E. O.; Holland, L. A., Challenging Bioanalyses with Capillary Electrophoresis. Anal. Chem. 2020, 92 (1), 49-66.

31. Dawod, M.; Arvin, N. E.; Kennedy, R. T., Recent advances in protein analysis by capillary and microchip electrophoresis. Analyst 2017, 142 (11), 1847-1866. 
32. Hajba, L.; Guttman, A., Recent advances in column coatings for capillary electrophoresis of proteins. Trends Anal. Chem. 2017, 90, 38-44.

33. Gulcev, M. D.; Lucy, C. A., Factors affecting the behavior and effectiveness of phospholipid bilayer coatings for capillary electrophoretic separations of basic proteins. Anal. Chem. 2008, 80 (5), 1806-1812.

34. Wang, C. Z.; Lucy, C. A., Mixed cationic/anionic surfactants for semipermanent wall coatings in capillary electrophoresis. Electrophoresis 2004, 25 (6), 825-832.

35. Znaleziona, J.; Drahonovsky, D.; Drahos, B.; Sevcik, J.; Maier, V., Novel cationic coating agent for protein separation by capillary electrophoresis. J. Sep. Sci. 2016, 39 (12), 2406-2412.

36. Liu, Q.; Yang, Y. M.; Huang, Y.; Pan, C. F.; Nie, Z.; Yao, S. Z., Separation of acidic and basic proteins by CE with CTAB additive and its applications in peptide and protein profiling. Electrophoresis 2009, 30 (12), 2151-2158.

37. Hermanson, G., Bioconjugate Techniques. Third ed.; Academic Press: San Diego, CA, 2013.

38. Huhn, C.; Ramautar, R.; Wuhrer, M.; Somsen, G. W., Relevance and use of capillary coatings in capillary electrophoresis-mass spectrometry. Anal. Bioanal. Chem. 2010, 396 (1), 297-314.

39. Hernandez-Borges, J.; Neususs, C.; Cifuentes, A.; Pelzing, M., On-line capillary electrophoresis-mass spectrometry for the analysis of biomolecules. Electrophoresis 2004, 25 (14), 2257-2281.

40. Sciex https://us-store.sciex.com/USD/-/--zidCoated-Capillary (accessed July 15).

41. Molex https://www.molex.com/molex/products/group/polymicro (accessed July 15).

42. Sciex Coated Capillary. https://us-store.sciex.com/USD/capillaryelectrophoresis/capillaries-and-cartridges/capillaries/Coated-Capillary-zidCoatedCapillary (accessed July 15)

43. Agilent https://www.agilent.com/store/en US/LCat-SubCat3ECS 32189/-181-SILWAX-Capillaries-with-Windows (accessed July 15).

44. Lucy, C. A.; MacDonald, A. M.; Gulcev, M. D., Non-covalent capillary coatings for protein separations in capillary electrophoresis. J. Chromatogr. A 2008, 1184 (1-2), $81-105$.

45. iCE Systems. https://www.proteinsimple.com/ice overview.html (accessed June 23).

46. Vidanapathirana, P.; Hasan, F.; Mussio, K.; Pande, A.; Brands, M.; Siraj, N.; Grove, A.; Warner, I. M., Cationic ionic liquid surfactant-polyacrylamide gel electrophoresis for enhanced separation of acidic and basic proteins with single-step ribonuclease b glycoforms separation. J. Chromatogr. A 2017, 1515, 245-251.

47. Hasan, F.; Vidanapathirana, P.; Das, S.; Fernand, V. E.; Siraj, N.; Losso, J. N.; Warner, I. M., Ionic liquids as buffer additives in ionic liquid-polyacrylamide gel electrophoresis separation of mixtures of low and high molecular weight proteins. Rsc Adv. 2015, 5 (85), 69229-69237.

48. Skoog, D.; Holler, J.; Crouch, S., Principles of Instrumental Analysis. Sixth ed.; Thomas Brooks/Cole: Canada, 2007.

49. Zhu, Z. F.; Lu, J. J.; Liu, S. R., Protein separation by capillary gel electrophoresis: A review. Anal. Chim. Acta 2012, 709, 21-31. 
50. Widhalm, A.; Schwer, C.; Blaas, D.; Kenndler, E., Capillary zone electrophoresis with a linear, non-cross-linked polyacrylamide-gel - Separation of proteins according to molecular mass. J. Chromatogr. 1991, 549 (1-2), 446-451.

51. Liu, Y.; Reddy, P.; Ratnayake, C.; Koh, E. Methods and Compositions for Capillary Electrophoresis (CE). 2003.

52. Njoya, N. K.; Birdsall, R. E.; Wirth, M. J., Silica Colloidal Crystals as Emerging Materials for High-Throughput Protein Electrophoresis. AAPS J. 2013, 15 (4), 962969.

53. Ragland, T. S.; Gossage, M. D.; Furtaw, M. D.; Anderson, J. P.; Steffens, D. L.; Wirth, M. J., Electrophoresis of megaDalton proteins inside colloidal silica. Electrophoresis 2019, 40 (5), 817-823.

54. Azim, M.; Malekpourkoupaei, A.; Ye, W. M.; Jemere, A. B.; Harrison, D. J., Evaluation of protein separation mechanism and pore size distribution in colloidal self-assembled nanoparticle sieves for on-chip protein sizing. Electrophoresis 2017, 38 (2), 342-349.

55. Hautala, J. T.; Linden, M. V.; Wiedmer, S. K.; Ryhanen, S. J.; Saily, M. J.; Kinnunen, P. K. J.; Riekkola, M. L., Simple coating of capillaries with anionic liposomes in capillary electrophoresis. J. Chromatogr. A 2003, 1004 (1-2), 81-90.

56. Hautala, J. T.; Wiedmer, S. K.; Riekkola, M. L., Anionic liposomes in capillary electrophoresis: Effect of calcium on 1-palmitoyl-2-oleyl-sn-glycero-3phosphatidylcholine/phosphatidylserine- coating in silica capillaries. Anal. Bioanal. Chem. 2004, 378 (7), 1769-1776.

57. Adem, S. M.; Mansfield, E.; Keogh, J. P.; Hall, H. K.; Aspinwall, C. A., Practical considerations for preparing polymerized phospholipid bilayer capillary coatings for protein separations. Anal. Chim. Acta 2013, 772, 93-98.

58. Lokajova, J.; Tiala, H.; Viitala, T.; Riekkola, M. L.; Wiedmer, S. K., Covalent binding of phospholipid vesicles on fused silica capillaries for electrochromatography. Soft Matter 2011, 7 (13), 6041-6050.

59. Bo, T.; Wiedmer, S. K.; Riekkola, M. L., Phospholipid-lysozyme coating for chiral separation in capillary electrophoresis. Electrophoresis 2004, 25 (12), 1784-1791.

60. Wiedmer, S. K.; Bo, T.; Riekkola, M. L., Phospholipid-protein coatings for chiral capillary electrochromatography. Anal. Biochem. 2008, 373 (1), 26-33.

61. Wiedmer, S. K.; Jussila, M. S.; Riekkola, M. L., Phospholipids and liposomes in liquid chromatographic and capillary electromigration techniques. Trends Anal. Chem. 2004, 23 (8), 562-582.

62. White, C. M.; Luo, R.; Archer-Hartmann, S. A.; Holland, L. A., Electrophoretic screening of ligands under suppressed EOF with an inert phospholipid coating. Electrophoresis 2007, 28 (17), 3049-3055.

63. Langan, T. J.; Holland, L. A., Capillary electrophoresis coupled to electrospray mass spectrometry through a coaxial sheath flow interface and semi-permanent phospholipid coating for the determination of oligosaccharides labeled with 1aminopyrene-3,6,8-trisulfonic acid. Electrophoresis 2012, 33 (4), 607-613.

64. Luo, R.; Archer-Hartmann, S. A.; Holland, L. A., Transformable Capillary Electrophoresis for Oligosaccharide Separations Using Phospholipid Additives. Anal. Chem. 2010, 82 (4), 1228-1233. 
65. Archer-Hartmann, S. A.; Sargent, L. M.; Lowry, D. T.; Holland, L. A., Microscale Exoglycosidase Processing and Lectin Capture of Glycans with Phospholipid Assisted Capillary Electrophoresis Separations. Anal. Chem. 2011, 83 (7), 27402747.

66. Archer-Hartmann, S. A.; Crihfield, C. L.; Holland, L. A., Online enzymatic sequencing of glycans from Trastuzumab by phospholipid-assisted capillary electrophoresis. Electrophoresis 2011, 32 (24), 3491-3498.

67. Lu, G.; Holland, L. A., Profiling the N-Glycan Composition of IgG with Lectins and Capillary Nanogel Electrophoresis. Anal. Chem. 2019, 91 (2), 1375-1383.

68. Gattu, S.; Crihfield, C. L.; Holland, L. A., Microscale Measurements of MichaelisMenten Constants of Neuraminidase with Nanogel Capillary Electrophoresis for the Determination of the Sialic Acid Linkage. Anal. Chem. 2017, 89 (1), 929-936.

69. Holland, L. A.; Gattu, S.; Crihfield, C. L.; Bwanali, L., Capillary electrophoresis with stationary nanogel zones of galactosidase and Erythrina cristagalli lectin for the determination of beta(1,3)-linked galactose in glycans. J. Chromatogr. A 2017, 1523, 90-96.

70. Bwanali, L.; Crihfield, C. L.; Newton, E. O.; Zeger, V. R.; Gattu, S.; Holland, L. A., Quantification of the alpha 2-6 Sialic Acid Linkage in Branched N-Glycan Structures with Capillary Nanogel Electrophoresis. Anal. Chem. 2020, 92 (1), 1518-1524.

71. Durney, B. C.; Lounsbury, J. A.; Poe, B. L.; Landers, J. P.; Holland, L. A., A Thermally Responsive Phospholipid Pseudogel: Tunable DNA Sieving with Capillary Electrophoresis. Anal. Chem. 2013, 85 (14), 6617-6625.

72. Durney, B. C.; Bachert, B. A.; Sloane, H. S.; Lukomski, S.; Landers, J. P.; Holland, L. A., Reversible phospholipid nanogels for deoxyribonucleic acid fragment size determinations up to 1500 base pairs and integrated sample stacking. Anal. Chim. Acta 2015, 880, 136-144.

73. Wu, X.; Langan, T. J.; Durney, B. C.; Holland, L. A., Thermally responsive phospholipid preparations for fluid steering and separation in microfluidics. Electrophoresis 2012, 33 (17), 2674-2681.

74. Avanti https://avantilipids.com/ (accessed July 15).

75. Pappas, T. J.; Holland, L. A., Fluid steering in a microfluidic chip by means of thermally responsive phospholipids. Sens. Actuators B Chem. 2008, 128 (2), 427434.

76. Crihfield, C. L.; Kristoff, C. J.; Veltri, L. M.; Wilson, C. A.; Penny, W. M.; Holland, L. A., Data for semi-permanent cationic coating for protein separations. Data Brief 2020, $29,7$.

77. Crihfield, C.; Holland, L., Nanogel electrophoresis separations of proteins. In preparation. 


\section{Chapter 2: Semi-permanent cationic coating for protein separations}

\section{Adapted from}

Crihfield, C. L.; Kristoff, C. J.; Veltri, L. M.; Penny, W. M.; Holland, L.A., Semipermanent Cationic coating for protein separations. Journal of Chromatography $A$ 2019, 1407.

Crihfield, C. L.; Kristoff, C. J.; Veltri, L. M.; Wilson, C. A.; Penny, W. M.; Holland, L.A., Data for Semi-permanent cationic coating for protein separations. Data in Brief 2020, 29, 105123.

\section{Specific Aims:}

1. Develop a semi-permanent coating for capillary electrophoresis separations of proteins.

a. Simultaneous separation of acidic and basic proteins

b. Easy, self assembling modification process

c. Low cost ( $\$ 0.05$ per coat)

d. Reduce protein adsorption

e. Generate EOF across pH values

f. Accurate analysis of human serum proteins with standard addition

This material is based upon work supported by the National Science Foundation Grant No. CHE1506984. CLC acknowledges a National Science Foundation IGERT fellowship, DGE \#1144676. 


\subsection{Introduction}

Capillary electrophoresis is a versatile, cost-effective technique to study proteins for analyses, including purity assays $[1,2]$ as well as structural $[3,4]$, binding $[5,6]$, and stability $[7,8]$ studies. Despite the adaptation of the method for protein analyses, the fused silica capillary surface suffers from protein adsorption, leading to poor separation and reproducibility [9] as a result of band broadening and changes in the capillary surface over time. These issues associated with cationic protein adsorption are commonly circumvented by altering the charge on the capillary surface.

Permanent, dynamic, and semi-permanent capillary coatings have been developed to reduce this protein adsorption [10-12]. Each method has the potential to achieve high efficiency separations of cationic proteins but lacks the ability to separate acidic and basic proteins simultaneously. Capillary coatings reduce cationic protein adsorption by altering the charge on the surface to either be neutral $[13,14]$ or positive [15-18]. Permanent coatings are developed through physical or covalent modification of the capillary surface, which enables the separation to occur without the modification reagent in the background electrolyte [19-21]. Once the coating deteriorates, it cannot easily be restored with the same results. The modification procedures are often complex and time consuming. Permanently coated capillaries are commercially available; however, the inner diameters are usually limited to $50 \mu \mathrm{m}$ or greater [22, 23], with few vendors selling smaller diameters [24]. Dynamic coatings offer a simple means to modify the capillary by flushing the reagent through the capillary, so the coating is easily regenerated [25-27]. However, dynamic coating reagents must be in the background electrolyte $[14,28]$, which can lead to interference with the separation or detection [29]. Semi-permanent coatings are similar to permanent coatings in that the modification reagent can be excluded from the background electrolyte; however, the modification procedure is simple and often only demands that the modification reagent be flushed through the capillary between analyses to maintain a stable coating $[30,31]$. When cationic semi-permanent coatings are implemented, the goal is to overcome the adsorption of basic proteins observed on bare fused silica; therefore, only basic proteins are tested [6,15,16,20,30,32-39]. This challenge of semi-permanent coatings has been obviated by performing separate runs in 
positive polarity for cationic or negative polarity for anionic proteins [14, 40, 41]. A critical comparison of efficiencies is summarized in Table 2-1.

Cetyltrimethylammonium bromide (CTAB) coatings have been used in capillary electrophoresis to improve separations of cations by altering the capillary surface and therefore reducing protein adsorption. CTAB forms a positive double layer [18, 42] or micelles $[43,44]$ on the capillary surface depending on the concentration used. This results in the electroosmotic flow going from the cathode to the anode. Tsuda originally applied the coating for the separation of small molecules [45], but the coating has proven beneficial for the high efficiency separation of proteins as well $[17,18,46]$. The interaction of CTAB with the capillary wall is low, requiring that CTAB be included in the background electrolyte or the electroosmotic flow decreased rapidly [43]. The authors hypothesize that the low interaction is due to the micelle structure created by the single chained surfactant and demonstrate that moving toward a double chained surfactant, which was shown by atomic force microscopy to form flat bilayer structures [44], improved the stability [43]. Although, the dynamic nature of this coating requires CTAB to be included in the background electrolyte, which has been shown to denature the proteins [47]. Previously, CTAB has been combined with sodium dodecyl sulfate in order to form a stable semi-permanent coating, which circumvented the need to include CTAB in the background electrolyte; however, high adsorption of anionic myoglobin was observed [16]. While these separations were primarily applied to basic proteins $[13,14,16-18]$ at neutral $\mathrm{pH}$, one report included acidic proteins by lowering the $\mathrm{pH}$ to 3 where all the proteins would be cationic [48].

Physical coatings are promising reagents for protein separations. For example, separations performed with the cationic polysaccharide coating chitosan had reported plate counts $\geq 400,000$ plates/meter for basic proteins only [39]. Zwitterionic surfactants [49] and phospholipids [50,51] are also good reagents for the separation of proteins, especially when used with dynamic additives that generate electroosmotic flow. The zwitterionic molecule masks the silica surface in order to prevent protein adsorption. A prior study achieved high efficiency separations of cationic and anionic proteins by using 


\begin{tabular}{|c|c|c|c|c|c|c|c|}
\hline \multirow[b]{2}{*}{$\begin{array}{l}\text { Coating } \\
\text { Material }^{\mathrm{a}}\end{array}$} & \multirow[b]{2}{*}{$\underset{b}{\text { EOF }}$} & \multicolumn{3}{|c|}{ Protein Mixtures } & \multicolumn{2}{|c|}{ Plate $/ \mathrm{m} \times 10^{3}$} & \multirow[b]{2}{*}{ Ref } \\
\hline & & $\begin{array}{l}\text { Anions + } \\
\text { Cations }^{c}\end{array}$ & Anions $^{d}$ & Cations $^{d}$ & Anionic & Cationic & \\
\hline $\begin{array}{l}\text { DMPC- } \\
\text { CTAB }\end{array}$ & $\mathrm{Y}$ & $\begin{array}{l}\text { A1-3; } \\
\text { C1-C3 }\end{array}$ & $\mathrm{N} / \mathrm{A}$ & $\mathrm{N} / \mathrm{A}$ & $160-550$ & $460-940$ & $\begin{array}{l}\text { This } \\
\text { work }\end{array}$ \\
\hline DOPC & $S$ & $\begin{array}{l}\text { A4-5; } \\
\text { C1-C5 }\end{array}$ & A6-A8 & C1-C4 & $180-260$ & $180-930$ & [40] \\
\hline DMPC & $S$ & $\mathrm{~N} / \mathrm{A}$ & $\mathrm{N} / \mathrm{A}$ & C1-C5 & $\mathrm{N} / \mathrm{A}$ & $90-370$ & {$[14]$} \\
\hline $\begin{array}{l}\text { DODAB and } \\
\text { POE }\end{array}$ & $S$ & $\mathrm{~N} / \mathrm{A}$ & A6-A8 & C1-C4 & $120-640$ & $25-1300$ & [41] \\
\hline $\begin{array}{l}\text { DODAB +/- } \\
20 \mathrm{mM} \\
\mathrm{CaCl}_{2}\end{array}$ & $\mathrm{Y}$ & $\mathrm{N} / \mathrm{A}$ & A7-A8 & C1-C4 & 350 & $310-1200$ & [54] \\
\hline DODAB & $\mathrm{Y}$ & $\mathrm{N} / \mathrm{A}$ & $\mathrm{N} / \mathrm{A}$ & C1-C4 & $\mathrm{N} / \mathrm{A}$ & $900-1000$ & [32] \\
\hline DODAB & $\mathrm{Y}$ & $\mathrm{N} / \mathrm{A}$ & $\mathrm{N} / \mathrm{A}$ & $\mathrm{C} 1, \mathrm{C} 4$ & $\mathrm{~N} / \mathrm{A}$ & $90-500$ & [33] \\
\hline DODAB & $\mathrm{Y}$ & $\mathrm{N} / \mathrm{A}$ & $\mathrm{N} / \mathrm{A}$ & $\begin{array}{l}\text { C1, C3- } \\
\text { C4 }\end{array}$ & $\mathrm{N} / \mathrm{A}$ & $140-640$ & [30] \\
\hline DDAB & $\mathrm{Y}$ & $\mathrm{N} / \mathrm{A}$ & $\mathrm{N} / \mathrm{A}$ & C1-C4 & $\mathrm{N} / \mathrm{A}$ & $900-4200$ & [34] \\
\hline DDAB & $\mathrm{Y}$ & $\mathrm{N} / \mathrm{A}$ & $N / A$ & C1-C4 & $\mathrm{N} / \mathrm{A}$ & $750-1050$ & {$[37]$} \\
\hline $\begin{array}{l}\text { DDAB, } \\
\text { DHAB, } \\
\text { DTAB }\end{array}$ & $\mathrm{Y}$ & N/A & $N / A$ & C1-C4 & $\mathrm{N} / \mathrm{A}$ & $\begin{array}{l}1000- \\
4000\end{array}$ & [35] \\
\hline $\begin{array}{l}\text { DDAB and } \\
\text { CTAB }\end{array}$ & $\mathrm{Y}$ & $\mathrm{N} / \mathrm{A}$ & $\mathrm{N} / \mathrm{A}$ & C1-C4 & $\mathrm{N} / \mathrm{A}$ & $560-750$ & [38] \\
\hline $\begin{array}{l}2 \mathrm{C} 14 \mathrm{DAB} \\
\text { or } 2 \\
\mathrm{C} 18 \mathrm{DAB}\end{array}$ & $\mathrm{Y}$ & N/A & $N / A$ & C1-C4 & N/A & $700-800$ & {$[36]$} \\
\hline SDS/CTAB & $\mathrm{Y}$ & $\mathrm{N} / \mathrm{A}$ & $\mathrm{N} / \mathrm{A}$ & C1-C4 & $\mathrm{N} / \mathrm{A}$ & $364-562$ & {$[16]$} \\
\hline M7C4I & $\mathrm{Y}$ & $\mathrm{N} / \mathrm{A}$ & N/A & $\mathrm{C} 1-\mathrm{C} 4$ & $\mathrm{~N} / \mathrm{A}$ & 1800 & [15] \\
\hline
\end{tabular}




\begin{tabular}{|l|l|l|l|l|l|l|l|}
\hline linear PCA & $\mathrm{S}$ & $\mathrm{N} / \mathrm{A}$ & $\mathrm{N} / \mathrm{A}$ & $\begin{array}{l}\text { C1, C3- } \\
\text { C4 }\end{array}$ & N/A & N/A & {$[20]$} \\
\hline Chitosan & $\mathrm{Y}$ & $\mathrm{N} / \mathrm{A}$ & $\mathrm{N} / \mathrm{A}$ & $\begin{array}{l}\text { C1, C3- } \\
\text { C4, C6 }\end{array}$ & & & {$[39]$} \\
\hline
\end{tabular}

${ }^{a}$ Coating material abbreviations are as follows: DMPC- 1,2-dimyristoyl-sn-glycero-3phosphocholine; CTAB- cetyltrimethylammonium bromide; DOPC- 1,2-dioleoyl-snglycero-3-phosphocholine; DODAB- dimethyldioctadecylammonium bromide; POEpolyoxyethylene; DDAB - didodecyldimethylammonium bromide; DHAB- 2,2-

dihydroxyazobenzene; DTAB- dodecyltrimethylammonium bromide; M7C4I - 1-(4iodobutyl) 4-aza-1-azoniabicyclo[2,2,2] octane iodide; 2C14DAB-

dimethylditetradecylammonium bromide; 2C18DAB- dimethyldioctadecylammonium bromide; PCA- polyacrylamide

${ }^{b}$ For EOF, $\mathrm{Y}$ means EOF is present and reversed, while $\mathrm{S}$ means EOF is suppressed.

'Protein abbreviations are as follows: alpha-1-antitrypsin (A1), transferrin (A2), enolase (A3), hemoglobin (A4), carbonic anhydrase (A5), insulin chain A (A6), trypsin inhibitor (A7), alpha-lactalbumin (A8), ribonuclease $A(C 1)$, alpha-chymotrypsinogen $A(C 2)$, lysozyme (C3), cytochrome c (C4), myoglobin (C5), not applicable (N/A)

dProteins were listed as cationic or anionic based on the pl and background electrolyte reported in the referenced paper. 
Rewoteric AM CAS U, which is a zwitterionic coating containing a negative sulfonate group and positive amine group[49]. The commercial material was used in combination with perchlorate ions; however, this dynamic coating resulted in cationic protein interaction with the capillary surface at $\mathrm{pH}$ values below 5.5 [49], which limits the use of this coating to analysis of proteins above $\mathrm{pH} 5.5$ or to negative proteins. Other dynamic additives, such as metal ions in combination with phospholipid [51], fluorosurfactants [52], and poly(diallyldimethylammonium chloride) [53], have been utilized for the simultaneous separation of cationic and anionic proteins in the presence of electroosmotic flow, but coating additives are required in the background electrolyte in every case. Double chained surfactants [32, 41, 54] and phospholipids [40] have been used to develop semipermanent coatings that can achieve protein separation efficiencies above 100,000 plates/meter with some including both cationic and anionic proteins [40, 41]. The high efficiencies are an indication of the resolution that can be achieved. However, in the case of near neutral coatings $[40,41]$ strongly acidic $(\mathrm{pl}<6)$ and basic proteins had to be analyzed in separate runs with different polarities at $\mathrm{pH} 7$ due to the suppressed electroosmotic flow.

By utilizing a phospholipid-CTAB coating, the present study generates a stable electroosmotic flow without the need to include CTAB in the background electrolyte (which would limit the use of this coating in future applications and exclude mass spectrometry due to ionization suppression). The interaction between CTAB and the phospholipid bilayer involves insertion of the hydrophobic tail into the bilayer [55-57]. The interaction of CTAB with a phospholipid bilayer is concentration dependent [57-60]. CTAB is disruptive to the bilayer above the critical micelle concentration [61] but is stabilizing to the bilayer below the critical micelle concentration [59]. Furthermore, it has been demonstrated that exposing a phospholipid bilayer coating to calcium and CTAB coatings increases the stability of the bilayer coating [55,62]. The stable interaction between CTAB and phospholipids observed at concentrations below the critical micelle concentration is utilized in this study to generate a semi-permanent coating with a positive surface. This allows for the separation of cationic and anionic proteins in a single analysis with little to no protein adsorption. 
This research demonstrates the limitations of protein analyses using bare fused silica and phospholipid coated capillaries and provides insight into the mechanism, stability, and benefits of the phospholipid-CTAB coating for protein analyses. Severe protein adsorption is shown for cationic proteins using bare fused silica, and while the phospholipid coating alleviates issues with protein adsorption, the suppressed electroosmotic flow results in the requirement to perform anionic and cationic analyses separately. The hydrophobic tail of CTAB is shown to be important to the mechanism of forming the CTAB layer on the preexisting phospholipid coating for the generation of electroosmotic flow. The phospholipid-CTAB coating developed here does not require the addition of CTAB to the background electrolyte and maintains a reproducible electroosmotic flow even after extensive flushing and multiple protein analyses. Separations between $\mathrm{pH} 4$ and $\mathrm{pH} 9$ demonstrate the value of the phospholipid-CTAB coating for the analysis of acidic and basic proteins, as well as the distinction of protein isoforms.

\subsection{Materials and Methods}

2.2.1 Chemicals and reagents. Sodium phosphate, sodium acetate, dimethyl formamide, calcium chloride, tetramethyl ammonium bromide, sodium hydroxide, hydrochloric acid, a-1-antitrypsin from human plasma, alpha-1-acid glycoprotein, ribonuclease $A$ from bovine pancreas, enolase from baker's yeast, a-chymotrypsinogen $A$ from bovine pancreas, human lysozyme (L1667), serum (ERM-DA470k/IFCC), human albumin/immunoglobulin depletion kit (LSKMAGHDKIT) and human transferrin, were purchased from Millipore Sigma (Burlington, MA). Cetyltrimethylammonium bromide was purchased from Acros Organics (Geel, Belgium). Deionized water was filtered using an Elga Purelab ultra water system (Lowell, MA). The phospholipids 1,2-dimyristoyl-snglycero-3-phosphocholine (DMPC) and 1,2-dihexanoyl-sn-glycero-3-phosphocholine (DHPC) were purchased from Avanti Polar Lipids (Alabaster, AL). All buffers were filtered through $0.45 \mu \mathrm{m}$ PTFE filters (VRW) before use.

2.2.2 Preparation of Phospholipid and CTAB solutions. Phospholipid solutions were prepared as described previously $[63,64]$. Briefly, the DMPC and DHPC were weighed 
out so that the sample contained a molar ratio of DMPC: DHPC $=0.5$. The phospholipid powder was then hydrated with $50 \mathrm{mM} \mathrm{pH} 6$ sodium phosphate buffer so that the solution contained 5\% phospholipid (w/v). The phospholipid preparations were thoroughly dissolved using a vortex mixer before undergoing three freeze-thaw cycles, which homogeneously reassemble pre-existing morphologies formed during the process of dissolution. The solutions were then centrifuged at $10000 \mathrm{rpm}$ for $10 \mathrm{~min}$ at $4^{\circ} \mathrm{C}$ to ensure any particulate or undissolved phospholipid could either be isolated from the phospholipids or better dissolved. After centrifugation, samples were aliquoted and stored at $-20^{\circ} \mathrm{C}$. Before use, calcium chloride was added to the phospholipid solution at a concentration of $1.25 \mathrm{mM}$. Calcium chloride is included in the preparations to fuse the bilayer and create a continuous surface [65].

The solution for the CTAB coating was prepared from powder daily. The stock solution was prepared at $8 \mathrm{mM}$ using $50 \mathrm{mM}$ phosphate $50 \mathrm{mM}$ acetate $\mathrm{pH} 7.4$ buffer. The solution was mixed using a vortex mixer. After the powder was dissolved, the stock was diluted with run buffer, which was $50 \mathrm{mM}$ phosphate $50 \mathrm{mM}$ acetate buffered at $\mathrm{pH} 5-8$. The final CTAB concentration for the coating solution ranged from 50-500 $\mu \mathrm{M}$.

2.2.3 Capillary Electrophoresis. Separations were performed using a P/ACE MDQ or MDQ Plus (Sciex, Redwood City, CA) with UV-vis absorbance detection at $200 \mathrm{~nm}$. Bare fused silica capillaries with a $25 \mu \mathrm{m}$ internal diameter, total length of $60 \mathrm{~cm}$, and effective length of $10 \mathrm{~cm}$ or $50 \mathrm{~cm}$ (Polymicro Technologies, Phoenix, AZ) were used for separations. For electroosmotic flow measurements, dimethyl formamide was prepared at a concentration of $2 \mathrm{mM}$ with $50 \mathrm{mM}$ phosphate $50 \mathrm{mM}$ acetate buffered at $\mathrm{pH}$ 7.4. Stock concentrations of proteins were dissolved to $250 \mu \mathrm{M}$ in $50 \mathrm{mM}$ phosphate buffer $\mathrm{pH} 7.4$ and were stored at $4^{\circ} \mathrm{C}$. Protein standards were diluted in the background electrolyte to $40 \mu \mathrm{M} \alpha$-1-antitrypsin, $10 \mu \mathrm{M}$ transferrin, $10 \mu \mathrm{M}$ enolase, $40 \mu \mathrm{M} \alpha$ chymotrypsinogen $\mathrm{A}, 50 \mu \mathrm{M}$ ribonuclease $\mathrm{A}$, and $50 \mu \mathrm{M}$ lysozyme in order to keep similar signals between proteins despite differences in absorbance. The only exception to this was that proteins were suspended in $\mathrm{pH} 7$ for the $\mathrm{pH} 4$ separations to avoid problems with protein stability in solution. Protein stocks were prepared weekly, while protein 
samples were prepared fresh daily. Serum was depleted of immunoglobulins and albumins using the depletion kit according to the manufacturer's protocol because the concentration of these proteins are much higher than the concentrations of the other abundant proteins. As a result of processing and reconstitution in phosphate buffered saline the sample that was analyzed was diluted by a factor of 1.96 .

2.2.4 Preparation of bare fused silica capillaries. For bare fused silica studies, the capillaries were conditioned with sodium hydroxide for $60 \mathrm{~min}$ and water for $10 \mathrm{~min}$ at 172 $\mathrm{kPa}$ (25 psi). Between runs, the capillary was flushed with $1 \mathrm{M}$ sodium hydroxide for 10 min, deionized water for $7.5 \mathrm{~min}$, and BGE for $4.5 \mathrm{~min}$ at $172 \mathrm{kPa}$ (25 psi). Protein standards were injected serially as two separate mixtures, standard 1 ( $\alpha$-1-antitrypsin, transferrin, and enolase) and standard 2 (ribonuclease A, and lysozyme), at $3.4 \mathrm{kPa}(0.5$ psi) for $5 \mathrm{~s}$. Separations were performed using normal polarity at a field strength of 400 $\mathrm{V} / \mathrm{cm}$ and an effective capillary length of $10 \mathrm{~cm}$.

2.2.5 Preparation of the phospholipid coated capillaries. For separations employing the phospholipid coating, capillaries were prepared as follows. First bare fused silica capillaries were conditioned with $1 \mathrm{M}$ sodium hydroxide for $30 \mathrm{~min}$, deionized water for $15 \mathrm{~min}$, methanol for $15 \mathrm{~min}$, and deionized water for $15 \mathrm{~min}$ at $172 \mathrm{kPa}$ (25 psi). Phospholipid bilayers self-assemble on silica surfaces to form a semi-permanent bilayer to passivate and suppress electroosmotic flow $[50,51]$. To create the non-covalent phospholipid surface modification, the discrete nanodisks formed from the phospholipid coating solution are introduced to self-assemble on the silica surface [31]. Capillaries were then flushed with $50 \mathrm{mM}$ phosphate $50 \mathrm{mM}$ acetate buffered at $\mathrm{pH} 7$ for $3 \mathrm{~min}$, phospholipid ([DMPC]/[DHPC] $=0.5,5 \%$ phospholipid by weight) in sodium phosphate buffered at $\mathrm{pH} 6$ for $20 \mathrm{~min}$, and $50 \mathrm{mM}$ phosphate $50 \mathrm{mM}$ acetate buffered at $\mathrm{pH} 7$ for 3 min at $172 \mathrm{kPa}(25 \mathrm{psi})$. Between each analysis, capillaries were flushed with run buffer for $7.5 \mathrm{~min}$, [DMPC]/[DHPC] $=0.5,5 \%$ phospholipid for $7.5 \mathrm{~min}$, and run buffer for 4.5 min at $172 \mathrm{kPa}(25 \mathrm{psi})$. An injection of protein standard 1 or protein standard 2 at 3.4 $\mathrm{kPa}(0.5 \mathrm{psi})$ for $5 \mathrm{~s}$ was performed. Analyses were performed at $400 \mathrm{~V} / \mathrm{cm}$ in reverse polarity for anions and in normal polarity for cations with an effective length of $10 \mathrm{~cm}$. 
2.2.6 Preparation of the phospholipid-CTAB coated capillaries. For separations using the phospholipid-CTAB coating, capillaries were prepared in the same manner as for the phospholipid coating with two additional steps. The flush before each run was modified to include a $7.5 \mathrm{~min}$ flush with CTAB at $172 \mathrm{kPa}(25 \mathrm{psi})$ after the $7.5 \mathrm{~min}$ phospholipid flush. For CTAB separations at different $\mathrm{pH}$ values, the CTAB solution was made in the background electrolyte buffered at the same $\mathrm{pH}$ value as that used for the separation except for the analyses performed at a $\mathrm{pH}$ of 4 . The CTAB solution for the $\mathrm{pH} 4$ separations was reconstituted in background electrolyte buffered at $\mathrm{pH}$. The CTAB concentration was $100 \mu \mathrm{M}$ except where otherwise noted. A wait step was programmed so that the capillary was dipped into a buffer vial specifically used to remove any residual CTAB from the exterior surface of the capillary before continuing the flush sequence. Analyses were performed at $400 \mathrm{~V} / \mathrm{cm}$ with injections occurring at the cathode and detection at the anode. The effective length for experiments that compared the hybrid phospholipid-CTAB coating to the bare fused silica and phospholipid coating was $10 \mathrm{~cm}$, while the effective length for analyses across different $\mathrm{pH}$ values was $50 \mathrm{~cm}$. All coating and capillary preparative steps occurred at $19^{\circ} \mathrm{C}$ and all separations occurred at $25^{\circ} \mathrm{C}$ using thermostated capillary cartridges. Data collection and analyses were performed using 32 Karat Software versions 7.0 or 10.2 .

\subsection{Results and Discussion}

2.3.1 Bare fused silica analyses. Bare fused silica capillary electrophoresis separations are limited by the adsorption of cationic proteins to the negative capillary surface. This is demonstrated in Figure 2-1 trace $A$ through the separation of five model proteins with a range of isoelectric points [66-71]: lysozyme, ribonuclease $A$, enolase, transferrin, and $\alpha$ 1-antitrypsin. Proteins that are more cationic experienced more adsorption to the silica surface. Lysozyme, which is the most cationic protein with an isoelectric point above 11 [71], interacts so strongly with the capillary it is absent from the electropherogram, a phenomenon which has been reported in the literature [13]. For the other proteins, peak tailing attributed to adsorption is quantified using peak asymmetry. The asymmetry values for ribonuclease $A$ and enolase are 3.1 and 1.8, respectively, indicating that ribonuclease $A$ experiences significantly more adsorption than enolase, which is anionic. 


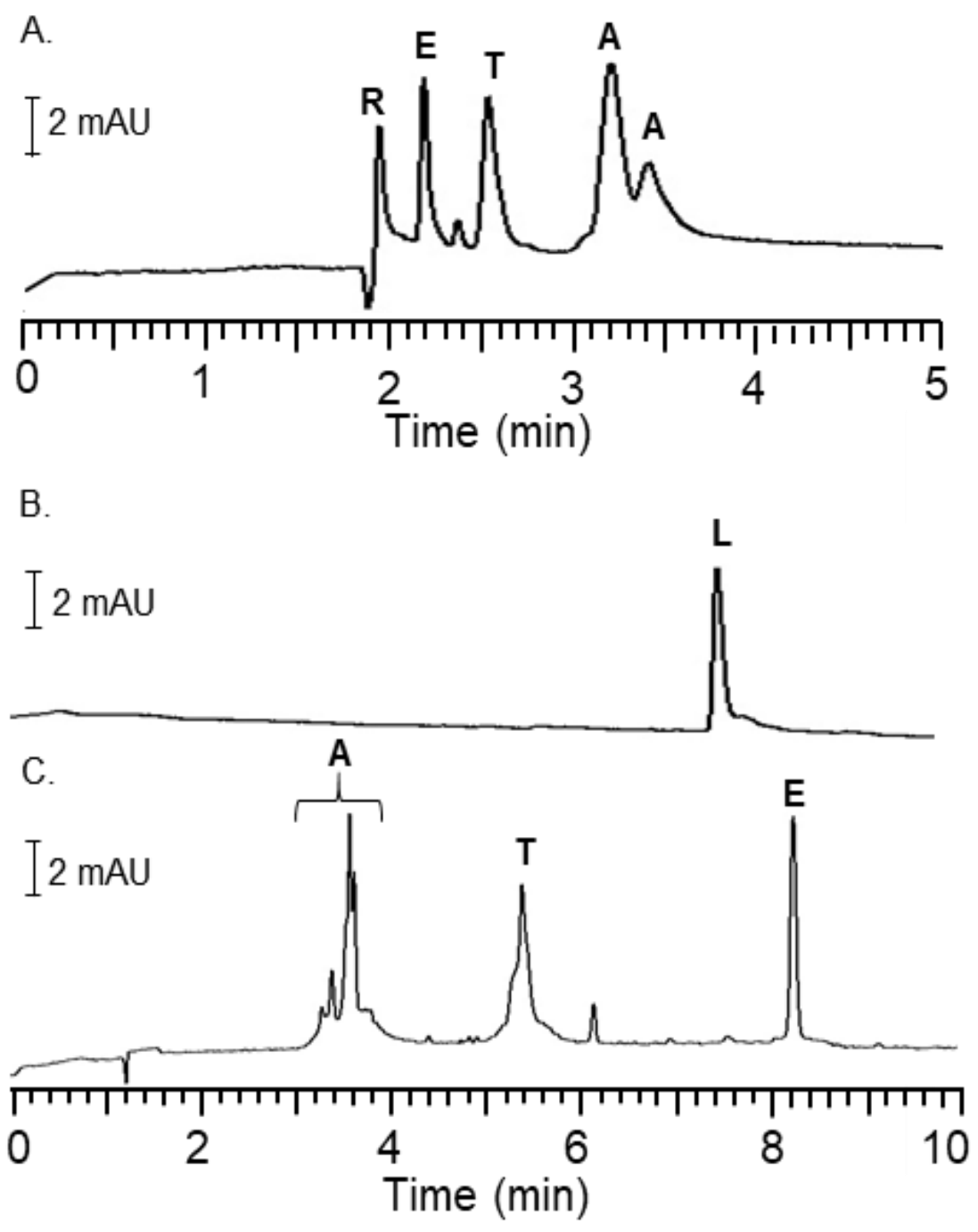

Figure 2-1. Bare fused silica and phospholipid coated separations of proteins. The protein models $\alpha$-1-antitrypsin (AAT, $[A]$ ), transferrin $[T]$, enolase $[E]$, ribonuclease $A$ (RNAse) $[R]$, and lysozyme $[L]$ were separated on $(A)$ bare fused silica and $(B, C)$ phospholipid coated capillary to demonstrate the reduction of protein adsorption achieved with the phospholipid coated capillary. Run conditions: UV detection at $200 \mathrm{~nm}$; Ltot $=60$ $\mathrm{cm}$; Leff $=10 \mathrm{~cm} ; 24 \mathrm{kV}$ applied voltage in normal polarity (A, B); $24 \mathrm{kV}$ applied voltage in reverse polarity $(\mathrm{C}) ; 50 \mathrm{mM}$ phosphate $50 \mathrm{mM}$ acetate buffer, $\mathrm{pH}$ 7. Reproduced from Crihfield 2019. 
Pressure injections were used throughout the study in order to avoid preferential injections or biases in the data resulting from differences in protein mobilities. Transferrin and $\alpha-1$-antitrypsin are excluded from this comparison since both proteins have multiple isoforms [66,72], which makes the peak shape asymmetric even in the absence of adsorption to the wall.

2.3.2 Phospholipid coated analyses. A semi-permanent phospholipid coating is employed for the protein separations, see Figure 2-1 traces $B$ and $C$, to reduce the negative charge on the surface and prevent protein adsorption on the capillary wall. The coating results in a slight electroosmotic flow from the cathode to the anode, which is quantified [73] as $-0.2 \times 10^{-4} \mathrm{~cm}^{2} \mathrm{~V}^{-1} \mathrm{~s}^{-1}$ using a previously established method [74], and is shown in Figure S-2-2A. However, electroosmotic flow of this magnitude is not sufficient for anions and cations to be analyzed in a single run, which is why the cations are analyzed in normal polarity (trace B) and the anions are analyzed in reverse polarity (trace C). The phospholipid coating alleviates the cationic adsorption as evidenced by the detection of lysozyme in Figure 2-1 trace B with an asymmetry factor of 1.3. However, ribonuclease $A$ is not detected in the phospholipid coating analyses due to the suppressed electroosmotic flow and the low mobility of ribonuclease $A$. As shown in Figure 2-2B, the mobility is determined to be $0.08 \times 10^{-4} \mathrm{~cm}^{2} \mathrm{~V}^{-1} \mathrm{~s}^{-1}$ using an established method [74]. Furthermore, the phospholipid coating reduces the adsorption of anionic proteins as well, which is demonstrated by the improvement in the asymmetry factor for enolase from bare fused silica (1.8) to phospholipid coating analyses (1.1). Theoretical plate counts, which are summarized in Table 2-2, improve by 2-fold or more for the phospholipid analyses further corroborating that interaction between proteins and the capillary wall is reduced with a phospholipid coated capillary. While the barrier of protein adsorption is overcome using the phospholipid coating, the coating is not capable of separating cationic and anionic proteins in a single run.

2.3.3 Phospholipid-CTAB coated analyses. Electroosmotic flow with an inert phospholipid surface is generated through the addition of CTAB. The hydrophobic tail of CTAB is postulated to insert into the lipid bilayer [56-58], as depicted conceptually in Figure 2-3A. 

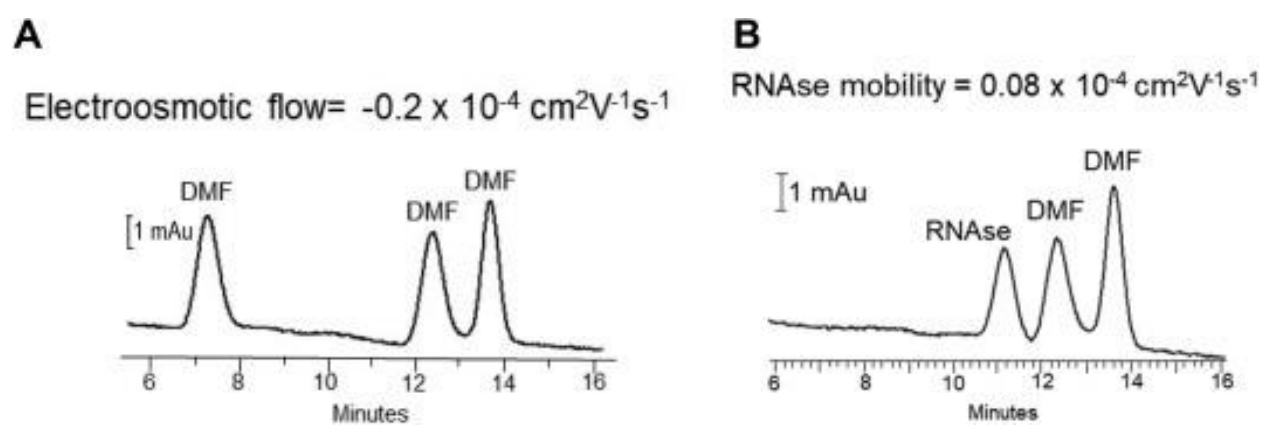

Figure 2-2. A. The electroosmotic flow in a phospholipid coated capillary was determined to be $-0.2 \times 10^{-4} \mathrm{~cm}^{2} \mathrm{~V}^{-1} \mathrm{~s}^{-1}$ using the method previously reported in the literature [2]. For this analysis, the specified pressure and push step into the capillary was $3.4 \mathrm{kPa}(0.5 \mathrm{psi}) 5 \mathrm{~min}$ and the electrophoresis time was $3 \mathrm{~min}$ at 24 $\mathrm{kV}$. In B, the electrophoretic mobility of Ribonuclease A (RNAse) in a phospholipid coated capillary was determined with slight modification and required only two injections, the first one containing DMF and ribonuclease $A$ and the second containing only DMF. The push step was $3.4 \mathrm{kPa}(0.5 \mathrm{psi})$ for $5 \mathrm{~min}$ and the electrophoresis time was 3 min at 24 kV. Reproduced from Crihfield 2020. 
Table 2-2. Impact of capillary surface on efficiency

\section{Average plates (RSD)}

\begin{tabular}{|c|c|c|c|c|c|}
\hline & $\mathrm{AAT}^{\mathrm{b}}$ & Tf & Enol & RNAse & Lys \\
\hline Bare fused & $\mathrm{N} / \mathrm{A}$ & $5,000(21)$ & $14,000(18)$ & $11,000(9)$ & $\mathrm{N} / \mathrm{A}^{\mathrm{c}}$ \\
\hline Phospholipid & $\mathrm{N} / \mathrm{A}$ & $11,000(2)$ & $79,000(4)$ & $N / A^{d}$ & $16,000(11)$ \\
\hline \multicolumn{6}{|c|}{$\begin{array}{l}\text { a Separations obtained using a background electrolyte of } 50 \mathrm{mM} \text { sodium phosphate } 50 \\
\text { mM sodium acetate buffered at pH 7, a } 25 \mu \mathrm{m} \text { internal diameter fused silica capillary with } \\
\text { a total length of } 60 \mathrm{~cm} \text {, an effective length of } 10 \mathrm{~cm} \text { and } \mathrm{E}=400 \mathrm{~V} / \mathrm{cm} \text {. Relative standard } \\
\text { deviation (RSD) and average are based on } n=6 \text { measurements. } \\
{ }^{\mathrm{b}} \mathrm{\alpha}-1 \text {-antitrypsin not included because the isoforms produced multiple peaks. } \\
\text { cAdsorption of lysozyme to the silica wall, prevented calculation of plate count. } \\
\text { dRibonuclease A migrated too slowly to be seen within the separation timeframe. }\end{array}$} \\
\hline
\end{tabular}




\section{A. Phospholipid}

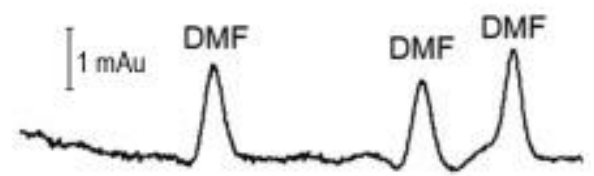

B. Phospholipid + HG

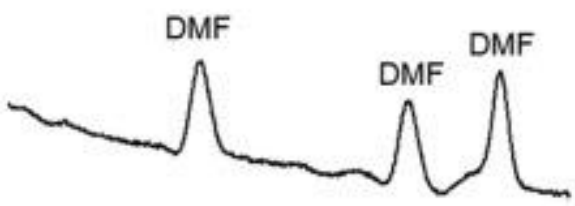

C. Phospholipid + CTAB

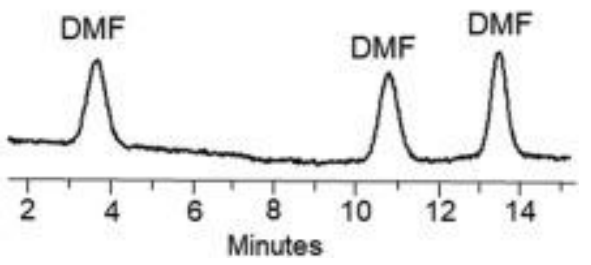

Figure 2-3. The electroosmotic flow for a phospholipid coated capillary (A) for phospholipid capillary coated with the tetramethyl ammonium bromide head group $(\mathrm{HG})$ of CTAB (B) and for phospholipid capillary coated with CTAB (C) was determined using the method described in Fig. 1, with some modifications. The phospholipid (A) and phospholipid with HG (B) were analyzed with no modification, which resulted in electroosmotic flow of $-0.2 \times 10^{-4} \mathrm{~cm}^{2} \mathrm{~V}^{-1} \mathrm{~s}^{-1}$. Due to the high electroosmotic flow in the phospholipid with CTAB capillary $(C)$, the method was modified to have a $3.4 \mathrm{kPa}(0.5 \mathrm{psi}) 7 \mathrm{~min}$ push step and $30 \mathrm{~s}$ electrophoresis to keep the peaks between the injection and detection sites. The phospholipid with CTAB capillary had an electroosmotic flow of $-4.2 \times 10^{-4} \mathrm{~cm}^{2} \mathrm{~V}^{-1} \mathrm{~s}^{-1}$. Reproduced from Crihfield 2020. 
In order to verify the importance of the hydrophobic tail, the electroosmotic flow is measured for phospholipid alone, phospholipid with only the charged group of CTAB, and phospholipid with CTAB, seen in Figure 2-3. Fast and accurate determinations of mobility were achieved [73] as reported previously [74] by introducing 3 sample injections segregated by background electrolyte and monitoring the effect of electric field on the spacing between the analyte bands. The electroosmotic flows for the phospholipid coating and the phospholipid coating with the charged group are the same (i.e. $-0.2 \times 10^{-}$ ${ }^{4} \mathrm{~cm}^{2} \mathrm{~V}^{-1} \mathrm{~s}^{-1}$ ), while the phospholipid-CTAB coating generated an electroosmotic flow of $3.1 \times 10^{-4} \mathrm{~cm}^{2} \mathrm{~V}^{-1} \mathrm{~s}^{-1}$, signifying that the hydrophobic tail is necessary for the hybrid coating formation. Furthermore, the chain length of the surfactant is important for the hydrophobic interaction and insertion. As shown in Table 1 in Appendix 1, this was confirmed by achieving the same electroosmotic flow as the phospholipid coating when octyltrimethyl ammonium bromide, which has an 8 carbon chain and the same head group as CTAB, is utilized instead of the 16 carbon chain of CTAB.

A stable electroosmotic flow is achieved once the CTAB saturates the surface. As summarized in Table 2-3, once CTAB concentrations above $50 \mu \mathrm{M}$ are utilized in the coat, the electroosmotic flow does not change. There is no need to include CTAB in the background electrolyte as the phospholipid-CTAB coating remains stable even after extensive flushing with background electrolyte ( $>2 \mathrm{hr}$ ) that does not contain CTAB, see Table 2-4. No significant change in electroosmotic flow was observed across flushing times [73].

The effect of $\mathrm{pH}$ on the coating performance was evaluated and is shown in Table 2-5. A combination of sodium phosphate and sodium acetate was used for the background electrolyte so that each of the $5 \mathrm{pH}$ values tested was buffered while maintaining the same salt ion composition in the separation medium. The phospholipid-CTAB coating generated electroosmotic flow across a range of $\mathrm{pH}$ values. While the electroosmotic flow varied less than $1 \%$ within $\mathrm{pH}$, the electroosmotic flow increased $16 \%$ between $\mathrm{pH} 5$ and $\mathrm{pH} 7$ [73]. This may be the result of an increase in the lipid packing at low $\mathrm{pH}$ values [75] improving the capacity for CTAB to insert into the bilayer. 


\section{Table 2-3. Impact of CTAB concentration on electroosmotic flow}

\begin{tabular}{|c|c|}
\hline [CTAB], $\mu \mathrm{M}$ & $\begin{array}{l}\text { Electroosmotic flow } \\
\times 10^{-4} \mathrm{~cm}^{2} \mathrm{~V}^{-1} \mathrm{~s}^{-1} \text { (RSD) }\end{array}$ \\
\hline 50 & $2.04(3)$ \\
\hline $100^{a, b}$ & $3.14(0.3)$ \\
\hline $300^{b}$ & $3.14(0)$ \\
\hline $500^{b}$ & $3.14(0.2)$ \\
\hline \multicolumn{2}{|c|}{$\begin{array}{l}\text { aSeparation conditions as described in Table } 1 \text {. Relative } \\
\text { standard deviation (RSD) and average at } 100 \mu \mathrm{M} \text { CTAB were } \\
\text { obtained from } n=3 \text { measurements, while all other } \\
\text { concentrations were obtained from } n=5 \text { measurements. } \\
\text { 'These concentrations are statistically the same as determined } \\
\text { with ANOVA }(\rho<0.2516, \mathrm{~F} \text { value } 1.752<5.14) \text {. }\end{array}$} \\
\hline
\end{tabular}




\section{Table 2-4. Impact of buffer flush time on}

electroosmotic flow

\begin{tabular}{|c|c|}
\hline Flush time (min) ${ }^{a}$ & $\begin{array}{l}\text { Electroosmotic flow } \\
\times 10^{-4} \mathrm{~cm}^{2} \mathrm{~V}^{-1} \mathrm{~s}^{-1} \text { (RSD) }^{\mathrm{b}}\end{array}$ \\
\hline 4.5 & $3.10(0)$ \\
\hline 7.5 & $3.10(0.3)$ \\
\hline 10 & $3.14(0)$ \\
\hline 15 & $3.11(0.3)$ \\
\hline 30 & $3.11(0.2)$ \\
\hline 60 & $3.12(0.6)$ \\
\hline 120 & $3.15(0.2)$ \\
\hline \multicolumn{2}{|c|}{$\begin{array}{l}\text { aThe flush time listed is the buffer flush after the CTAB } \\
\text { flush and programmed wait step to prevent } \\
\text { contamination in the CTAB flushing sequence. }\end{array}$} \\
\hline $\begin{array}{l}\text { beparation conditions as } \\
\text { standard deviation (RSD } \\
\text { with } n=3 \text { measurement }\end{array}$ & $\begin{array}{l}\text { scribed in Table 1. Relative } \\
\text { ad average were obtained }\end{array}$ \\
\hline
\end{tabular}


Table 2-5. Impact of $\mathrm{pH}$ on electroosmotic flow ${ }^{\mathrm{a}, \mathrm{b}}$

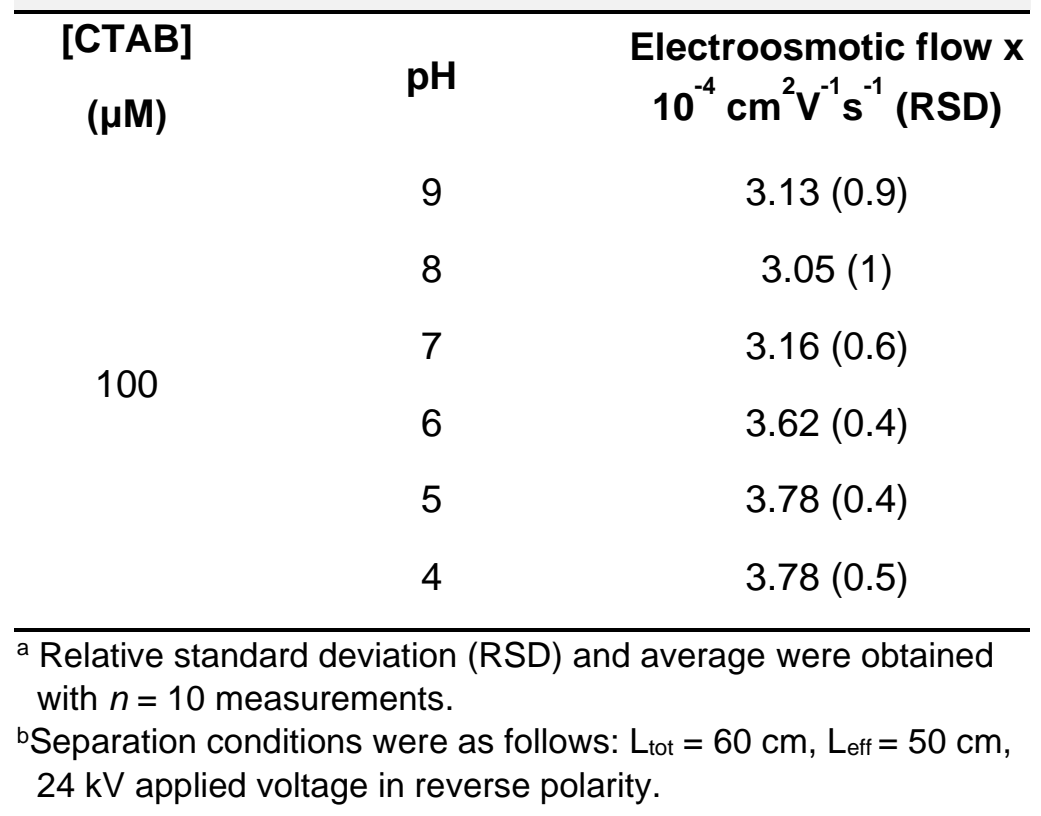


The stability of the coating developed in this research is different from one previously reported that used CTAB with an egg-phosphotidylcholine coating [55]. This prior coating demonstrated high efficiency separations but required frequent replenishing of the coating between analyses. In the previous study, the CTAB was incorporated in the phospholipid solution prior to coating the capillary at concentrations at or below $15 \mu \mathrm{M}$ [55]. These differences in the procedure and stability of the coating indicate that the structure of the surface is impacted by whether the phospholipid bilayer is already established on the capillary surface prior to the addition of CTAB. Furthermore, the previously developed coating had a much lower charge on the surface at the concentrations tested, which resulted in the coating only being used for the separation of basic proteins.

Cationic and anionic proteins are analyzed using the developed phospholipid-CTAB coating without adsorption to the capillary surface, as shown in Figure 2-4. In these analyses, the most anionic proteins migrate first since the electroosmotic flow is from the cathode to the anode. Band broadening associated with protein-wall interaction was not observed [73] as the theoretical plate counts for the phospholipid-CTAB analyses were equal to or greater than those observed in the phospholipid capillary. The plate count for enolase was the exception, which generated a 6-fold change in migration time between the two analyses and the width of the peak is injection limited in the CTAB analyses [73]. This was confirmed by establishing that the plates per meter increased when the effective length was increased from $10 \mathrm{~cm}$ to $50 \mathrm{~cm}$ [73]. A $50 \mathrm{~cm}$ effective length was used for the remainder of the studies.

To further substantiate that proteins did not interact with the surface, 6 consecutive runs were performed without flushing between analyses. The two proteins separated in this experiment, $\alpha-1$-antitrypsin and lysozyme, were the most anionic and cationic proteins of the 5-protein set used in this research. The migration times and the electroosmotic flow had a relative standard deviation (RSD) of $1 \%$ from the first to the sixth analyses. The first and last trace are shown in Figure 2-5 to demonstrate the similarities in the traces. This result corroborated the assertion that there was no change in the capillary surface due to protein adsorption. Since CTAB was not required in the background electrolyte to 


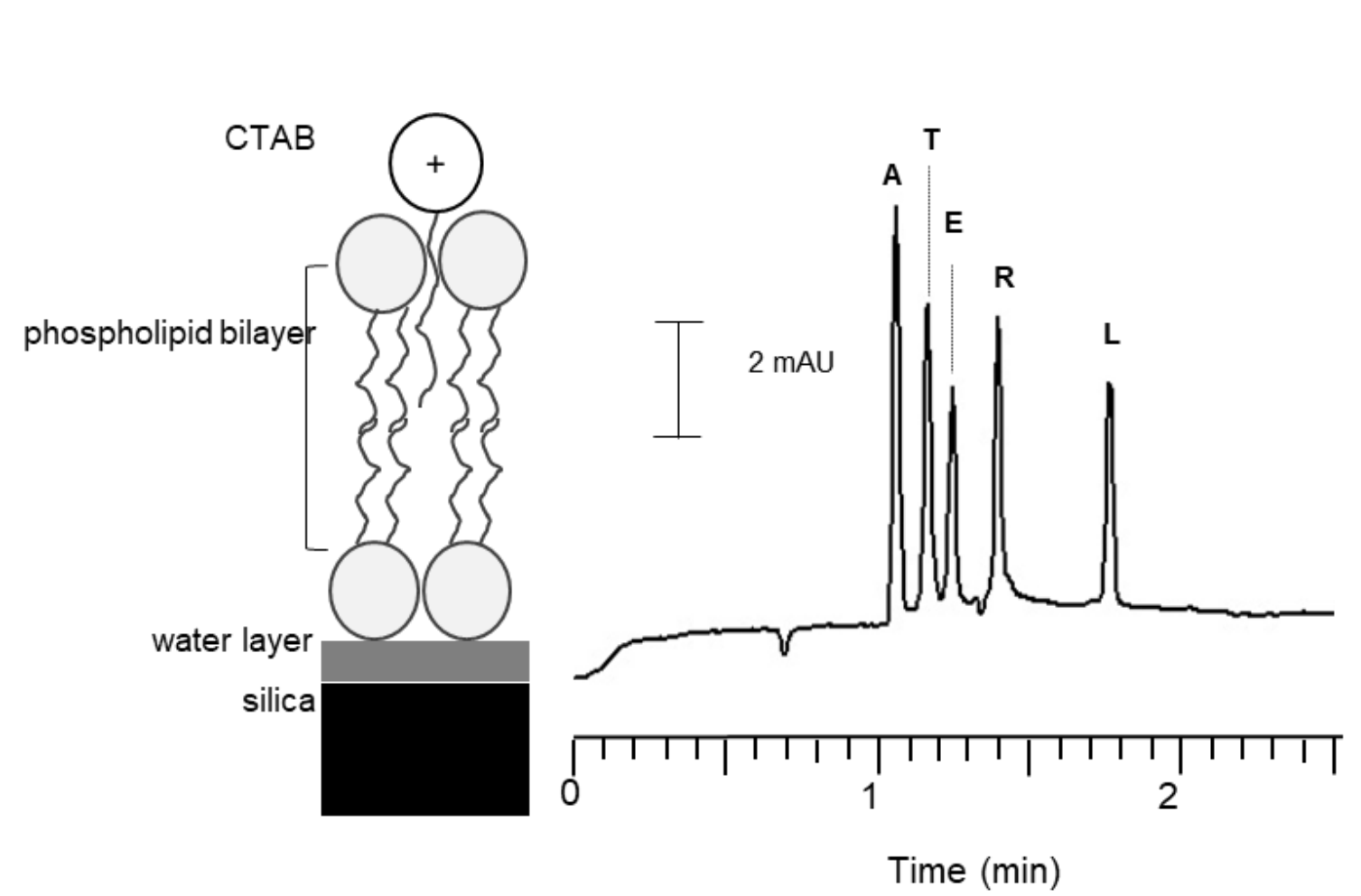

Figure 2-4. Phospholipid-CTAB coated surface and separation. The hydrophobic chain of CTAB inserts into the phospholipid bilayer to form a stable coating (A). The resulting electroosmotic flow allows for separation of cationic and anionic proteins (B). Abbreviations and separation conditions are as noted in Figure 1 with the use of reverse polarity. Reproduced from Crihfield 2019. 


\section{A. Run 1}

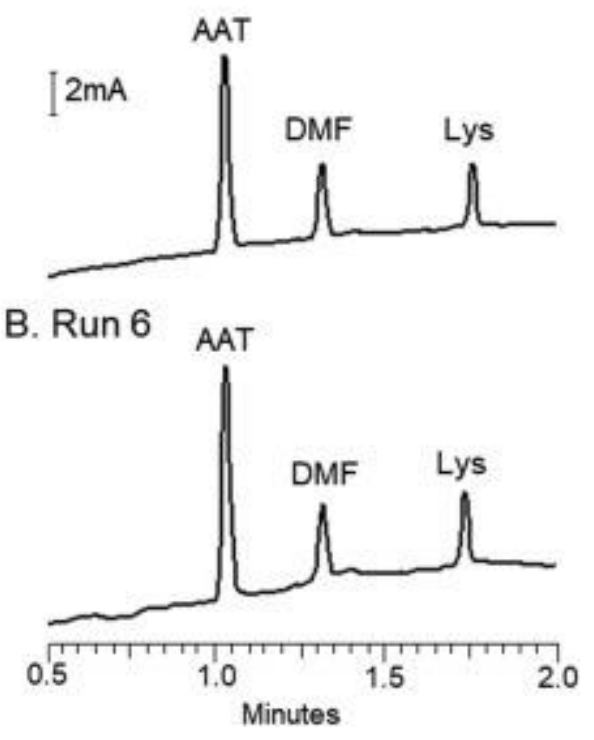

Figure 2-5. The absence of protein adsorption when the phospholipid-CTAB coating is applied was proven by performing consecutive analyses of $\alpha$-1antitrypsin, neutral marker (DMF), and lysozyme without flushing between each run. The migration times of the proteins and neutral marker vary by $1 \%$ from run 1 (A) to run 6 (B), which indicates that no adsorption occurred. Reproduced from Crihfield 2020. 
maintain a stable coating, no CTAB-protein complex formation occurred. This was confirmed by the observation that the electrophoretic mobilities obtained using the phospholipid-CTAB coating were within $8 \%$ of the electrophoretic mobilities obtained from phospholipid analyses [73].

2.3.4 Tuning protein separations using $\mathrm{pH}$. The electrophoretic mobility of each protein is impacted by the $\mathrm{pH}$ as a function of the isoelectric point. The effect of $\mathrm{pH}$ on mobility is summarized in Table 2-6. When the $\mathrm{pH}$ of the background electrolyte is above the isoelectric point, the protein is negative and migrates with an electrophoretic mobility toward the anode. As the $\mathrm{pH}$ approaches the isoelectric point, the electrophoretic mobility decreases until the protein is neutral, which occurs when the $\mathrm{pH}$ is the same as the isoelectric point. When the $\mathrm{pH}$ is below the isoelectric point, the protein is cationic and migrates toward the cathode. The migration times were reproducible with in each $\mathrm{pH}$ (RSD $<1 \%$ ) as shown in Table 2-7. The migration times were reproducible across three days for the background electrolyte buffered to $\mathrm{pH}$ of 7 (RSD $\leq 1 \%$ ). The electroosmotic flow was measured at each $\mathrm{pH}$, as summarized in Table 2-5, and was found to be stable with RSDs less than $1 \%$. The electroosmotic flow was used to calculate the electrophoretic mobilities. It should be noted that in cases where the electrophoretic mobility was zero (e.g. transferrin at $\mathrm{pH} 5$, enolase at $\mathrm{pH} 6$, and ribonuclease $\mathrm{A}$ at $\mathrm{pH} 8$ ) the measurement of electrophoretic mobility was subject to high error because the electrophoretic mobility, obtained by subtracting the electroosmotic mobility from the apparent mobility, was so small that there were effectively no significant figures in the measurement. While the phospholipid-CTAB coating is stable within a range of $\mathrm{pH} 4$ to 8 , the coating was unstable at a $\mathrm{pH}$ of 3 , as the migration times varied substantially for repeated separations. Although at a $\mathrm{pH}$ of 9 the phospholipid coating produced migration times with $\leq 1 \% \operatorname{RSD}(n=10)$, this $\mathrm{pH}$ value was beyond the buffered region of the phosphate-acetate background electrolyte. Please note the time difference between Figure 2-4 and Figure 2-6 is the result of the latter separations being performed with a 
Table 2-6. Effect of pH on mobility

Electrophoretic Mobility $\times 10^{-4} \mathrm{~cm}^{2} \mathrm{~V}^{-1} \mathrm{~s}^{-1}(\mathrm{RSD})^{\mathrm{a}}$

$\begin{array}{lllllll}\text { pH } 9^{\mathrm{b}} & \mathrm{pH} 8 & \mathrm{pH} 7 & \mathrm{pH} 6 & \mathrm{pH} 5 & \mathrm{pH} 4\end{array}$

\begin{tabular}{|c|c|c|c|c|c|c|}
\hline$\alpha-1-A n t i t r y p \sin$ & $-1.18(2)$ & $-1.09(4)$ & $-0.93(2)$ & $\begin{array}{l}-0.78(2) \\
-0.70(10)\end{array}$ & $\begin{array}{l}-0.49(3) \\
-0.46(4) \\
-0.34(5)\end{array}$ & $N / A^{c}$ \\
\hline Transferrin & $-0.81(3)$ & $-0.64(6)$ & $-0.53(4)$ & $-0.32(5)$ & $-0.02(80)^{d}$ & $N / A^{c}$ \\
\hline Enolase & $-0.69(3)$ & $-0.40(9)$ & $-0.27(7)$ & $0(200)^{e}$ & $0.28(6)$ & $0.99(2)$ \\
\hline $\begin{array}{l}\text { a-Chymo- } \\
\text { trypsinogen }\end{array}$ & $-0.31(7)$ & $-0.05(70)$ & $0.06(40)$ & $0.37(4)$ & $0.59(3)$ & $0.88(2)$ \\
\hline Ribonuclease A & $-0.23(10)$ & $-0.03(100)^{f}$ & f $0.10(20)$ & $0.45(3)$ & $0.72(2)$ & $1.06(2)$ \\
\hline Lysozyme & 0.48 (5) & $0.66(6)$ & $0.78(3)$ & $1.2(2)$ & $1.3(1)$ & $1.51(2)$ \\
\hline
\end{tabular}

axcept where noted, measurements are based on $n=20$ for the proteins and $n=10$ for DMF.

${ }^{b}$ All measurements at $\mathrm{pH} 9$ were based on $n=10$.

${ }^{\circ} \mathrm{\alpha}-1$-antitrypsin and transferrin were removed at $\mathrm{pH} 4$.

${ }^{\mathrm{d}}$ Transferrin was removed at $\mathrm{pH} 5$ when DMF was ran. $(n=10)$

eEnolase was removed at $\mathrm{pH} 6$ when DMF was ran. $(n=10)$

fRibonuclease A was removed at $\mathrm{pH} 8$ when DMF. $(n=10)$ 


\begin{tabular}{|c|c|c|c|c|c|c|}
\hline \multirow{5}{*}{$\alpha-1-A n t i t r y p \sin ^{c}$} & \multicolumn{6}{|c|}{ 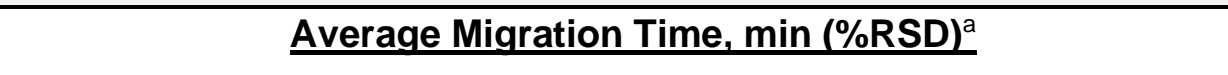 } \\
\hline & pH $9^{b}$ & pH 8 & pH 7 & pH 6 & pH 5 & pH 4 \\
\hline & $4.83(0.4)$ & $5.03(1)$ & $5.10(0.4)$ & $4.74(0.4)$ & $4.88(0.3)$ & $N / A^{d}$ \\
\hline & & & & $4.82(0.4)$ & $4.91(0.3)$ & \\
\hline & & & & & $5.05(0.4)$ & \\
\hline Transferrin & $5.28(1)$ & $5.65(1)$ & $5.65(0.5)$ & $5.29(0.4)$ & $5.48(0.2)^{\mathrm{e}}$ & $N / A^{d}$ \\
\hline Enolase & $5.43(1)$ & $6.03(2)$ & $6.08(0.5)$ & $5.74(0.7)^{\dagger}$ & $5.96(0.5)$ & $7.45(2)$ \\
\hline $\begin{array}{l}\text { a-Chymo- } \\
\text { trypsinogen A }\end{array}$ & $5.94(4)$ & $6.71(2)$ & $6.72(0.4)$ & $6.40(0.6)$ & $6.54(0.5)$ & $7.17(1)$ \\
\hline Ribonuclease A & $6.18(1)$ & $6.77(2)^{g}$ & $6.83(0.4)$ & $6.58(0.7)$ & $6.80(0.5)$ & $7.66(1)$ \\
\hline Lysozyme & $7.74(3)$ & $8.73(3)$ & $8.78(0.6)$ & $8.50(0.9)$ & $8.48(0.7)$ & $9.17(2)$ \\
\hline
\end{tabular}

${ }^{a}$ Relative standard deviation (RSD) and average are based on $n=20$ measurements for the proteins and $n=10$ measurements for dimethylformamide, except as noted below.

-Measurements obtained at $\mathrm{pH} 9$ are based on $n=10$.

- $\alpha$-1-antitrypsin isoforms are resolved at $\mathrm{pH} 6$ and 5 , which resulted in multiple migration times.

${ }^{d} \alpha-1$-antitrypsin and transferrin were excluded from the sample at $\mathrm{pH} 4$.

eTransferrin was excluded from the sample at $\mathrm{pH} 5$ when dimethylformamide was included. $(n=10)$

'Enolase was excluded from the sample at $\mathrm{pH} 6$ when dimethylformamide was included. $(n=10)$

${ }^{9}$ Ribonuclease $\mathrm{A}$ was excluded from the sample at $\mathrm{pH} 8$ when dimethylformamide was included. ( $n=$ 10) 
Table 2-8. Impact of capillary length on plates/meter ${ }^{\mathrm{a}}$

\section{Average plates/meter (RSD)}

$\begin{array}{llll}\text { AAT }^{\mathrm{b}} & \text { Tf } & \text { Enol } & \text { RNAse }\end{array}$

$50 \mathrm{~cm} \mathrm{~L}$ eff $\quad \mathrm{N} / \mathrm{A} \quad 170,000(20) \quad 1,010,000(0.5) \quad 800,000(10) \quad 950,000(1)$

$10 \mathrm{~cm} \mathrm{~L}$ eff $\quad \mathrm{N} / \mathrm{A} \quad 110,000(10) \quad 130,000(20) \quad 190,000(20) \quad 250,000(20)$

$\bar{a}$ Effective length is specified. Other separation conditions as described in Table 1. Relative standard deviation (RSD) and average were obtained are based on $n=6$ measurements.

${ }^{b}$ AAT was excluded due to the presence of multiple isoforms, making plate count measurements not applicable (N/A). 


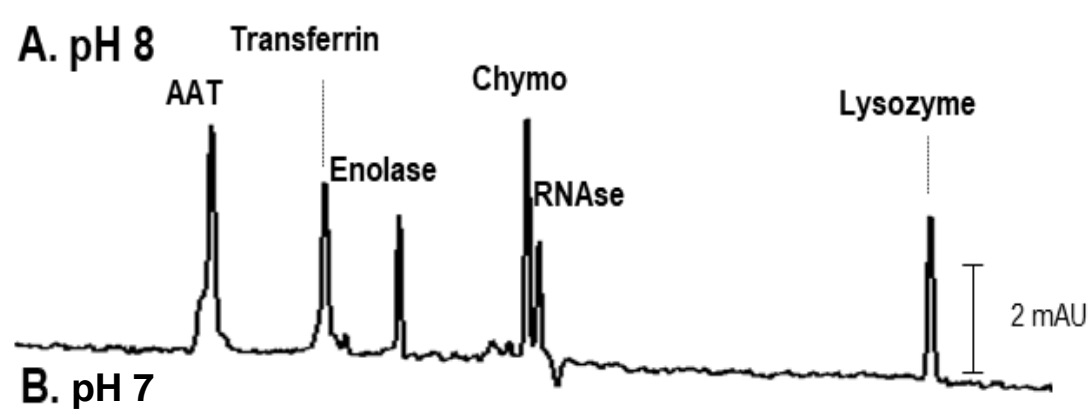

B. $\mathrm{pH} 7$

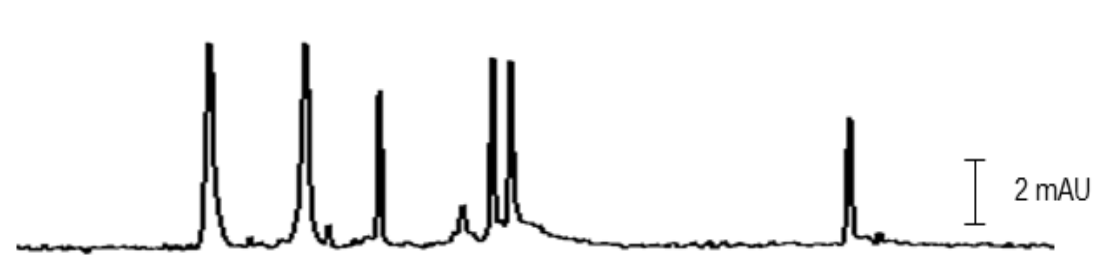

C. $\mathrm{pH} 6$

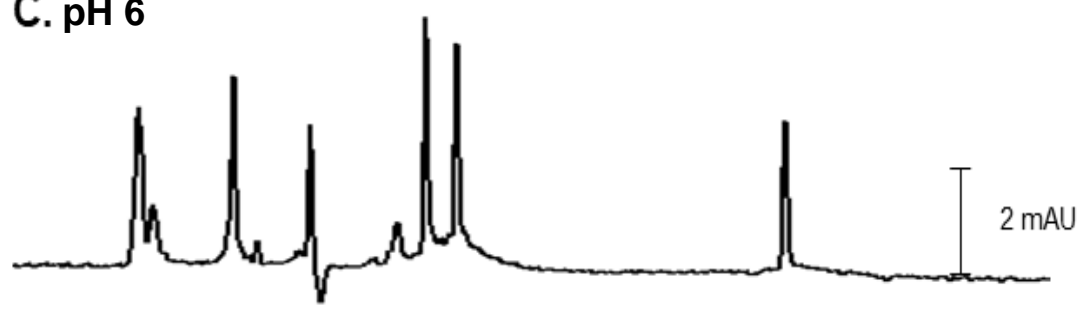

D. pH 5

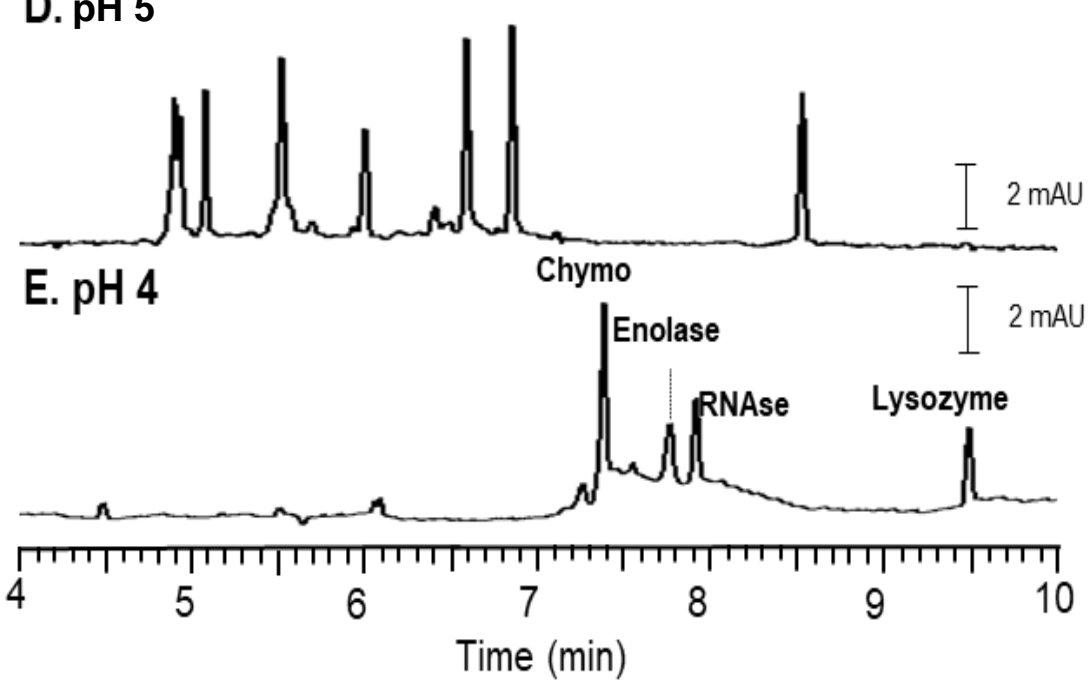

Figure 2-6. Compatibility of the phospholipid-CTAB coated capillary with background electrolyte buffered to a $\mathrm{pH}$ ranging from 4 to 8 . The separation was tailored to see resolution differences by performing the separation at pH 8 (a), 7 (b), 6 (c), 5 (d), and 4 (e). Separation conditions are as listed in Figure 1 with the exceptions that the Leff was 50 $\mathrm{cm}$ and the $\mathrm{pH}$ changed as noted. Abbreviations for proteins are as noted in Figure 1, $\alpha-$ chymotrypsinogen A (chymo). Reproduced from Crihfield 2019. 
$50 \mathrm{~cm}$ effective length in order to achieve better separations and plate counts compares to the $10 \mathrm{~cm}$ effective length used for comparing the coatings and barefused silica. The plate counts measured at $\mathrm{pH} 6$ are provided in Table 2-8 for the two effective lengths for comparison.

Tunable separations of proteins are achievable by controlling the $\mathrm{pH}$ of the background electrolyte. To demonstrate this concept, $\alpha$-chymotrypsinogen $A$ was added to the protein mixture. A noticeable change in the resolution of $\alpha$-chymotrypsinogen $A$ and ribonuclease $\mathrm{A}$ is achieved by lowering the $\mathrm{pH}$ from 8 to 4 as a result of the protein charge changing in response to $\mathrm{pH}$, as seen in Figure 2-5 traces $A$ through $E$. The resolution of $\alpha-$

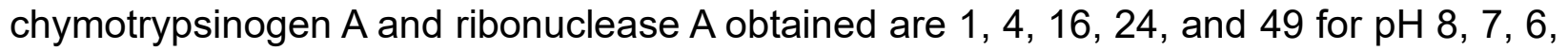
5 , and 4, respectively. Slight differences in the mobility of protein isoforms are distinguished when the $\mathrm{pH}$ of the separation is near the isoelectric point. This is demonstrated using a-1-antitrypsin, which is composed of multiple high abundance isoforms with slightly different mobilities that differentiates the isoforms at $\mathrm{pH}$ 5. The $\alpha-1$-antitrypsin peak changes drastically as the $\mathrm{pH}$ is dropped from $\mathrm{pH} 8$ to 5 , with broadening at the base occurring from $\mathrm{pH} 8$ to 7 , two distinguishable peaks occurring at $\mathrm{pH} 6$, and three distinguishable peaks occurring at $\mathrm{pH} 5$.

The stability of the acidic proteins at low $\mathrm{pH}$ values is a limitation that must be considered when performing the analysis of proteins across $\mathrm{pH}$. A drop in the intensity of the enolase peak is observed at $\mathrm{pH}$ values below 7 . This is attributed to the decrease in stability of enolase below pH 6.8 [76]. Transferrin and $\alpha-1$-antitrypsin were both excluded from the $\mathrm{pH} 4$ analyses due to the documented aggregation of $\alpha$-1-antitrypsin [77] and the instability of transferrin [78] at acidic $\mathrm{pH}$ values. When these proteins were included in $\mathrm{pH} 4$ analyses, peaks were not reproducible and spikes occurred in the electropherogram, which is attributed to the aggregation. Finally, while there is a decreasing trend in plate count with decreasing $\mathrm{pH}$ seen in Table 2-9, all $\mathrm{pH}$ values yielded theoretical plates between 80,000 and 270,000 for anions without isoforms and 230,000 and 475,000 for cations [73]. These efficiencies are comparable to other literature reports summarized in 


\section{Table 2-9. Effect of $\mathrm{pH}$ on plate count}

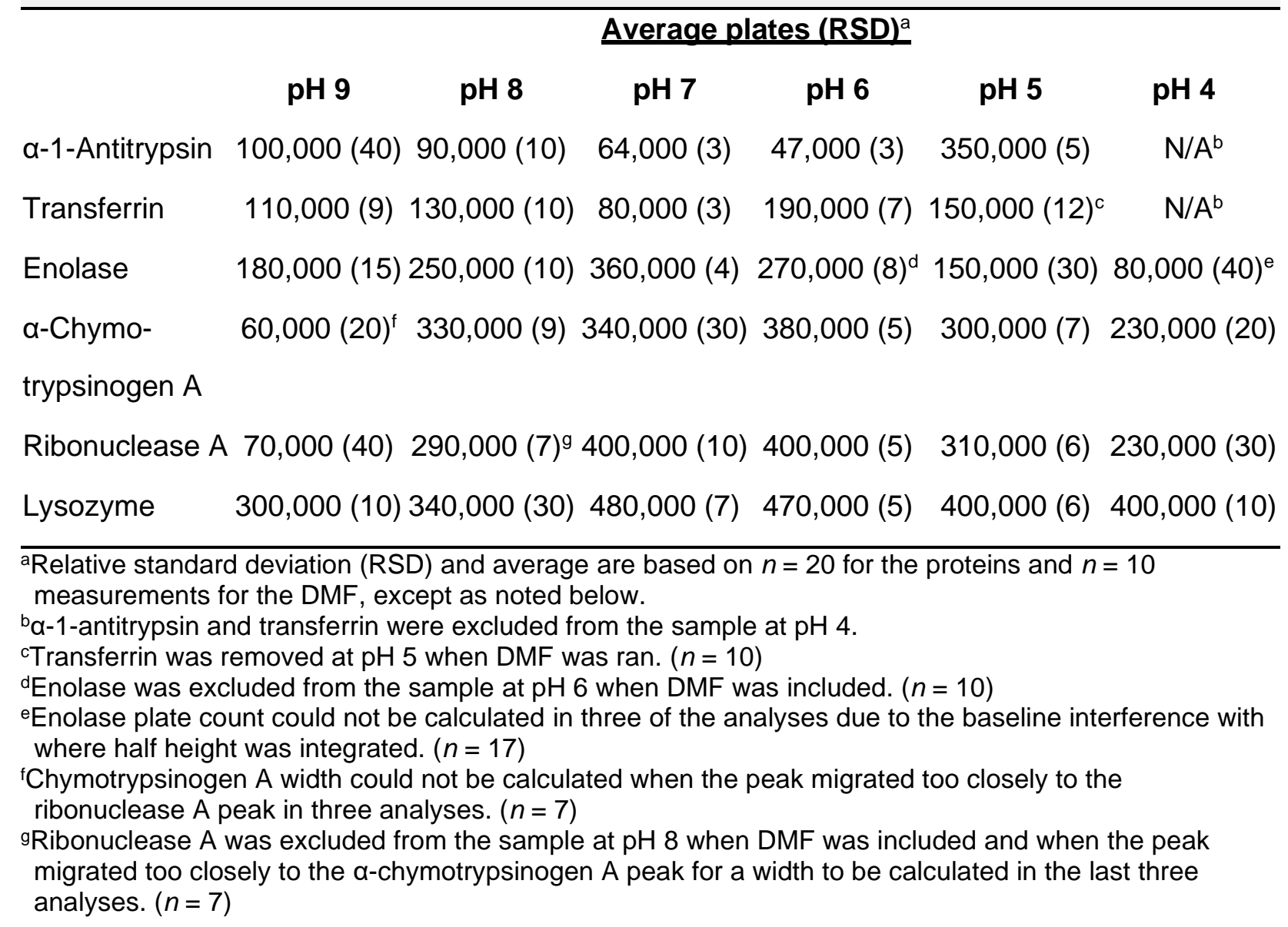




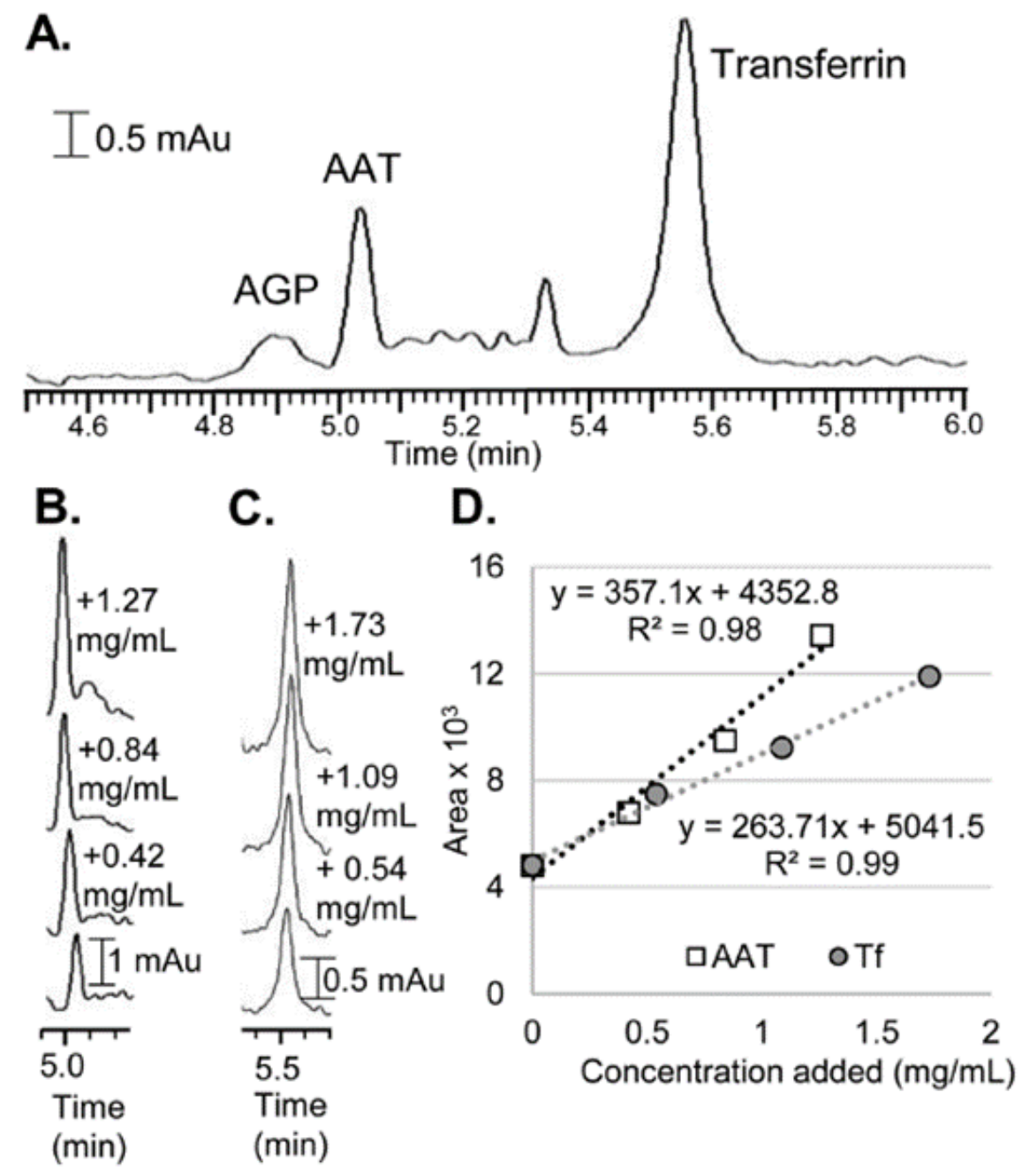

Figure 2-7. Analysis of human serum using the phospholipid-CTAB coated capillary. Alpha-1-acid glycoprotein (AGP), AAT, and transferrin were analyzed in albumin and immunoglobulin depleted serum (A). AAT (B) and transferrin (C) were quantified using the method of standard addition, as shown in the resulting standard addition curve (D). Abbreviations for proteins and conditions are as noted in Figure 1 with the use of reverse polarity, an Leff $=50 \mathrm{~cm}$, and an injection of 2 psi $3.5 \mathrm{~s}(\mathrm{~A}, \mathrm{~B})$ or 0.5 psi for $5 \mathrm{~s}(\mathrm{C})$. Reproduced from Crihfield 2019. 
Table 2-1, but the phospholipid-CTAB coating has the advantage that it can also be used to separate anionic proteins simultaneously.

2.3.5 Analysis of human serum. The utility of the method for protein separations at a particular $\mathrm{pH}$ depending on the protein isoelectric point was demonstrated. An albumin and immunoglobulin depleted serum sample was separated with the phospholipid-CTAB coated capillary. Alpha-1-antitrypsin and transferrin are abundant proteins with isoelectric points ranging from 4.4 to 5.6. Alpha-1-antitrypsin contains isoforms that generated multiple peaks below $\mathrm{pH} 6$. Therefore, the serum sample was separated at a $\mathrm{pH}$ of 7 , as shown in Figure 2-7. Both proteins were identified qualitatively with spiking. Additionally, alpha-1-acid glycoprotein was identified with spiking. To obviate matrix effect from the serum, the protein quantification was accomplished using the method of standard addition and yielded values of $1.2 \pm 0.2 \mathrm{mg} / \mathrm{mL}$ and $2.44 \pm 0.07 \mathrm{mg} / \mathrm{mL} \mathrm{mg} / \mathrm{mL}$ for alpha-1antitrypsin and transferrin, respectively. The values for alpha-1-antitrypsin, and transferrin were comparable to levels in healthy adults, which were reported to be $1.12 \pm$ $0.03 \mathrm{mg} / \mathrm{mL}$ and $2.36 \pm 0.08$ for alpha-1-antitrypsin and transferrin in the serum samples [79].

An advantage of the phospholipid-CTAB coating is the flexibility in choosing $\mathrm{pH}$ of separation based on the protein pl values. As the electroosmotic flow generated by the phospholipid-CTAB coating is similar across $\mathrm{pH}$ values the $\mathrm{pH}$ of the separation does not affect the run time or flow rate. This is particularly beneficial in mass spectrometry applications where separations at $\mathrm{pH}$ values that do not denature proteins are desired. The phospholipid-CTAB is compatible with ammonium acetate maintained at a $\mathrm{pH}$ of 6.5 , as demonstrated in Figure 2-8 and holds potential for capillary electrophoresis analyses. In developing these separations, $50 \mathrm{mM}$ ammonium acetate was also tested but resulted in substantial peak tailing as shown in Figure A1-1 in Appendix 1, which indicates that the ionic strength of the background electrolyte is important for separation performance. 


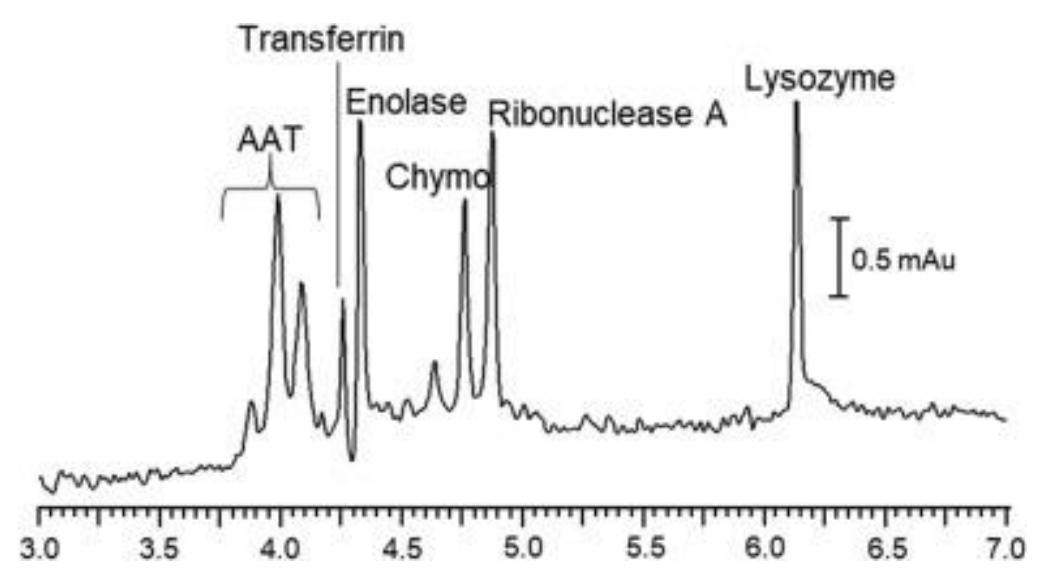

Figure 2-8. An electropherogram of a 6 protein mixture obtained using a phospholipid-CTAB coated fused silica capillary. The background electrolyte is $100 \mathrm{mM}$ ammonium acetate ( $\mathrm{pH}$ of 6.5). Run conditions: UV detection at $200 \mathrm{~nm}$; $L_{\text {tot }}=60 \mathrm{~cm}$; Leff $=50 \mathrm{~cm} ; 24 \mathrm{kV}$ applied voltage in reversed polarity. Standards are injected at $3.4 \mathrm{kPa}(0.5 \mathrm{psi})$ for $5 \mathrm{~s}$. Reproduced from Crihfield 2020. 


\subsection{Conclusions and Future Directions}

This study provides a fundamental investigation of the performance of a new phospholipid-CTAB coating. The high efficiency separation of strongly acidic ( $\mathrm{pl}<6)$ and basic proteins in the same run has not been reported while employing a semi-permanent coating. The findings presented here establish a stable, semi-permanent coating based on phospholipids to prevent adsorption by masking the silica surface and CTAB to generate sufficient electroosmotic flow for cationic and anionic protein separations. This technique demonstrates high efficiency separations of model proteins with the ability to use $\mathrm{pH}$ to tune the separation to achieve resolution between proteins with similar mobilities, as well as protein isoforms.

The phospholipid-CTAB coating holds great potential for use with a capillary electrophoresis electrospray ionization mass spectrometry interface. The stable electroosmotic flow across $\mathrm{pH}$ values will allow for resolution to be tuned without impacting the flow generated for ionization. Preliminary studies, Figure 2-6, indicate that the coating is stable with mass spectrometry friendly buffers, such as ammonium acetate. This combined with the biocompatibility of the phospholipid, which means protein function and structure are preserved, presents great potential for the native capillary electrophoresis mass spectrometry analysis of proteins in the future.

\subsection{Acknowledgements}

This material is based upon work supported by the National Science Foundation Grant No. CHE1506984. CLC acknowledges a National Science Foundation IGERT fellowship, DBG \#1144676. 


\subsection{References}

1. J. Beckman, Y. Song, Y. Gu, S. Voronov, N. Chennamsetty, S. Krystek, N. Mussa, Z.J. Li, Purity determination by capillary electrophoresis sodium hexadecyl sulfate (CE-SHS): A novel application for therapeutic protein characterization, Anal. Chem., 90 (2018) 2542-2547.

2. C.E. Espinosa-de la Garza, F.C. Perdomo-Abúndez, V.R. Campos-García, N.O. Pérez, L.F. Flores-Ortiz, E. Medina-Rivero, Capillary gel electrophoresis for the quantification and purity determination of recombinant proteins in inclusion bodies, Electrophoresis, 34 (2013) 2754-2759.

3. A.M. Belov, R. Viner, M.R. Santos, D.M. Horn, M. Bern, B.L. Karger, A.R. Ivanov, Analysis of proteins, protein complexes, and organellar proteomes using sheathless capillary zone electrophoresis - native mass spectrometry, J. Am. Soc. Mass Spectrom., 28 (2017) 2614-2634.

4. M. He, P. Luo, J. Hong, X. Wang, H. Wu, R. Zhang, F. Qu, Y. Xiang, W. Xu, Structural analysis of biomolecules through a combination of mobility capillary electrophoresis and mass spectrometry, ACS Omega, 4 (2019) 2377-2386.

5. C. Qian, H. Fu, K.A. Kovalchik, H. Li, D.D.Y. Chen, Specific binding constant and stoichiometry determination in free solution by mass spectrometry and capillary electrophoresis frontal analysis, Anal. Chem., 89 (2017) 9483-9490.

6. S. Liu, H. Wang, M. Song, J. Yin, G. Jiang, Study of protein binding and micellar partition of highly hydrophobic molecules in a single system using capillary electrophoresis, Electrophoresis, 29 (2008) 3038-3046.

7. H. Wu, K. Truncali, J. Ritchie, R. Kroe-Barrett, S. Singh, A.S. Robinson, C.J. Roberts, Weak protein interactions and $\mathrm{pH}$ - and temperature-dependent aggregation of human Fc1, mAbs, 7 (2015) 1072-1083.

8. M. Han, J.T. Pearson, Y. Wang, D. Winters, M. Soto, D.A. Rock, B.M. Rock, Immunoaffinity capture coupled with capillary electrophoresis - mass spectrometry to study therapeutic protein stability in vivo, Anal. Biochem., 539 (2017) 118-126.

9. S. Hjerten, K. Kubo, A new type of $\mathrm{pH}$ - and detergent-stable coating for elimination of electroendosmosis and adsorption in (capillary) electrophoresis, Electrophoresis, 14 (1993) 390-395.

10. H. Stutz, Protein attachment onto silica surfaces - a survey of molecular fundamentals, resulting effects and novel preventive strategies in CE, Electrophoresis, 30 (2009) 2032-2061.

11. L. Hajba, A. Guttman, Recent advances in column coatings for capillary electrophoresis of proteins, TrAC, Trends Anal. Chem., 90 (2017) 38-44.

12. C.A. Lucy, A.M. MacDonald, M.D. Gulcev, Non-covalent capillary coatings for protein separations in capillary electrophoresis, J. Chromatogr. A, 1184 (2008) 81105.

13. K.K.C. Yeung, C.A. Lucy, Suppression of electroosmotic flow and prevention of wall adsorption in capillary zone electrophoresis using zwitterionic surfactants, Anal. Chem., 69 (1997) 3435-3441.

14. M.D. Gulcev, C.A. Lucy, Factors affecting the behavior and effectiveness of phospholipid bilayer coatings for capillary electrophoretic separations of basic proteins, Anal. Chem., 80 (2008) 1806-1812. 
15. A. Elhamili, M. Wetterhall, B. Arvidsson, R. Sebastiano, P.G. Righetti, J. Bergquist, Rapid capillary electrophoresis time-of-flight mass spectrometry separations of peptides and proteins using a monoquaternarized piperazine compound (M7C4I) for capillary coatings, Electrophoresis, 29 (2008) 1619-1625.

16. C. Wang, C.A. Lucy, Mixed cationic/anionic surfactants for semipermanent wall coatings in capillary electrophoresis, Electrophoresis, 25 (2004) 825-832.

17. J. Znaleziona, D. Drahoňovský, B. Drahoš, J. Ševčík, V. Maier, Novel cationic coating agent for protein separation by capillary electrophoresis, J. Sep. Sci., 39 (2016) 2406-2412.

18. C.A. Lucy, R.S. Underhill, Characterization of the cationic surfactant induced reversal of electroosmotic flow in capillary electrophoresis, Anal. Chem., 68 (1996) 300-305.

19. T.T. Razunguzwa, M. Warrier, A.T. Timperman, ESI-MS compatible permanent coating of glass surfaces using poly(ethylene glycol)-terminated alkoxysilanes for capillary zone electrophoretic protein separations, Anal. Chem., 78 (2006) 43264333.

20. J. Bodnar, L. Hajba, A. Guttman, A fully automated linear polyacrylamide coating and regeneration method for capillary electrophoresis of proteins, Electrophoresis, 37 (2016) 3154-3159.

21. B. Yu, M. Jiao, H. Cong, X. Shu, S. Yang, A novel diazoresin/poly $(N$-vinyl aminobutyric acid) covalent capillary coating for the analysis of proteins by capillary electrophoresis, J. Sep. Sci., 37 (2014) 725-730.

22. https://us-store.sciex.com/USD/capillary-electrophoresis/capillaries-andcartridges/capillaries/Coated-Capillary-zidCoated-Capillary. accessed March 11, 2019.

23. https://www.agilent.com/cs/library/catalogs/public/5991-5623EN.pdf. accessed March 11, 2019.

24. https://www.sepax-tech.com/CE.php. accessed March 11, 2019.

25. Y. Tian, Y. Li, J. Mei, B. Cai, J. Dong, Z. Shi, Y. Xiao, Simultaneous separation of acidic and basic proteins using gemini pyrrolidinium surfactants and hexafluoroisopropanol as dynamic coating additives in capillary electrophoresis, J. Chromatogr. A, 1412 (2015) 151-158.

26. X.-F. Guo, H.-Y. Chen, X.-H. Zhou, H. Wang, H.-S. Zhang, N-methyl-2pyrrolidonium methyl sulfonate acidic ionic liquid as a new dynamic coating for separation of basic proteins by capillary electrophoresis, Electrophoresis, 34 (2013) 3287-3292.

27. W.W.P. Chang, C. Hobson, D.C. Bomberger, L.V. Schneider, Rapid separation of protein isoforms by capillary zone electrophoresis with new dynamic coatings, Electrophoresis, 26 (2005) 2179-2186.

28. J.S. Creamer, N.J. Oborny, S.M. Lunte, Recent advances in the analysis of therapeutic proteins by capillary and microchip electrophoresis, Anal. Methods, 6 (2014) 5427-5449.

29. C. Huhn, R. Ramautar, M. Wuhrer, G.W. Somsen, Relevance and use of capillary coatings in capillary electrophoresis-mass spectrometry, Anal. Bioanal. Chem., 396 (2010) 297-314. 
30. M.D. Gulcev, C.A. Lucy, Effect of coating electrolytes on two-tailed surfactant bilayer coatings in capillary electrophoresis, Anal. Chim. Acta, 690 (2011) 116-121.

31. C.M. White, R. Luo, S.A. Archer-Hartmann, L.A. Holland, Electrophoretic screening of ligands under suppressed EOF with an inert phospholipid coating, Electrophoresis, 28 (2007) 3049-3055.

32. M.D. Gulcev, T.M. McGinitie, M.F. Bahnasy, C.A. Lucy, Surfactant bilayer coatings in narrow-bore capillaries in capillary electrophoresis, Analyst, 135 (2010) 26882693.

33. L. Shulman, L. Pei, M.F. Bahnasy, C.A. Lucy, High ph instability of quaternary ammonium surfactant coatings in capillary electrophoresis, Analyst, 142 (2017) $2145-2151$.

34. S. Mohabbati, S. Hjertén, D. Westerlund, Studies on the analytical performance of a non-covalent coating with $\mathrm{N}, \mathrm{N}$-didodecyl- $\mathrm{N}, \mathrm{N}$-dimethylammonium bromide for separation of basic proteins by capillary electrophoresis in acidic buffers in 25-and 50- $\mu \mathrm{m}$ capillaries, Anal. Bioanal. Chem., 390 (2008) 667-678.

35. S. Mohabbati, D. Westerlund, Improved properties of the non-covalent coating with $\mathrm{N}, \mathrm{N}$-didodecyl- $\mathrm{N}, \mathrm{N}$-dimethylammonium bromide for the separation of basic proteins by capillary electrophoresis with acidic buffers in $25 \mu \mathrm{m}$ capillaries, J. Chromatogr. A, 1121 (2006) 32-39.

36. M.M. Yassine, C.A. Lucy, Enhanced stability self-assembled coatings for protein separations by capillary zone electrophoresis through the use of long-chained surfactants, Anal. Chem., 77 (2005) 620-625.

37. M.M. Yassine, C.A. Lucy, Factors affecting the temporal stability of semipermanent bilayer coatings in capillary electrophoresis prepared using double-chained surfactants., Anal. Chem., 76 (2004) 2983-2990.

38. J.E. Melanson, N.E. Baryla, C.A. Lucy, Double-chained surfactants for semipermanent wall coatings in capillary electrophoresis, Anal. Chem., 72 (2000) 4110-4114.

39. Y.J. Yao, S.F.Y. Li, Capillary zone electrophoresis of basic proteins with chitosan as a capillary modifier, J. Chromatogr. A, 663 (1994) 97-104.

40. C. Wang, C.A. Lucy, Oligomerized phospholipid bilayers as semipermanent coatings in capillary electrophoresis, Anal. Chem., 77 (2005) 2015-2021.

41. A.M. MacDonald, C.A. Lucy, Highly efficient protein separations in capillary electrophoresis using a supported bilayer/diblock copolymer coating, J. Chromatogr. A, 1130 (2006) 265-271.

42. G.M. Janini, K.C. Chan, J.A. Barnes, G.M. Muschik, H.J. Issaq, Separation of pyridinecarboxylic acid isomers and related compounds by capillary zone electrophoresis: Effect of cetyltrimethylammonium bromide on electroosmotic flow and resolution, J. Chromatogr. A, 653 (1993) 321-327.

43. J.E. Melanson, N.E. Baryla, C.A. Lucy, Dynamic capillary coatings for electroosmotic flow control in capillary electrophoresis, TrAC, Trends Anal. Chem., 20 (2001) 365374.

44. N.E. Baryla, J.E. Melanson, M.T. McDermott, C.A. Lucy, Characterization of surfactant coatings in capillary electrophoresis by atomic force microscopy, Anal. Chem., 73 (2001) 4558-4565. 
45. T. Tsuda, Modification of electroosmotic flow with cetyltrimethylammonium bromide in capillary zone electrophoresis, J. High Resolut. Chromatogr., 10 (1987) 622-624.

46. W. Ding, J.S. Frit, Separation of basic proteins and peptides by capillary electrophoresis using a cationic surfactant, J. High Resolut. Chromatogr., 20 (1997) 575-580.

47. Y. Nozaki, J.A. Reynolds, C. Tanford, The interaction of a cationic detergent with bovine serum albumin and other proteins, J. Biol. Chem., 249 (1974) 4452-4459.

48. Q. Liu, Y. Yang, Y. Huang, C. Pan, Z. Nie, S. Yao, Separation of acidic and basic proteins by $C E$ with $C T A B$ additive and its applications in peptide and protein profiling, Electrophoresis, 30 (2009) 2151-2158.

49. N.E. Baryla, C.A. Lucy, Simultaneous separation of cationic and anionic proteins using zwitterionic surfactants in capillary electrophoresis, Anal. Chem., 72 (2000) 2280-2284.

50. J.M. Cunliffe, N.E. Baryla, C.A. Lucy, Phospholipid bilayer coatings for the separation of proteins in capillary electrophoresis, Anal. Chem., 74 (2002) 776-783.

51. S.S. Wells, E. De La Toba, C.R. Harrison, Metal cation control of electroosmotic flow magnitude in phospholipid-coated capillaries, Electrophoresis, 37 (2016) 13031309.

52. E.L. Hult, Å. Emmer, J. Roeraade, Capillary electrophoretic separation of acidic and basic proteins in the presence of cationic and anionic fluorosurfactants, J. Chromatogr. A, 757 (1997) 255-262.

53. C.-Y. Lin, C.-J. Yu, Y.-M. Chen, H.-C. Chang, W.-L. Tseng, Simultaneous separation of anionic and cationic proteins by capillary electrophoresis using high concentration of poly(diallyldimethylammonium chloride) as an additive, J. Chromatogr. A, 1165 (2007) 219-225.

54. A.M. MacDonald, M.F. Bahnasy, C.A. Lucy, A modified supported bilayer/diblock polymer - working towards a tunable coating for capillary electrophoresis, J. Chromatogr. A, 1218 (2011) 178-184.

55. R. Kuldvee, M.V. Lindén, S.K. Wiedmer, M.-L. Riekkola, Influence of cetyltrimethylammonium bromide on phosphatidylcholine-coated capillaries, Anal. Bioanal. Chem., 380 (2004) 293-302.

56. A. de la Maza, J.L. Parra, Solubilization of unilamellar liposomes caused by quaternary ammonium surfactants, J. Controlled Release, 37 (1995) 33-42.

57. H.-K. Tsao, W.L. Tseng, The interactions between ionic surfactants and phosphatidylcholine vesicles: Conductometry, J. Chem. Phys., 115 (2001) 81258132.

58. P. Podevin, L. Correia, J.C. Montet, F. Conti, C. Chéreau, Y. Calmus, R. Poupon, Effects of bile salts and aliphatic ionic surfactants on human lymphocyte proliferation, Eur. J. Clin. Invest., 31 (2001) 367-373.

59. J. Sujatha, A.K. Mishra, Effect of ionic and neutral surfactants on the properties of phospholipid vesicles: Investigation using fluorescent probes, J. Photochem. Photobiol., A, 104 (1997) 173-178.

60. M.A. Urbaneja, A. Alonso, J.M. Gonzalez-Mañas, F.M. Goñi, M.A. Partearroyo, M. Tribout, S. Paredes, Detergent solubilization of phospholipid vesicle. Effect of electric charge, Biochem. J., 270 (1990) 305-308. 
61. A.B. Artyukhin, P. Stroeve, Effects of corrosive chemicals on solid-supported lipid bilayers as measured by surface plasmon resonance, Ind. Eng. Chem. Res., 42 (2003) 2156-2162.

62. F. Duša, W. Chen, J. Witos, S.K. Wiedmer, Nanoplasmonic sensing and capillary electrophoresis for fast screening of interactions between phosphatidylcholine biomembranes and surfactants, Langmuir, 34 (2018) 5889-5900.

63. S.A. Archer-Hartmann, L.M. Sargent, D.T. Lowry, L.A. Holland, Microscale exoglycosidase processing and lectin capture of glycans with phospholipid assisted capillary electrophoresis separations, Anal. Chem., 83 (2011) 2740-2747.

64. R. Luo, S.A. Archer-Hartmann, L.A. Holland, Transformable capillary electrophoresis for oligosaccharide separations using phospholipid additives, Anal. Chem., 82 (2010) 1228-1233.

65. R. Rapuano, A.M. Carmona-Ribeiro, Physical adsorption of bilayer membranes on silica, J. Colloid Interface Sci., 193 (1997) 104-111.

66. J.-O. Jeppsson, C.-B. LaurellL, M. Fagerhol, Properties of isolated human a1antitrypsins of Pi types M, S and Z, Eur. J. Biochem., 83 (1978) 143-153.

67. D.C. Harris, P. Aisen, Iron-donating properties of transferrin, Biochemistry, 14 (1975) 262-268.

68. L.J. Porcelli, E.D. Small, J.M. Brewer, Origin of multiple species of yeast enolase a on isoelectric focusing, Biochem. Biophys. Res. Commun., 82 (1978) 316-321.

69. D. Bobb, The use of gel isoelectricfocusing in monitoring chemical modifications of proteins, Ann. N. Y. Acad. Sci., 209 (1973) 225-236.

70. C. Tanford, J.D. Hauenstein, Hydrogen ion equilibria of ribonuclease1, J. Am. Chem. Soc., 78 (1956) 5287-5291.

71. G. Lundblad, O. Vesterberg, R. Zimmerman, J. Lind, Studies on lysozyme from human leucemic urine by isoelectric focusing, Acta Chem. Scand., 26 (1972) 1711 1713.

72. F. Kilár, S. Hjertén, Fast and high resolution analysis of human serum transferrin by high performance isoelectric focusing in capillaries, Electrophoresis, 10 (1989) 2329.

73. C.L. Crihfield, C.J. Kristof, L.M. Veltri, C.A. Wilson, W.M. Penny, L.A. Holland, Semipermanent cationic coating for protein separations, Data in Brief, (submitted).

74. B.A. Williams, G. Vigh, Fast, accurate mobility determination method for capillary electrophoresis, Anal. Chem., 68 (1996) 1174-1180.

75. S.P. Moura, A.M. Carmona-Ribeiro, Biomimetic particles: Optimization of phospholipid bilayer coverage on silica and colloid stabilization, Langmuir, 21 (2005) 10160-10164.

76. B.G. Malmström, L.E. Westlund, The effect of $\mathrm{pH}$ on the interaction of enolase with activating metal ions, Arch. Biochem. Biophys., 61 (1956) 186-196.

77. C.B. Glaser, L. Karic, A.B. Cohen, Low pH stability of alpha-1-antitrypsin, Biochim. Biophys. Acta, Protein Struct., 491 (1977) 325-330.

78. A.P. Turkewitz, A.L. Schwartz, S.C. Harrison, A pH-dependent reversible conformational transition of the human transferrin receptor leads to self-association, J. Biol. Chem., 263 (1988) 16309-16315. 
79. European Commission Joint Research Centre reference material ERMDA470k_IFCC human serum, certification report (certification report ERMDA470k_report.pdf) available at https://crm.jrc.ec.europa.eu/p/40456/40491/byanalyte-group/protein-content/erm-da470k-ifcc-human-serum-proteins/ermda470k ifcc. accessed June 16, 2019. 


\section{Chapter 3: Protein Sieving with Capillary Nanogel Electrophoresis}

\section{Adapted from}

Crihfield, C. L.; Holland, L.A., Protein Sieving with Capillary Nanogel Electrophoresis. Analytical Chemistry, submitted.

\section{Specific Aims}

\section{Capillary gel electrophoresis protein separations using phospholipid nanogels}

a. Size-based separations of proteins using phospholipid nanogels

b. Thermally-dependent viscosity for easy introduction in-capillary

c. Low cost ( $\$ 0.14$ per $5 \mu \mathrm{L} ; \$ 0.04$ per analysis)

d. Determination of the transition of the separation into a sieving mechanism

e. Accurate quantification of human serum proteins with external calibration

This material is based upon work supported by the National Science Foundation Grant No. $\underline{\mathrm{CHE} 1506984 .}$ 


\subsection{Introduction}

Capillary electrophoresis is advantageous for protein analysis because the method provides rapid and efficient separations and consumes only picoliter sample volumes[1,2]. The technique is compatible with absorbance, fluorescence and mass spectrometry detection, which are commonly used for protein assays. Moreover, the consumables are cost effective when fused silica capillary is used at a cost of $\$ 10 /$ meter and the solvents used for the assay are limited to few millilters for the anodic and cathodic reservoirs. Although protein analyses with free solution electrophoresis are based on charge-to-size ratio, the selectivity can be modified to leverage different separation mechanisms to resolve proteins. Recent examples in the literature of such microscale electrophoresis separations include sorting analytes according to isoelectric point $[3,4]$, stacking them based on mobilities[5], or including additives[6,7] or gels[8-11] that lead to separation. These separations can be easily automated in commercial instruments, which is important for protein analyses in industrial applications[7,10,12-14].

Capillary gel sieving electrophoresis is a widely accepted and a heavily used biotechnology method, especially in DNA analyses[1]. In comparison to electrophoresis in a slab gel, electrophoresis in a gel-filled capillary provides sharper peaks and better resolution of biopolymers in a shorter separation time[15,16]. The proteins separated by sieving are driven through the gel with a similar electrophoretic transport without any additive[17,18] or by including a surfactant $[7,10,12,19]$ or an ionic liquid[20,21] in the gel to bind to the proteins and cause them to have the same charge-to-size ratio. A porous gel in the capillary creates obstructed path through which the proteins pass. In a sievingbased separation the gel impedes the analyte migration. In comparison to a larger analyte, a smaller analyte has a higher probability to pass through the pores without interacting with the matrix. The apparent pore size of the gel matrix is the primary factor that determines the resolution that can be achieved for the analytes within a sample. In

order to resolve all of the analytes within a sample, the pore size must be appropriate for the analyte size range. 
Gels can be composed of permanently cross-linked polymers[22] or even packed silica colloids $[6,23,24]$ to create pores of specific size range. More frequently capillary gel electrophoresis utilizes linear gels that entangle to form apparent pores. This type of gel must be used under conditions of suppressed electroosmotic flow to prevent the gel from creeping out of the capillary. Although a variety of polymer matrices are reported[25], entangled sieving matrices based on polyacrylamide[15,26] and dextran[10,14,27], are frequently used for protein sieving. For sieving separations accomplished with entangled gels, the concentration of the gel determines the apparent pore size of the media[28]. Smaller pores are achieved at higher gel concentration. Because the gel is not permanently bonded in the capillary it is replaced after each run, eliminating carry-over and mitigating the potential for the sample matrix to foul the gel. Although physical gels are renewable, in order to introduce or replace the viscous polymers into a small inner diameter separation channel a higher pressure is required than that used for aqueous solutions. Physical gels based on thermally-responsive materials[29] overcome this challenge of using a high viscosity gel matrix because they possess switchable viscosities. As a result, a thermally responsive medium can be introduced into the capillary at temperatures where the material has a low viscosity. Once loaded into the capillary, the temperature is switched to create a highly viscous gel to support sieving. Examples of thermally switchable self-assembled materials reported for DNA sieving and in some cases for proteins include hydroxypropyl cellulose[30], pluronic gels[5,31-33], and phospholipid nanogels[34,35].

Phospholipid nanogels, which are an appealing matrix for protein separations, are composed of DMPC and DHPC phospholipids that self-assemble to form thermallydependent structures. The viscosity of a $20 \%$ nanogel changes 480 -fold with only a $6{ }^{\circ} \mathrm{C}$ temperature decrease and 1800-fold increase in shear rate, from 24 to $0.05 \mathrm{~Pa} \cdot \mathrm{s}[36]$. Low viscosity materials result from nanodisks below $24^{\circ} \mathrm{C}$, while high viscosity materials result from entangled ribbons at temperatures above $24^{\circ} \mathrm{C}$. Nanogels are compatible with proteins, improving[37] or sustaining[38,39] protein activity. Nanogel sieving had previously been demonstrated for DNA[34,35,40], which is a much larger biopolymer as compared to proteins. The prior work established that a $6-12 \%$ nanogel had an apparent 
pore size of 30-32 $\mathrm{nm}[34]$. This apparent pore size is significantly larger than proteins. For example, spherical proteins spanning a mass range of 5 to $500 \mathrm{kDa}$ correspond to radii that range from 1 to $5.2 \mathrm{~nm}$, respectively[41]. In order to realize the advantages of phospholipid nanogels for protein sieving the media must be used at a higher concentration than previously reported in order to create smaller pores which are more suitable for proteins.

In this work, phospholipid nanogel was utilized for protein separations for the first time to resolve proteins with similar charge-to-size ratios. The study was designed to establish the concentration of nanogel suitable for protein sieving. A peptide standard was used to demonstrate the difference between transport based on charge-to-size ratio versus sieving. The transition from electrophoresis to sieving was observed at concentrations greater than 20\% nanogel. The performance was characterized for the sieving separations. The efficiency and reproducibility in migration time and area were similar for separations performed using nanogels of concentrations of $0,10,20,25$, and $30 \%$. The slowest migration times were obtained at the highest nanogel concentration; however, nanogel composed of $25 \%$ phospholipid was sufficient to resolve trypsin inhibitor and alpha-1-antitrypsin. The benefit of utilizing a nanogel sieving-method was demonstrated with a human serum sample. The nanogel separation resulted in baseline resolution of proteins that could not be achieved with free solution capillary electrophoresis, allowing for accurate quantification.

\subsection{Materials and Methods}

3.2.1 Chemicals and reagents. The trypsin inhibitor (T6522), alpha-1-antitrypsin (A6150), transferrin (T8158), alpha-1-acid glycoprotein (G9885), human serum (ERMDA470KIFCC), sodium phosphate, and calcium chloride were purchased from Sigma Aldrich (St. Louis, MO). Deionized water was obtained from an Elga Purelab ultra water system (Lowell, MA). The phospholipids, 1,2-dimyristoyl-sn-glycero-3phosphocholine (DMPC) and 1,2-dihexanoyl-sn-glycero-3-phosphocholine (DHPC), were purchased from Avanti Polar Lipids (Alabaster, AL). 
3.2.2 Preparations of buffers and phospholipids. The separation background electrolyte in the anodic and cathodic reservoirs was $50 \mathrm{mM}$ sodium phosphate buffered to $\mathrm{pH} 8$ using sodium hydroxide. Phospholipid nanogels were prepared as described previously, aliquoted, and stored at $-20^{\circ} \mathrm{C}[42,43]$. The preparation used as the semi-permanent phospholipid surface coating was comprised of a [DMPC]:[DHPC] ratio of 0.5 at a concentration of $5 \%(\mathrm{w} / \mathrm{v})$. For the nanogel, the phospholipids were prepared at a [DMPC]:[DHPC] ratio of 2.5 and at concentrations of 10,20 , and $25 \%(\mathrm{w} / \mathrm{v})$. The $50 \mathrm{mM}$ $\mathrm{pH} 8$ sodium phosphate buffer was used to hydrate the phospholipid to the final $\mathrm{w} / \mathrm{v}$ concentration required. After dissolving using a vortex, the phospholipids were subjected to three freeze-thaws and then centrifuged at $4{ }^{\circ} \mathrm{C}, 10,000 \mathrm{rpm}$ for $10 \mathrm{~min}$. The phospholipids were aliquoted and stored at $-20^{\circ} \mathrm{C}$. Immediately prior to use, calcium chloride was added to the thawed phospholipid coat at a final concentration of $1.25 \mathrm{mM}$.

3.2.3 Preparation of standards and samples. Standards and samples were prepared in $50 \mathrm{mM}$ sodium phosphate buffered at $\mathrm{pH}$ 8. Individual protein samples were dissolved and desalted using $10 \mathrm{kDa}$ molecular weight cut-off filters (cat\# UFC501024, Millipore Sigma, Allentown, PA). Proteins were diluted to $50 \mu \mathrm{M}$ in $50 \mathrm{mM}$ sodium phosphate buffered to $\mathrm{pH} 8$ and concentrations were determined using a Nanodrop spectrophotometer (Model 1000, ThermoFisher, Madison, WI). The proteins from human serum were aliquoted and stored in a $-70^{\circ} \mathrm{C}$. The albumin and IgG were depleted using a kit from Pierce (Cat no. 89875) as per the manufacturer instructions and then buffer exchanged into the sodium phosphate buffer prior to analysis.

3.2.4 Capillary electrophoresis methods. Separations were performed using a P/ACE MDQ Plus (Sciex, Redwood City, CA) with UV-visible absorbance detection at $200 \mathrm{~nm}$. Capillaries (Polymicro Technologies, Phoenix, AZ) with a $25 \mu \mathrm{m}$ inner diameter, $40 \mathrm{~cm}$ total length, and $10 \mathrm{~cm}$ effective length were used for the analyses. The separation capillary was flushed daily at $172 \mathrm{kPa}$ (25 psi) using the following sequence $1 \mathrm{~N}$ sodium hydroxide $30 \mathrm{~min}$, deionized water $5 \mathrm{~min}$, methanol $15 \mathrm{~min}$, and deionized water $5 \mathrm{~min}$. The phospholipid coating was then applied to the capillary, which was maintained at 
$19^{\circ} \mathrm{C}$, by flushing at $172 \mathrm{kPa}$ ( $25 \mathrm{psi}$ ) with $50 \mathrm{mM}$ sodium phosphate buffered to $\mathrm{pH} 8$ ( 3 $\mathrm{min}$ ), semi-permanent surface coating of $5 \%$ phospholipid w/v (20 min), and buffer 3 (min). Between analyses, the capillary was flushed with $50 \mathrm{mM}$ sodium phosphate buffered to $\mathrm{pH} 8$ (5 $\mathrm{min}$ ), semi-permanent surface coating ( $3 \mathrm{~min}$ ), and $50 \mathrm{mM}$ sodium phosphate buffered to $\mathrm{pH} 8$ (3 min). For the nanogel analyses, the nanogel was flushed through the capillary $(7.5 \mathrm{~min}$ ) at $172 \mathrm{kPa}(25 \mathrm{psi})$ followed by a $10 \mathrm{~s}$ pre-plug of $50 \mathrm{mM}$ sodium phosphate buffered to $\mathrm{pH} 8$ at $13.8 \mathrm{kPa}(2 \mathrm{psi})$. The capillary temperature was raised to $27^{\circ} \mathrm{C}$ prior to sample injection at $10 \mathrm{kV}$ for $4 \mathrm{~s}$. Following the sample injection, a post plug of $50 \mathrm{mM}$ sodium phosphate buffered to $\mathrm{pH} 8$ was introduced into the capillary at $3.4 \mathrm{kPa}(0.5 \mathrm{psi})$ for $5 \mathrm{~s}$. Separations were performed using reverse polarity at a field strength of $100 \mathrm{~V} / \mathrm{cm}$.

3.2.5 Electroosmotic flow measurements. A previously reported method[44] was used to calculate the electroosmotic flow. Three neutral marker peaks were patterned in the capillary and spaced with the background electrolyte. The first two peaks were separated only by pressure. The same pressure and time was then used in combination with electrophoresis to push the peaks into the capillary. Afterwards, the third injection was made. The patterned zones were then pushed to the detection window and the mobilization time for each peak was recorded. The presence of electroosmotic flow was evidenced as an unequal distance between the first pair of peaks as compared to the last pair of peaks. In this work the measurements were achieved using a $3.4 \mathrm{kPa}(0.5 \mathrm{psi}) 5$ $\mathrm{s}$ injection of neutral marker (dimethylformamide) which was pushed at $3.4 \mathrm{kPa}(0.5 \mathrm{psi})$. This was followed by a second $3.4 \mathrm{kPa}(0.5 \mathrm{psi}) 5 \mathrm{~s}$ injection of the dimethylformamide neutral marker that was pushed at $3.4 \mathrm{kPA}(0.5 \mathrm{psi})$ and then electrophoresed at 24000 $V$ for $500 \mathrm{~s}$. A third $3.4 \mathrm{kPa}(0.5 \mathrm{psi}) 5 \mathrm{~s}$ injection of dimethylformamide was made. The three plugs of dimethylformamide were pushed to the detection window with $3.4 \mathrm{kPa}(0.5$ psi) of pressure. The distance between the first two peaks was strictly due to pressure, while the distance between the second two peaks was due to pressure and electroosmotic flow. Therefore, the difference between the separation time of the first pair of peaks and of the second pair peaks of peaks was used to calculate the electroosmotic flow using equation 3-1: 


$$
\mu_{\mathrm{eo}}=\frac{L_{e o} L_{t}}{V\left(t_{m}-t_{\text {rampup }} / 2-t_{\text {rampdown }} / 2\right)}
$$

where $\mu_{e o}$ is the electroosmotic flow, Leo is the distance traveled by the neutral markers during electrophoresis, $L_{t}$ is the total length of the capillary, $V$ is the applied voltage, $t_{m}$ is the migration time, and trampup and trampdown are the time required to ramp the applied voltage up and down, respectively.

\section{Results and Discussion}

3.3.1 Effect of nanogel on electrophoretic mobility. Whereas small molecules are unaffected by gel matrices, when the size of an analyte approaches the pore size of a sieving matrix, the electrophoretic mobility is retarded by the porous gel network. The presence of sieving was confirmed in nanogels by observing the effect of a gel matrix on molecular transport. The electrophoretic mobility was measured in the presence and absence of nanogel for a low molecular weight peptide, REDV $(0.57 \mathrm{kDA})$ and a protein, alpha-1-antitrypsin (52 kDa), with a molecular weight nearly 1000 times larger than that of the peptide. The isoelectric point of the REDV peptide, which was 4.4[45], was similar to the protein isoelectric point which ranged from 4.2 to 4.9 . The background electrolyte was buffered to a $\mathrm{pH}$ of 8 using sodium phosphate to mitigate protein denaturation by maintaining the separation near physiological $\mathrm{pH}$. By using a $\mathrm{pH}$ far enough away from the isoelectric points of the proteins, the differences in charge were reduced resulting in less resolution by charge-to-size ratio. This was demonstrated for the isoforms of alpha1 -antitrypsin in a prior report ${ }^{46}$ and was again confirmed by analyzing trypsin inhibitor and alpha-1-antitrypsin in a coated capillary void of nanogel at a range of $\mathrm{pH}$ values starting near the isoelectric points $(\mathrm{pH} 5)$ and ending at $\mathrm{pH} 8$, shown in Figure 3-1. At pH 5 , the protein migration times span 1.3 minutes, while this span is reduced to less than 1 minute at $\mathrm{pH} 8$ indicating more homogeneous charge-to-size ratios at $\mathrm{pH} 8$. For these reasons, a pH of 8 was selected. Additionally, at this $\mathrm{pH}$ value the selected analytes possessed a significant negative charge. With the electroosmotic flow suppressed, the runs were performed under reversed polarity. A field strength of $100 \mathrm{~V} / \mathrm{cm}$ was used to 
maintain low separation current (i.e. $<10 \mu \mathrm{A}$ ). Separations were performed at $27{ }^{\circ} \mathrm{C}$ because at temperatures ranging from $24-29^{\circ} \mathrm{C}$ an interconnected network of ribbons formed[46,47]. Controlling these factors resulted in a separation system that enabled a systematic evaluation of sieving.

Prior to further investigation of the nanogel system, beta-lactoglobulin was first used to demonstrate sieving, see Figure 3-2, and confirm the identification of standards. A protein mixture of beta-lactoglobulin, alpha-1-antitrypsin, and transferrin was analyzed in $25 \%$ nanogel. To confirm the identification, transferrin was left as a migration time marker and alpha-1-antitrypsin (Figure 3-2 trace B) and subsequently beta-lactoglobulin (Figure 3-2 trace $\mathrm{C}$ ) were analyzed without the other protein. Beta-lactoglobulin has a molecular weight of $18 \mathrm{kDa}$, and while the migration time was as expected based on size, the protein was ultimately dropped from further experiments as confirming whether the second peak was due to a protein isoform or the dimer structure would require mass spectrometry analysis. In order to avoid unnecessary experiments, beta-lactoglobulin was replaced with trypsin inhibitor.

In order to compare the effect of the nanogel on electrophoretic mobility, the analyte migration times were converted to mobilities. The calculation of the electrophoretic mobility from migration time was straightforward for the separation in $20 \%$ nanogel because the combination of the viscous nanogel and semi-permanent surface coating suppressed the electroosmotic flow significantly. However, for the separation obtained with aqueous electrolyte devoid of nanogel, a residual electroosmotic flow was generated in the presence of the semi-permanent lipid surface coating used in the capillary. In order to calculate the electrophoretic mobility of analyte the rate of electroosmotic flow was subtracted from the apparent analyte mobility. Direct measurement of electroosmotic flow through the separation of a neutral compound in aqueous electrolyte was not feasible because the mobility was too slow. Instead, a previously reported method[44] was used to determine the electroosmotic flow. As described in the Materials and Methods Section 


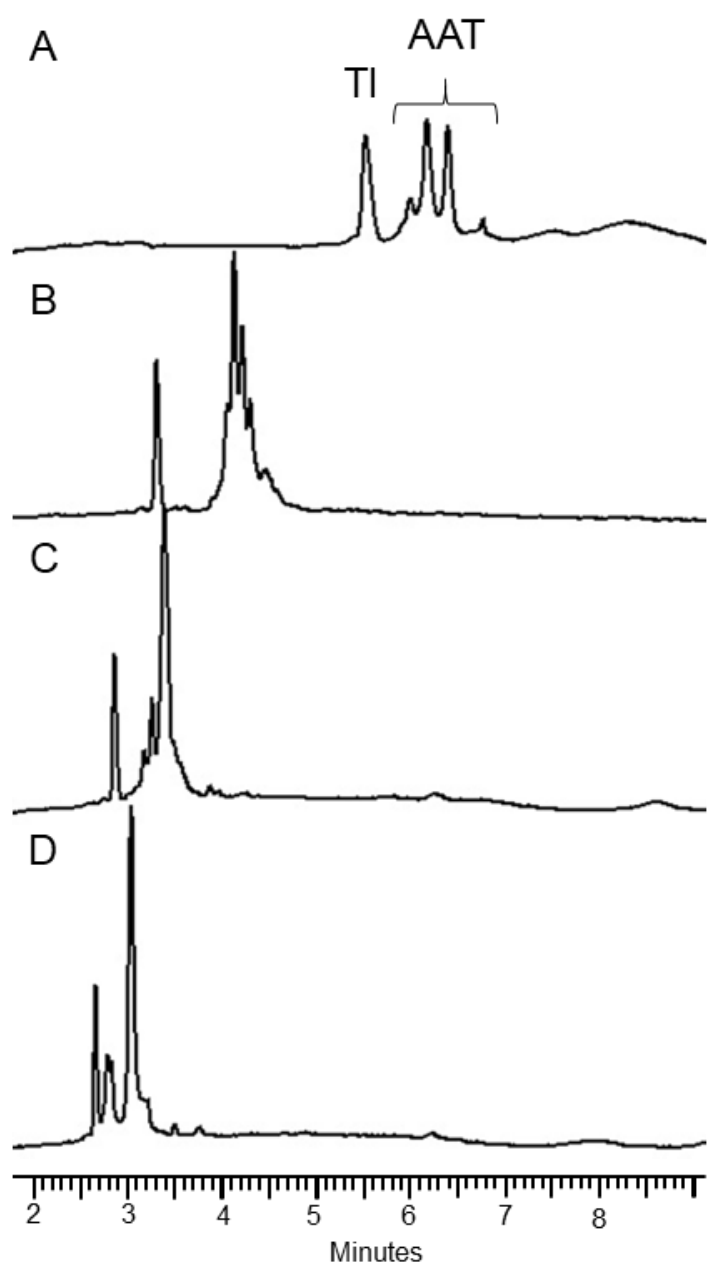

Figure 3-1. Separation of trypsin inhibitor (TI) and alpha-1-antitrypsin (AAT) at pH 5 (a), pH 6 (b), pH 7 (c), and pH 8 (d) in a coated capillary under reverse polarity in $50 \mathrm{mM}$ sodium phosphate acetate. Separation conditions were $27^{\circ} \mathrm{C}, 100 \mathrm{~V} / \mathrm{cm}, 10 \mathrm{~cm}$ Leff, 40 $\mathrm{cm} \mathrm{L}_{\text {tot, }}$ and UV-vis absorbance detection at $200 \mathrm{~nm}$. 


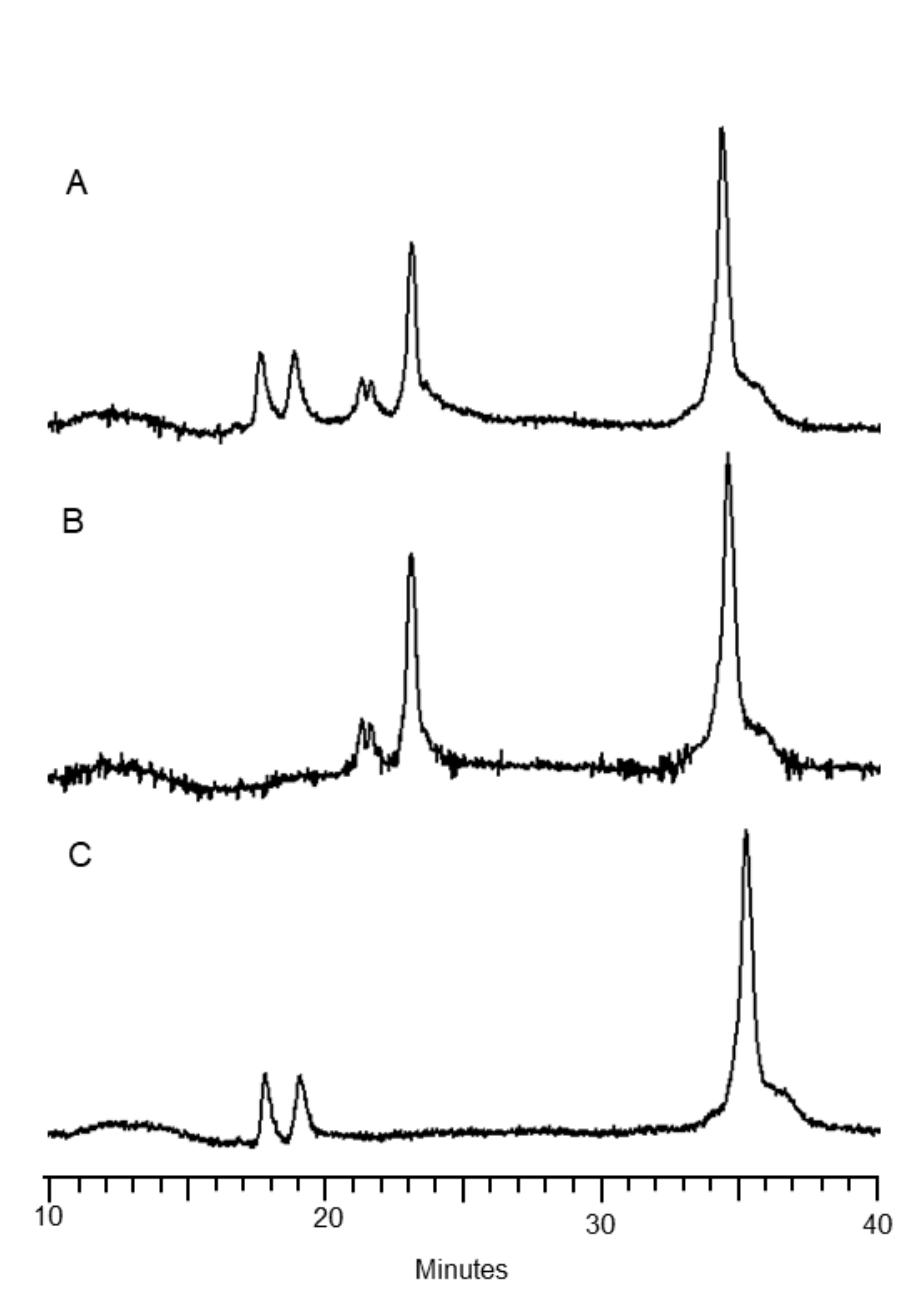

Figure 3-2. Identification of proteins in the separation of beta-lactoglobulin, alpha-1antitrypsin, and transferrin using $25 \%$ nanogel. Trace A contains all three proteins, trace $B$ contains alpha-1-antitrypsin and transferrin, and trace $C$ contained beta-lactoglobulin and transferrin. 
2.5, the measurement was based on monitoring the difference in the velocity of a neutral compound observed upon superimposing electrophoresis in flow injection analyses. When this method was applied to a capillary with a passivated surface and an aqueous electrolyte devoid of nanogel, the electroosmotic flow generated was $2.51 \times 10^{-5} \mathrm{~cm}^{2} / \mathrm{Vs}$ with a relative standard deviation of $1 \%$. The direction of this suppressed electroosmotic flow was towards the detection window (i.e. from the cathode toward the anode).

This value of electroosmotic flow was subtracted from the apparent mobility of each analyte obtained in the absence of nanogel to establish the electrophoretic mobility. The mobility of alpha-1-antitrypsin determined in the absence $(n=3)$ and presence $(n=3)$ of nanogel was $0.000110 \mathrm{~cm}^{2} \mathrm{~V}^{-1} \mathrm{~s}^{-1}$ and $0.000071 \mathrm{~cm}^{2} \mathrm{~V}^{-1} \mathrm{~s}^{-1}$, respectively. In contrast, the mobility of the low molecular weight peptide, REDV in the absence $(n=3)$ and presence $(n=3)$ of nanogel was $0.000150 \mathrm{~cm}^{2} \mathrm{~V}^{-1} \mathrm{~s}^{-1}$ and $0.000150 \mathrm{~cm}^{2} \mathrm{~V}^{-1} \mathrm{~s}^{-1}$, respectively. The relative standard deviation of the mobility measurements was less than or equal to $1 \%$. While the peptide mobility was the same in both separation systems, the protein mobility was statistically different $(\rho>0.05)$ when evaluated with a two-tailed student $t$ test. These differences in mobility observed for protein but not peptide indicated that protein was subject to a size-based separation mechanism attributed to nanogel sieving.

3.3.2 Separation figures of merit obtained for sieving. Nanogel at concentrations of 6 $12 \%$ were shown to have an apparent pore size of 30-32 nm[34]. Therefore, nanogels of concentrations higher than $12 \%$ were required for proteins, which are smaller than $10 \mathrm{~nm}$ in diameter[41]. Aqueous preparations at a concentration of $0,10,20,25$, and $30 \%$ nanogel were evaluated to quantify the effect of gel concentration on protein separations. The nanogel sieving was measured for three acidic proteins of different molecular weights, which were trypsin inhibitor (20.5 kDa), alpha-1-antitrypsin (52 kDa), and transferrin $(79.5 \mathrm{kDa})$. For trypsin inhibitor, a spherical protein, the size was calculated as a $1.8 \mathrm{~nm}$ radius based on molecular weight[41]. The dimensions for the aspherical proteins alpha-1-antitrypsin and transferrin were reported in the literature to be 7.8 by 4.9 
by $2.2 \mathrm{~nm}$ [48] and 4.8 by $9.6 \mathrm{~nm}$ [49], respectively. Additionally, these proteins had similar isoelectric points, which for trypsin inhibitor, alpha-1-antitrypsin, and transferrin were 4.5, $4.2-4.9$, and 5.2-5.6, respectively.

Separations of these proteins, shown in Figure 3-3, were performed with nanogel concentrations of $0,10,20,25$, and $30 \%$. The protein migration times increased with nanogel concentration (see Table 3-1). Precision in time and in area obtained for proteins was $\leq 1 \%$ and $<10 \%$ relative standard deviation, respectively, at each different nanogel concentration $(n=3)$ with one exception (i.e. transferrin at $30 \%$ nanogel). The peaks in Figure 3-3 are better resolved at higher nanogel concentrations. However, peak resolution was not calculated because in the presence of nanogel multiple peaks were observed for alpha-1-antitrypsin, and transferrin. As described previously[50], the proteins used in the study are composed of multiple isoforms. Therefore, for these proteins increased peak width resulted from the resolution of heterogeneous proteins rather than separation efficiency. As only a single peak was observed for trypsin inhibitor for all nanogel concentrations, changes in the theoretical plate count of this peak were used to evaluate the separation efficiency. For this protein the theoretical plate count obtained at 0, 10, 20, 25, and 30\% nanogel was 170,000, 297,000, 369,000, 380,000, and 410,000 plates. The plate counts obtained using the more viscous nanogel media $(20,25,30 \%)$ were statistically the same, but better than the values obtained at 0 at $10 \%$ nanogel. The improved separation efficiency could be due to band broadening associated with sample injection, if this source of peak broadening is larger than band broadening processes that occur during the separation. While the separation efficiency and precision were similar in the presence of nanogel, the increase in protein migration times with concentration was due to protein sieving. As summarized in Table 3-2, the change in protein mobility was more substantial for the 20,25 , and $30 \%$ nanogel. 


\section{A. $0 \%$}

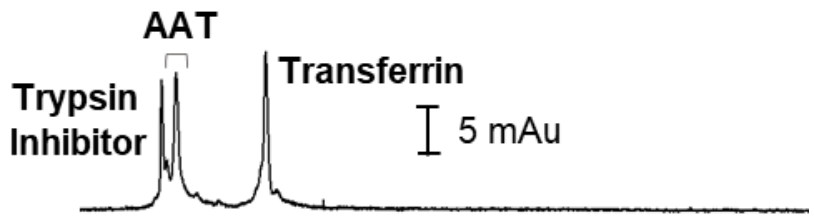

B. $10 \%$ AAT

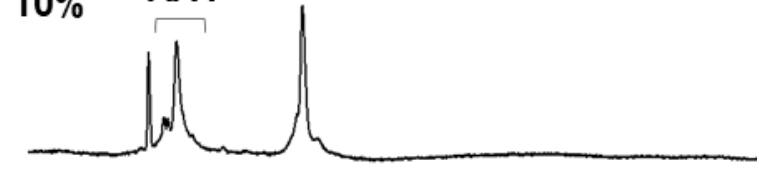

C. $20 \%$

\section{AAT}

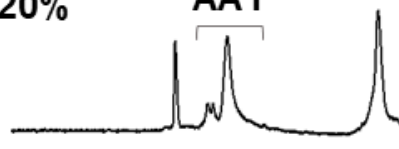

D. $25 \%$

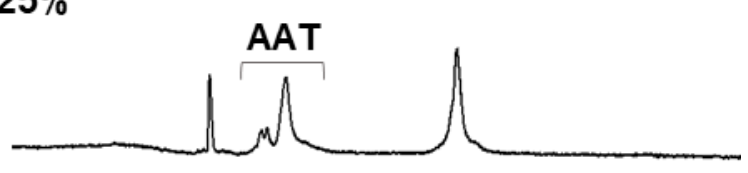

E. $30 \%$

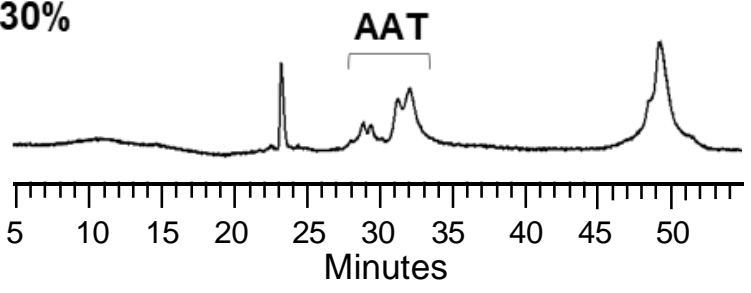

Figure 3-3. Separation of model proteins trypsin inhibitor, alpha-1-antitrypsin (AAT), and transferrin in the absence $(A)$ and presence $(B-E)$ of phospholipid nanogel. Separation conditions were $27^{\circ} \mathrm{C}, 100 \mathrm{~V} / \mathrm{cm}, 10 \mathrm{~cm}$ Leff, $40 \mathrm{~cm}$ Ltot, and UV-vis absorbance detection at $200 \mathrm{~nm}$. 


\begin{tabular}{lccccc}
\hline \multicolumn{6}{l}{ Table 3-1. Migration time obtained using different concentrations of nanogel } \\
\hline Protein & $\underline{0 \%}$ & $\underline{10 \%}$ & $\underline{20 \%}$ & $\underline{25 \%}$ & $\underline{30 \%}$ \\
trypsin inhibitor & 10.4 & 13.0 & 16.0 & 18.3 & 23.0 \\
$\alpha-1$-antitrypsin & 11.4 & 14.9 & 19.5 & 23.5 & 32.4 \\
transferrin & 35.4 & 23.1 & 29.8 & 35.4 & 50.
\end{tabular}
All migration times had relative standard deviations equal to or less than $1 \%$ with the exception of transferrin at $30 \%$ nanogel, which had a relative standard deviation of $3 \%$. 
3.3.3 Effect of nanogel concentration on protein sieving. The onset of sieving depicted in Table 3-3 was better visualized through graphical analysis of the logarithm of the mobility and gel concentration. For standard Ogston sieving, the electrophoretic mobility is exponentially related to molecular size and depicted through a Fergusson plot[25,51] The logarithm of the mobility was obtained by plotting the mobility of the protein isoform peak with the highest intensity against the nanogel concentration. When these graphs are created for sieving achieved with gels that are linear polymers they can be fit with a linear function[50], for which the figures of the linear regression are summarized in Table 3-3. The plot obtained with the self-assembled nanogels revealed two distinct regions of protein mobility. This is because the self-assembly of nanogels into entangled structures is concentration dependent[47], creating defined regions in which sieving occurs for proteins. As demonstrated in Figure 3-4, a transition in mobility was observed and was calculated to be $21 \%$ by determining the linear fit of the mobility below (i.e. $0,10,20 \%$ nanogel) and above (i.e. 20, 25, 30\% nanogel) the transition and solving for the percent nanogel obtained at the $\mathrm{Y}$-value in common for trypsin inhibitor, alpha-1-antitrypsin, and transferrin. The rate at which the mobility decreased for each protein was linear, with correlation coefficients ranging from 0.90 to 0.99 for the slopes obtained with $0,10,20 \%$ nanogels or with correlation coefficients ranging from 0.96 to 0.98 for the slopes obtained with the 20,25, and $30 \%$ nanogels. The slopes obtained in the sieving regime of 20, 25, and $30 \%$ nanogels, were then used to derive the retardation coefficient by taking the square root of each slope, which was then plotted against protein size. The hydrodynamic radius of the aspherical proteins was reported as the largest dimension of the actual measured sizes, which yielded radii of $3.9 \mathrm{~nm}$ and $4.8 \mathrm{~nm}[48,49]$. For the 20, 25, and $35 \%$ nanogel, this curve (see Figure 3-5) was linear with a correlation coefficient of 0.96 . The linearity of this curve further confirmed the suitability of nanogel to sieve proteins. Notably, when a similar plot was made for the separations performed at 0,10 , and $20 \%$ nanogel (see Figure 3-6), no correlation was observed. 
Table 3-2. Effect of Percent nanogel on protein mobility

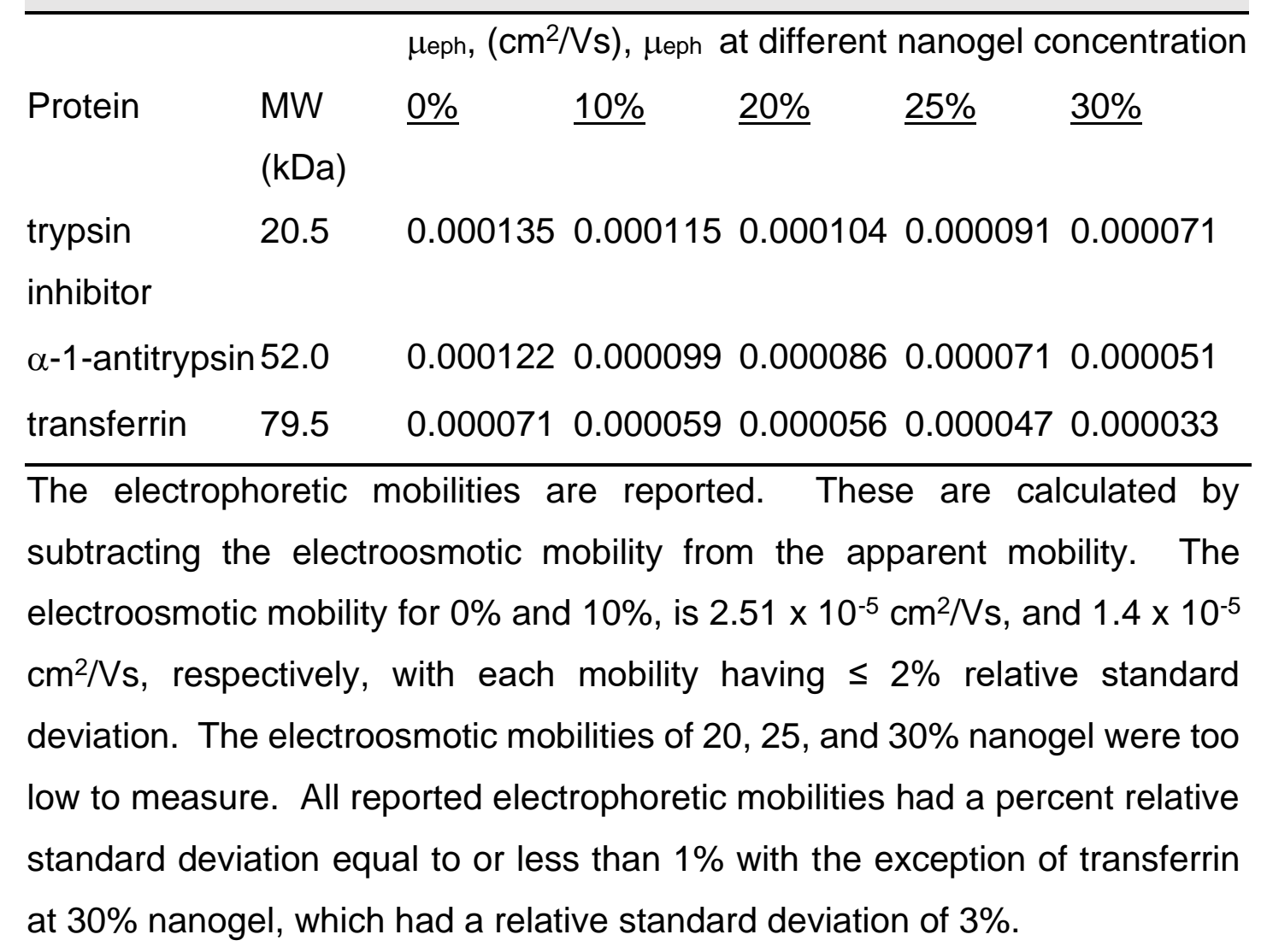




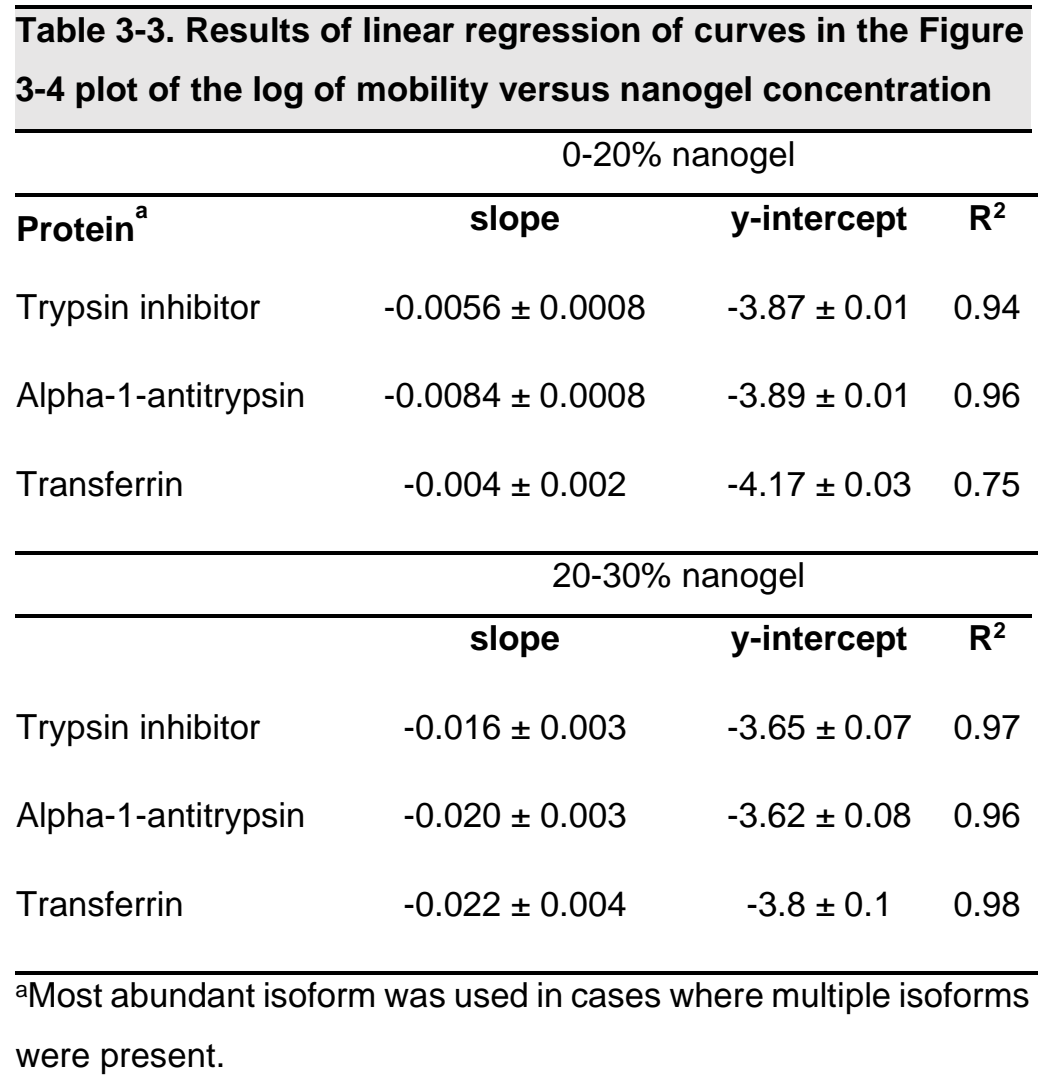




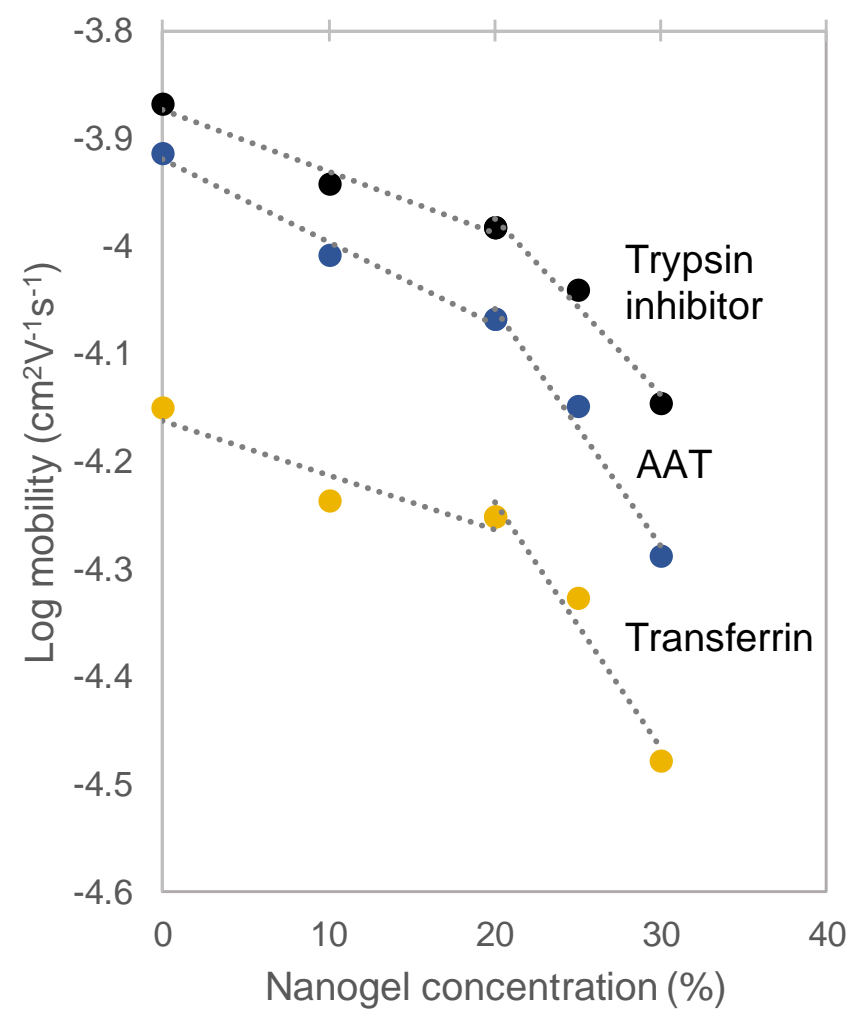

Figure 3-4. Ferguson plot for proteins analyzed using phospholipid nanogel. The logarithm of the mobility of trypsin inhibitor, alpha-1-antitrypsin, and transferrin were plotted versus the percent nanogel. Two distinct slopes were observed for each protein. The beginning of the sieving regime for each protein is indicated by where the two lines for each protein intersect. All relative standard deviations in mobility were $\leq 1 \%$ with the exception of transferrin when analyzed using $30 \%$ nanogel, which gave a relative standard deviation of 3\%. Error bars are not shown as they are asymmetric in a logarithmic plot. 


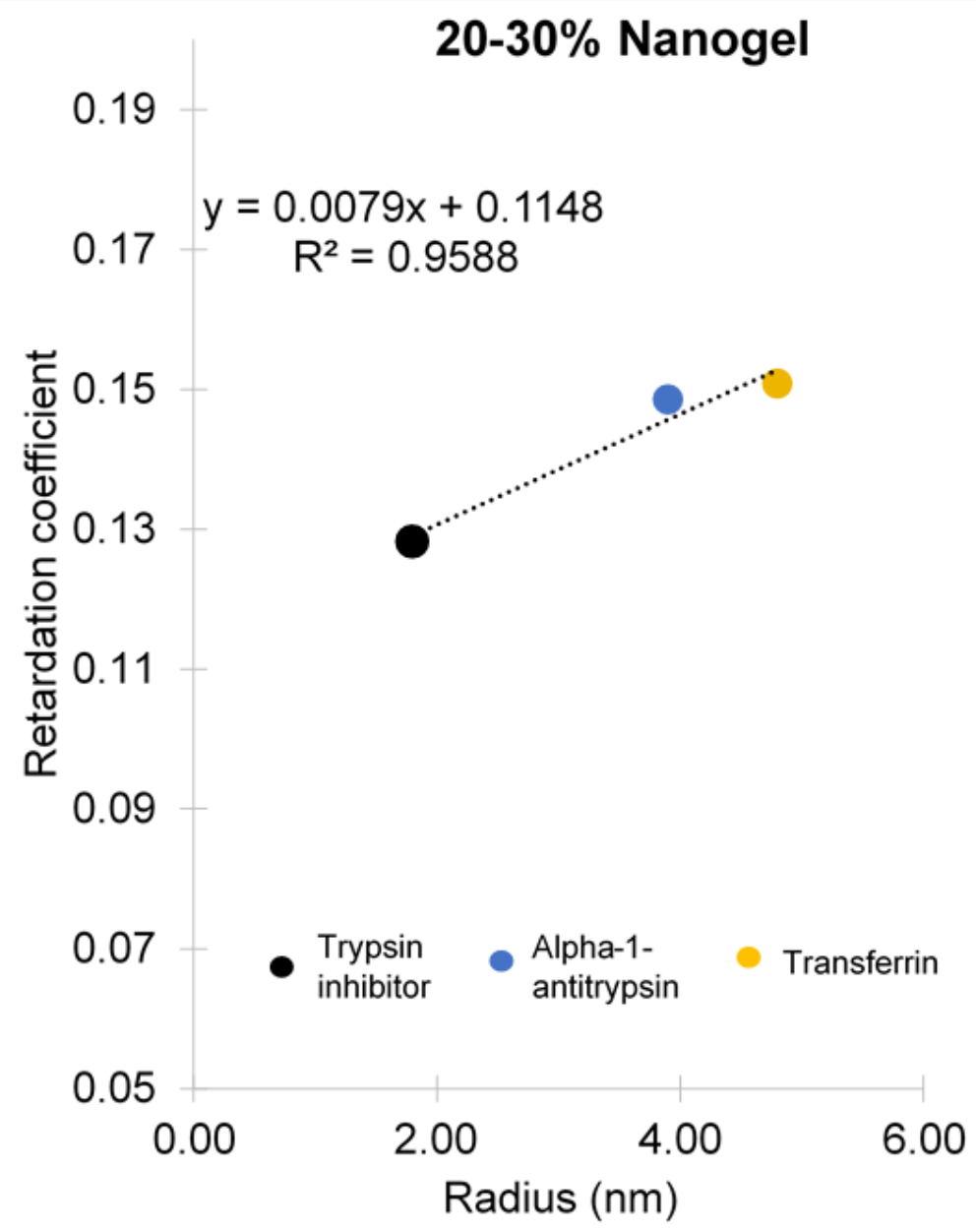

Figure 3-5 shows the plot of the retardation versus molecular size of trypsin inhibitor, alpha-1-antitrypsin, and transferrin separated using 20-30\% nanogel. 


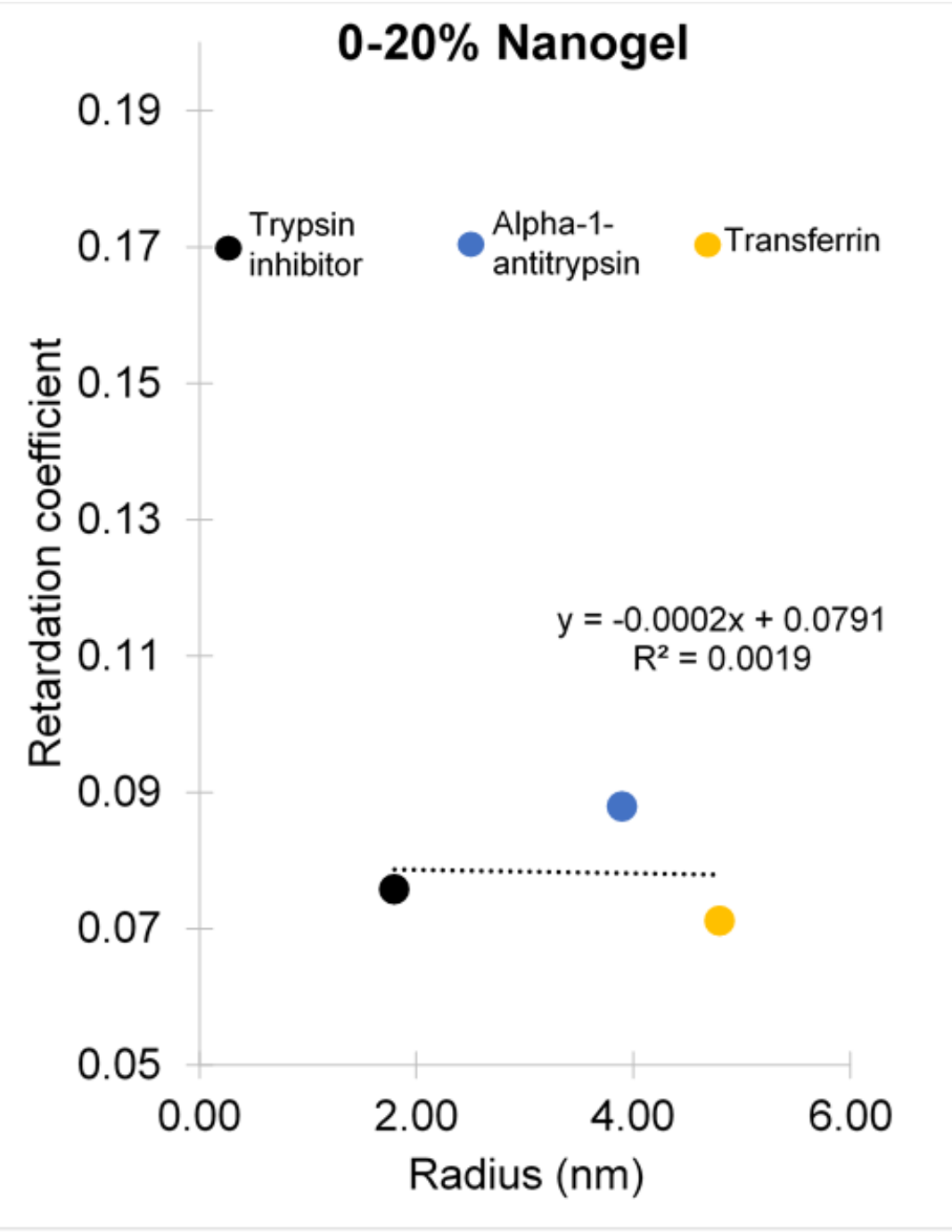

Figure 3-6 shows the plot of the retardation versus molecular size of trypsin inhibitor, alpha-1-antitrypsin, and transferrin separated using 0-20\% nanogel. The slope was zero when the proteins were separated in $0-20 \%$ nanogel, which indicated that migration was not impacted by size. 
3.3.4 Quantification of human serum proteins using nanogel. Based on the findings of the nanogel sieving experiments the $25 \%$ nanogel was selected to resolve human serum proteins that differed in size. Resolution of acidic proteins ranging from 20 to $80 \mathrm{kDa}$ in human serum samples was achievable using a sieving-based separation instead of a separation based on charge-to-size ratio. A human serum sample depleted of albumin and $\operatorname{lgG}$ was analyzed in the presence and absence of the nanogel to emphasize the utility of capillary sieving. When the sample was separated with free solution capillary electrophoresis, the charge-to-size ratios of alpha-1-acid glycoprotein and alpha-1antitrypsin were too similar to resolve and subsequently quantify the proteins as seen in Figure 3-7 trace A. However, when the sieving was introduced with nanogel, the two proteins were baseline resolved, Figure 3-7 trace B. The broadness of the AGP peak in both traces was due to the heterogeneity of the protein, which had multiple isoforms with different sizes[52] and glycosylation[53]. Additionally, the large (>140 kDa) non IgG immunoglobulins ( $\lg Y$ ), shifted to a slower migration time, (Fig 3-7), making quantification possible. With baseline resolution achieved, each of the three most abundant proteins was quantified using an external calibration curve. The external calibration curves (Figure 3-8) were obtained using standards that each contained all three proteins. The quantified concentrations of alpha-1-acid glycoprotein, alpha-1-antitrypsin, and transferrin were 15.2 $\pm 0.8 \mu \mathrm{M}, 19.5 \pm 0.9 \mu \mathrm{M}$, and $27 \pm 1 \mu \mathrm{M}$, respectively, as shown in the external calibration curves in Figure 3-8. When evaluated with a student's $t$ test $(p>0.05)$, these numbers were statistically the same as the concentrations reported by the manufacturer[54], which were $14.3 \pm 0.3 \mu \mathrm{M}, 20.7 \pm 0.6 \mu \mathrm{M}$, and $29 \pm 1 \mu \mathrm{M}$, for alpha-1-acid glycoprotein, alpha1 -antitrypsin, and transferrin, respectively. This demonstrated the advantage of separating the proteins based on size to enable superior resolution and accurate quantification of mixtures. 
A. Electrophoresis

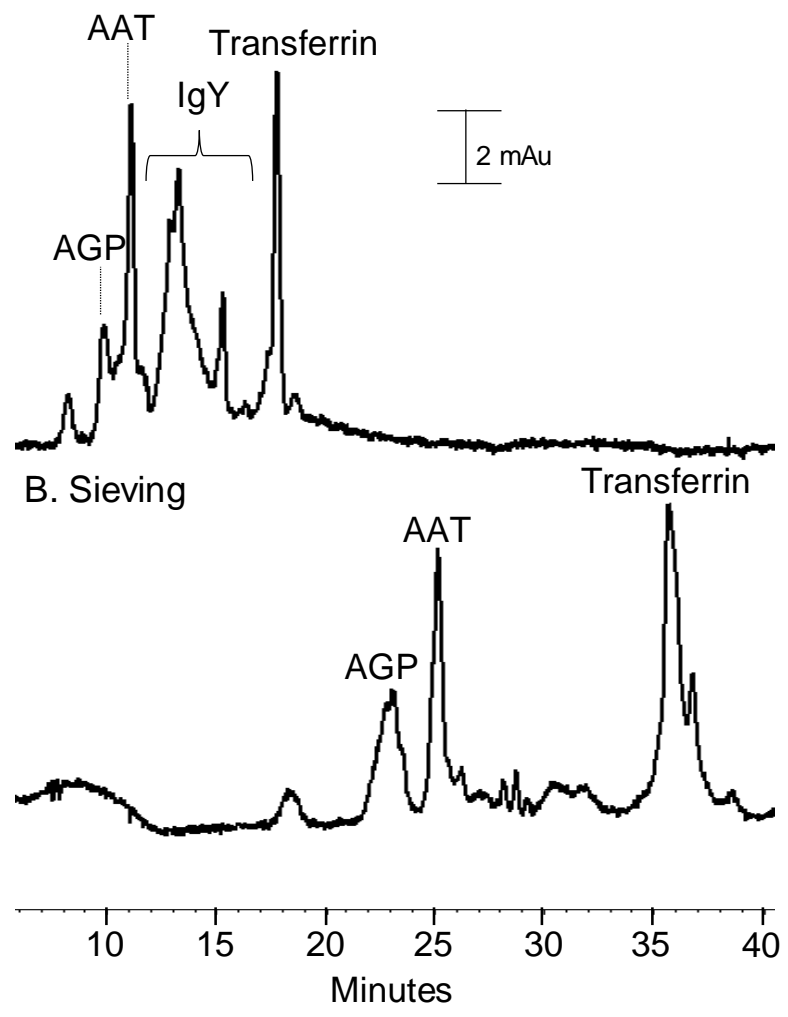

Figure 3-7. Separation of human serum using the free solution capillary electrophoresis (A) or sieving (B). The most abundant proteins, alpha-1-acid glycoprotein (AGP), alpha1-antitrypsin (AAT), non IgG immunoglobulins (IgY), and transferrin (Tf) are separated to demonstrate better resolution and the ability to shift large molecules like immunoglobulins out of the separation window. Using the free solution capillary electrophoresis, AGP, AAT, and Tf were quantified as $15.2 \mu \mathrm{M}, 19.5 \mu \mathrm{M}$, and $27 \mu \mathrm{M}$, respectively. Separation conditions are the same as Figure 3-3. 

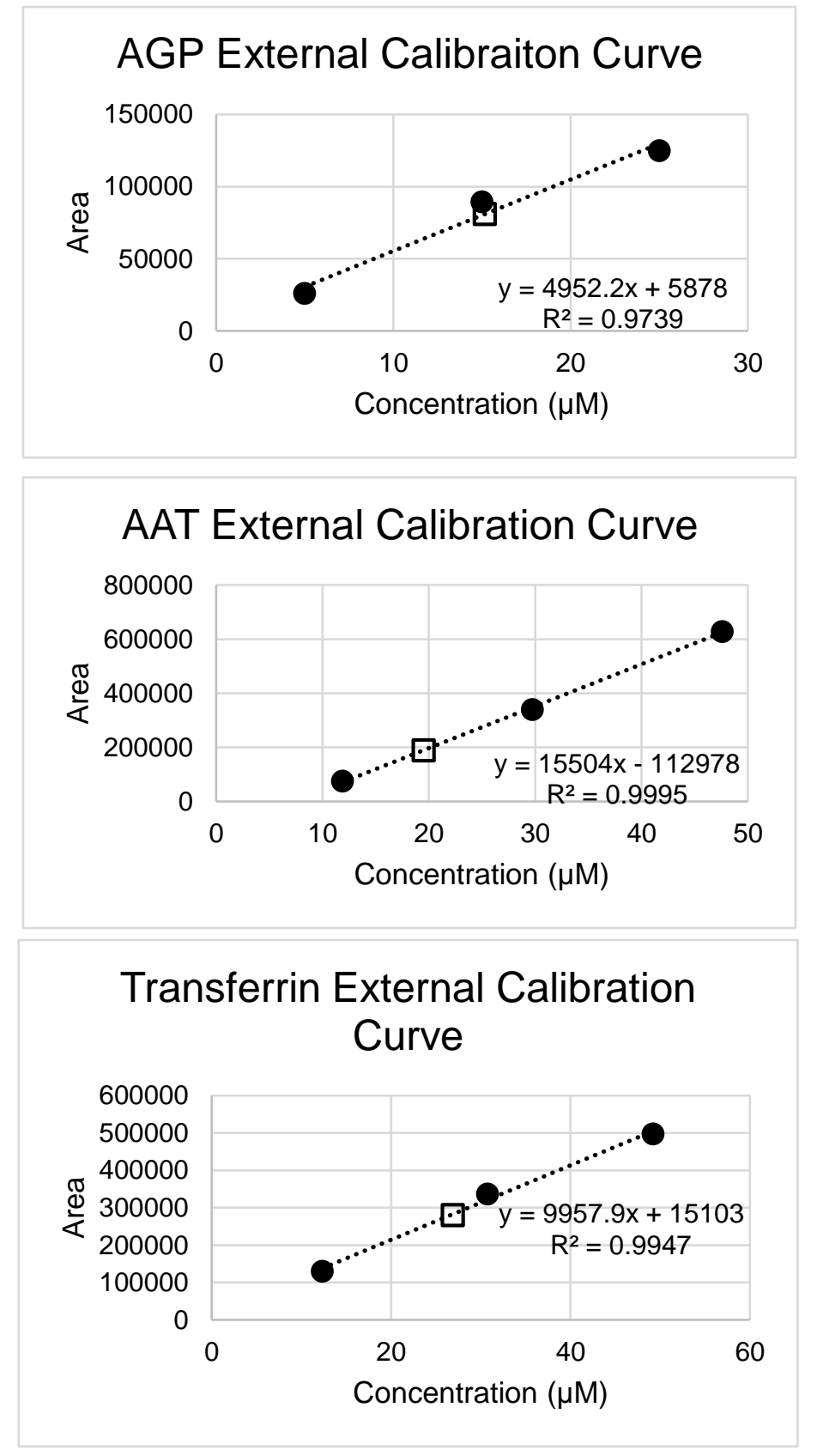

Figure 3-8 shows the external calibration curves used for quantifying alpha-1-acid glycoprotein (AGP), alpha-1-antitrypsin (AAT), and transferrin in human serum. The solid circles $(\bullet)$ are the standard points, while the open squares $(\square)$ represent the serum sample. 


\subsection{Conclusions and Future Directions.}

Nanogels are an effective media for protein sieving in capillary electrophoresis. The results from this report demonstrate the utility of 20,25 , and $30 \%$ nanogels to separate proteins with a molecular weight of 20.5 to $79.5 \mathrm{kDa}$, which range in size from 1.8 to 4.8 $\mathrm{nm}$ radius. The thermally responsive nanogels were easily replaced in the capillary by using temperature to switch between high and low viscosity. Nanogels are a nondenaturing media and are inexpensive, costing $\$ 0.04$ per run[55,56]. The utility of a sieving based separation for serum proteins was demonstrated with an improved separation of human serum which enabled the accurate quantification of proteins that were previously unresolved.

Following this demonstration of the utility of nanogel sieving for proteins additional studies are needed to further evaluate the material. The apparent pore size of $20-30 \%$ nanogel matrices can be measured with a DNA size ladder by observing the transition from Ogston sieving to reptation, as this occurs when the size of the DNA approaches the apparent pore size of the medium. Additionally, more precise size ladders, such as DNA between 5-50 bp in length, which correspond to diameters of approximately $1.7 \mathrm{~nm}$ to $17 \mathrm{~nm}$, will address issues related to aspherical geometries of some proteins. Irregular shapes of non-denatured proteins lead to inaccurate protein sizing with sieving. For example, when molecular weight is used to estimate the radii of alpha-1-antitrypsin and transferrin, the radii are $2.5 \mathrm{~nm}$ and $2.9 \mathrm{~nm}$, respectively[41], but when the largest dimension of the actual measured sizes of these aspherical proteins are used, the radii increase to $3.9 \mathrm{~nm}$ and $4.8 \mathrm{~nm}$, respectively[48,49]. A final aim for expanding the applicability of these separations is to determine the compatibility of the nanogel with additives, such as sodium dodecyl sulfate, that are typically used to equalize the charge-to-size ratio. A more detailed understanding of the nanogel performance will render the method applicable to a wide range of proteins. 


\subsection{Acknowledgements}

This material is based upon work supported by the National Science Foundation Grant No. CHE1506984.

\subsection{References}

1. Kristoff, C. J.; Bwanali, L.; Veltri, L. M.; Gautam, G. P.; Rutto, P. K.; Newton, E. O.; Holland, L. A. Challenging Bioanalyses with Capillary Electrophoresis Anal. Chem. 2020, 92, 49-66.

2. Voeten, R. L. C.; Ventouri, I. K.; Haselberg, R.; Somsen, G. W. Capillary Electrophoresis: Trends and Recent Advances. Anal. Chem. 2018, 90, 1464-1481.

3. Wang, L.; Bo, T.; Zhang, Z.; Wang, G.; Tong, W.; Da Yong Chen, D. High Resolution Capillary Isoelectric Focusing Mass Spectrometry Analysis of Peptides, Proteins, And Monoclonal Antibodies with a Flow-through Microvial Interface. Anal. Chem. 2018, 90, 9495-9503.

4. Kahle, J.; Wätzig, H. Determination of protein charge variants with (imaged) capillary isoelectric focusing and capillary zone electrophoresis. Electrophoresis 2018, 39, 2492-2511.

5. Burton, J. B.; Ward, C. L.; Klemet, D. M.; Linz, T. H. Incorporation of thermal gels for facile microfluidic transient isotachophoresis. Anal. Methods 2019.

6. Ragland, T. S.; Gossage, M. D.; Furtaw, M. D.; Anderson, J. P.; Steffens, D. L.; Wirth, M. J. Electrophoresis of megaDalton proteins inside colloidal silica. Electrophoresis 2019, 40, 817-823.

7. Beckman, J.; Song, Y.; Gu, Y.; Voronov, S.; Chennamsetty, N.; Krystek, S.; Mussa, N.; Li, Z. J. Purity Determination by Capillary Electrophoresis Sodium Hexadecyl Sulfate (CE-SHS): A Novel Application For Therapeutic Protein Characterization. Anal. Chem. 2018, 90, 2542-2547.

8. Peli Thanthri, S. H.; Ward, C. L.; Cornejo, M. A.; Linz, T. H. Simultaneous Preconcentration and Separation of Native Protein Variants Using Thermal Gel Electrophoresis. Anal. Chem. 2020, 92, 6741-6747.

9. Ouimet, C. M.; D'Amico, C. I.; Kennedy, R. T. Droplet sample introduction to microchip gel and zone electrophoresis for rapid analysis of protein-protein complexes and enzymatic reactions. Anal. Bioanal. Chem. 2019, 411, 6155-6163.

10. Filep, C.; Guttman, A. The Effect of Temperature in Sodium Dodecyl Sulfate Capillary Gel Electrophoresis of Protein Therapeutics. Anal. Chem. 2020, 92, 4023-4028.

11. Kahle, J.; Maul, K. J.; Wätzig, H. The next generation of capillary electrophoresis instruments: Performance of CE-SDS protein analysis. Electrophoresis 2018, 39, 311-325.

12. Rustandi, R. R.; Hamm, M. Development of an ADP-ribosylation assay for residual toxicity in $C$. difficile binary toxin CDTa using automated capillary western blot. $J$. Pharm. Biomed. Anal. 2020, 182, 113125.

13. Loughney, J. W.; Ha, S.; Rustandi, R. R. Quantitation of CRM197 using imaged capillary isoelectric focusing with fluorescence detection and capillary Western. Anal. Biochem. 2017, 534, 19-23. 
14. Lacher, N. A.; Wang, Q.; Roberts, R. K.; Holovics, H. J.; Aykent, S.; Schlittler, M. R.; Thompson, M. R.; Demarest, C. W. Development of a capillary gel electrophoresis method for monitoring disulfide isomer heterogeneity in IgG2 antibodies. Electrophoresis 2010, 31, 448-458.

15. Cohen, A. S.; Paulus, A.; Karger, B. L. High-performance capillary electrophoresis using open tubes and gels. Chromatographia 1987, 24, 15-24.

16. Ganzler, K.; Greve, K. S.; Cohen, A. S.; Karger, B. L.; Guttman, A.; Cooke, N. C. High-performance capillary electrophoresis of SDS-protein complexes using UVtransparent polymer networks. Anal. Chem. 1992, 64, 2665-2671.

17. Römer, J.; Montealegre, C.; Schlecht, J.; Kiessig, S.; Moritz, B.; Neusüß, C. Online mass spectrometry of CE (SDS)-separated proteins by two-dimensional capillary electrophoresis. Anal. Bioanal. Chem. 2019, 411, 7197-7206.

18. Ramos, Y.; González, A.; Sosa-Acosta, P.; Perez-Riverol, Y.; García, Y.; Castellanos-Serra, L.; Gil, J.; Sánchez, A.; González, L. J.; Besada, V. Sodium dodecyl sulfate free gel electrophoresis/electroelution sorting for peptide fractionation. J. Sep. Sci. 2019, 42, 3712-3717.

19. Sänger-van de Griend, C. E. CE-SDS method development, validation, and best practice-An overview. Electrophoresis 2019, 40, 2361-2374.

20. Vidanapathirana, P.; Hasan, F.; Mussio, K.; Pande, A.; Brands, M.; Siraj, N.; Grove, A.; Warner, I. M. Cationic ionic liquid surfactant-polyacrylamide gel electrophoresis for enhanced separation of acidic and basic proteins with single-step ribonuclease $b$ glycoforms separation. J. Chromatogr. A 2017, 1515, 245-251.

21. Hasan, F.; Vidanapathirana, P.; Das, S.; Fernand, V. E.; Siraj, N.; Losso, J. N.; Warner, I. M. Ionic liquids as buffer additives in ionic liquid-polyacrylamide gel electrophoresis separation of mixtures of low and high molecular weight proteins. RSC Adv. 2015, 5, 69229-69237.

22. Hjertén, S. High-performance electrophoresis: the electrophoretic counterpart of high-performance liquid chromatography. J. Chromatogr. A 1983, 270, 1-6.

23. Birdsall, R. E.; Koshel, B. M.; Hua, Y.; Ratnayaka, S. N.; Wirth, M. J. Modeling of protein electrophoresis in silica colloidal crystals having brush layers of polyacrylamide. Electrophoresis 2013, 34, 753-760.

24. Njoya, N.; Birdsall, R.; Wirth, M. Silica Colloidal Crystals as Emerging Materials for High-Throughput Protein Electrophoresis. AAPS J 2013, 15, 962-969.

25. Chung, M.; Kim, D.; Herr, A. E. Polymer sieving matrices in microanalytical electrophoresis. Analyst 2014, 139, 5635-5654.

26. Widhalm, A.; Schwer, C.; Blaas, D.; Kenndler, E. Capillary zone electrophoresis with a linear, non-cross-linked polyacrylamide gel: separation of proteins according to molecular mass. J. Chromatogr. A 1991, 549, 446-451.

27. Liu, Y.; Reddy, M. P.; Ratnayake, C. K.; Koh, E. V., Beckman Coulter Inc, US7381317B2, 2008.

28. Chrambach, A.; Rodbard, D. Polyacrylamide Gel Electrophoresis. Science 1971, 172, 440-451.

29. Buchholz, B. A.; Shi, W.; Barron, A. E. Microchannel DNA sequencing matrices with switchable viscosities. Electrophoresis 2002, 23, 1398-1409.

30. Kan, C. W.; Barron, A. E. A DNA sieving matrix with thermally tunable mesh size. Electrophoresis 2003, 24, 55-62. 
31. Mikšík, I.; Eckhardt, A.; Forgács, E.; Cserháti, T.; Deyl, Z. The effect of sodium dodecyl sulfate and Pluronic F127 on the electrophoretic separation of protein and polypeptide test mixtures at acid pH. Electrophoresis 2002, 23, 1882-1886.

32. Kř́žek, T.; Coufal, P.; Tesařová, E.; Sobotníková, J.; Bosáková, Z. Pluronic F-127 as the buffer additive in capillary entangled polymer electrophoresis: Some fundamental aspects. J. Sep. Sci. 2010, 33, 2458-2464.

33. Zhang, J.; Gassmann, M.; He, W.; Wana, F.; Chu, B. Reversible thermo-responsive sieving matrix for oligonucleotide separation. Lab Chip 2006, 6, 526-533.

34. Durney, B. C.; Lounsbury, J. A.; Poe, B. L.; Landers, J. P.; Holland, L. A. A Thermally Responsive Phospholipid Pseudogel: Tunable DNA Sieving with Capillary Electrophoresis. Anal. Chem. 2013, 85, 6617-6625.

35. Durney, B. C.; Bachert, B. A.; Sloane, H. S.; Lukomski, S.; Landers, J. P.; Holland, L. A. Reversible phospholipid nanogels for deoxyribonucleic acid fragment size determinations up to 1500 base pairs and integrated sample stacking. Anal. Chim. Acta 2015, 880, 136-144.

36. Wu, X.; Langan, T. J.; Durney, B. C.; Holland, L. A. Thermally responsive phospholipid preparations for fluid steering and separation in microfluidics. Electrophoresis 2012, 33, 2674-2681.

37. Gattu, S.; Crihfield, C. L.; Holland, L. A. Microscale Measurements of MichaelisMenten Constants of Neuraminidase with Nanogel Capillary Electrophoresis for the Determination of the Sialic Acid Linkage. Anal. Chem. 2017, 89, 929-936.

38. Bwanali, L.; Newton, E.; Crihfield, C. L.; Zeger, V.; Gattu, S.; Holland, L. A. Quantification of the a2-6 sialic acid linkage in branched N-glycan structures with capillary nanogel electrophoresis. Anal. Chem. 2020, 92, 1518-1524.

39. Lu, G.; Holland, L. A. Profiling the N-Glycan Composition of IgG with Lectins and Capillary Nanogel Electrophoresis. Anal. Chem. 2019, 91, 1375-1383.

40. Tuntevski, K.; Durney, B. C.; Snyder, A. K.; LaSala, P. R.; Nayak, A. P.; Green, B. J.; Beezhold, D. H.; Rio, R. V. M.; Holland, L. A.; Lukomski, S. Aspergillus collagen-like (acl) genes: identification, sequence polymorphism and assessment for PCR-based pathogen detection. Appl. Environ. Microbiol. 2013, 79, 7882-7895.

41. Erickson, H. P. Size and shape of protein molecules at the nanometer level determined by sedimentation, gel filtration, and electron microscopy. Biol Proced Online 2009, 11, 32-51.

42. Luo, R.; Archer-Hartmann, S. A.; Holland, L. A. Transformable capillary electrophoresis for oligosaccharide separations using phospholipid additives. Anal. Chem. 2010, 82, 1228-1233.

43. Archer-Hartmann, S. A.; Sargent, L. M.; Lowry, D. T.; Holland, L. A. Microscale exoglycosidase processing and lectin capture of glycans with phospholipid assisted capillary electrophoresis separations. Anal. Chem. 2011, 83, 2740-2747.

44. Williams, B. A.; Vigh, G. Fast, Accurate Mobility Determination Method for Capillary Electrophoresis. Anal. Chem. 1996, 68, 1174-1180.

45. https://web.expasy.org/compute_pi/, SIB ExPASy Bioformatics Resources Portal. Comput pl/MW, accessed July 16, 2020

46. Nieh, M. P.; Raghunathan, V. A.; Glinka, C. J.; Harroun, T. A.; Pabst, G.; Katsaras, $\mathrm{J}$. Magnetically alignable phase of phospholipid "bicelle" mixtures is a chiral nematic made up of wormlike micelles. Langmuir 2004, 20, 7893-7897. 
47. Harroun, T. A.; Koslowsky, M.; Nieh, M.-P.; de_Lannoy, C.-F.; Raghunathan, V. A.; Katsaras, J. Comprehensive examination of mesophases formed by DMPC and DHPC mixtures. Langmuir 2005, 21, 5356-5361.

48. Smith, K. F.; Harrison, R. A.; Perkins, S. J. Structural comparisons of the native and reactive-centre-cleaved forms of $\alpha 1$-antitrypsin by neutron- and X-ray-scattering in solution. Biochem. J. 1990, 267, 203-212.

49. Kilár, F.; Simon, I. The effect of iron binding on the conformation of transferrin. A small angle x-ray scattering study. Biophys. J. 1985, 48, 799-802.

50. Crihfield, C. L.; Kristoff, C. J.; Veltri, L. M.; Penny, W. M.; Holland, L. A. Semipermanent cationic coating for protein separations. J. Chromatogr. A 2019, 1607, 460397.

51. Stellwagen, N. C.; Stellwagen, E. Effect of the matrix on DNA electrophoretic mobility. J. Chromatogr., A 2009, 1216, 1917-1929.

52. Chen, L.; Feng, J.; Yang, D.; Tian, F.; Ye, X.; Qian, Q.; Wei, S.; Zhou, Y. Sequence isomerism-dependent self-assembly of glycopeptide mimetics with switchable antibiofilm properties. Chemical Science 2019, 10, 8171-8178.

53. Zhang, C.; Bi, C.; Clarke, W.; Hage, D. S. Glycoform analysis of alpha1-acid glycoprotein based on capillary electrophoresis and electrophoretic injection. J. Chromatogr. A 2017, 1523, 114-122.

54. European Commission Joint Research Centre Reference Material ERM-

DA470k_IFCC Human Serum, certification report (Certification report ERM-

DA470k_report.pdf) available at https://crm.jrc.ec.europa.eu/p/40456/40491/Byanalyte-group/Protein-content/ERM-DA470k-IFCC-HUMAN-SERUM-proteins/ERMDA470k_IFCC, accessed November 11, 2018

55. https://avantilipids.com/product/850305, 1,2-dihexanoyl-sn-glycero-3-phosphocholine 06:0 PC (DHPC), CAS number 34506-67-7, catalog number 850305P-1g, accessed July 21, 2020

56. https://avantilipids.com/product/850345, 1,2-ditetradecanoyl-sn-glycero-3-phosphocholine (DMPC) PC(14:0/14:0), CAS Number 18194-24-6, catalog number $850345 \mathrm{P}-1 \mathrm{~g}$, accessed July 21, 2020 
Chapter 4: Future Directions 


\subsection{Introduction}

Phospholipid nanogels continuously prove to hold many advantages as separation materials. The results discussed demonstrated the utility of the phospholipids for developing a hybrid coat capable of rapid, simultaneous separations of acidic and basic proteins without adsorption to the surface [1,2]. The coating was stable through extensive flushing and showed no indication or protein adsorption after 6 consecutive injections of proteins with no flushing in between. A stable electroosmotic flow was generated regardless of the $\mathrm{pH}$ value tested between $\mathrm{pH} 4$ and 9. Furthermore, when the phospholipids are used at a composition suitable for nanogel, a size-based component was added to the preexisting charge-to-size ratio mechanism [3]. This allows for enhanced separation of samples in which the proteins possess similar charge-to-size ratios, like in human serum.

The effort in this research can benefit many applications and can be expanded upon in the future. Both materials can be utilized with an inexpensive barefused capillary and cost less than $\$ 0.10$ per analysis. Furthermore, the materials make modification of the capillary or development of a sieving matrix in capillary a simple process without requiring in capillary chemistry for covalent bonds or high pressure systems not required for aqueous solutions. This improves the potential for the material to be adapted in other laboratories without extensive optimization. While the development of hybrid coatings using the phospholipids is maturing rapidly thus allowing it to be extended to new applications, the phospholipid material as a sieving matrix for proteins still demands more expansion on the fundamental understanding as this was the first demonstration of this specific technique. Currently, the Holland group is expanding on the coating research through altering the head group and utilizing the coating to generate electroosmotic flows compatible with mass spectrometry. Future studies for the phospholipid sieving matrix will focus on the ability to tune the nanogel using temperature and concentration to analyze a wider range of proteins that can be applicable to pharmaceuticals. 


\subsection{Phospholipid use as coating material}

The development of hybrid coatings based on the phospholipids presents a new avenue for combining the high efficiency separations of proteins via capillary electrophoresis with the structure analysis of mass spectrometry. The use of mass spectrometry for analysis of intact proteins is a growing field, with one review[4] citing that intact protein MS analysis methods are the most sought after techniques on the Consortium for Top-Down Proteomics[5]. In expansion of that research, many research groups are making great strides in not only analyzing in-tact proteins, but also analyzing proteins with the native structure[6-11]. Incorporating a separation into the analysis of intact and non-denatured proteins is a practical way to overcome some of the prior limitations with MS analysis, such as ionization suppression resulting from sample buffer and multiple proteins in a single sample[4,12,13]. As previously discussed, capillary electrophoresis is a powerful tool to meet this need, but coatings or other mechanisms to prevent protein adsorption are required. Furthermore, the technique employed still needs to provide sufficient flow for coupling online to the mass spectrometer, which means a neutral surface is undesirable and would require pressure assisted flow. This imposes laminar flow on the separation that will impair resolution.

Phospholipid coatings in combination with surfactants possessing hydrophobic tails and charged headgroups, such as the cetyltrimethylammonium bromide (CTAB) utilized in these studies[1,2], are ideal candidates to address this need. Work is currently underway in the Holland group to develop other coatings using the study presented in this dissertation as a model. These new coatings are being developed specifically to enable control over the electroosmotic flow across a range of $\mathrm{pH}$ values. This will enable the analysis of proteins in native and non-native conditions without impacting the separation through adsorption or varying electroosmotic flow. 


\subsection{Phospholipid use as a protein separation matrix}

This report demonstrated the first use of the phospholipid nanogel for sieving proteins; however, there is still much more investigation into this application to be performed. The optimization in the presented work[3] determined separation conditions appropriate for abundant non-immunoglobulin proteins, all of which are related to disease and potential biomarkers[14-16]. However, the versatility of the phospholipid material will allow the size range and resolution to be tuned to the protein range of interest through temperature and composition. To achieve this, fundamental studies will be required to investigate pore size and gain a better insight into the morphology of the higher compositions of phospholipid that have not been as extensively studied. This can be achieved in a manner similar to how it was performed previously for DNA[17, 18]. Of particular interest to the pharmaceutical field, the method should be adapted to analyze proteins of $100 \mathrm{kDa}$ and larger, which will make the technique applicable to antibody aggregation studies commonly employed for monoclonal antibodies. Furthermore, the phospholipid nanogel should be screened for compatibility with additives that will make it an even more attractive material for use in the pharmaceutical industry, such as surfactants, carrier ampholytes, etc. 


\subsection{References}

1. Crihfield, C. L.; Kristoff, C. J.; Veltri, L. M.; Penny, W. M.; Holland, L. A., Semipermanent cationic coating for protein separations. J Chromatogr A 2019, 1607, 460397.

2. Crihfield, C. L.; Kristoff, C. J.; Veltri, L. M.; Wilson, C. A.; Penny, W. M.; Holland, L. A., Data for semi-permanent cationic coating for protein separations. Data in Brief 2020, 29, 7.

3. Crihfield, C.; Holland, L., Nanogel electrophoresis separations of proteins.

4. Donnelly, D. P.; Rawlins, C. M.; DeHart, C. J.; Fornelli, L.; Schachner, L. F.; Lin, Z. Q.; Lippens, J. L.; Aluri, K. C.; Sarin, R.; Chen, B. F.; Lantz, C.; Jung, W.; Johnson, K. R.; Koller, A.; Wolff, J. J.; Campuzano, I. D. G.; Auclair, J. R.; Ivanov, A. R.; Whitelegge, J. P.; Pasa-Tolic, L.; Chamot-Rooke, J.; Danis, P. O.; Smith, L. M.; Tsybin, Y. O.; Loo, J. A.; Ge, Y.; Kelleher, N. L.; Agar, J. N., Best practices and benchmarks for intact protein analysis for top-down mass spectrometry. Nature Methods 2019, 16 (7), 587-594.

5. Fornelli, L.; Toby, T. K.; Schachner, L. F.; Doubleday, P. F.; Srzentic, K.; DeHart, C. J.; Kelleher, N. L., Top-down proteomics: Where we are, where we are going? Journal of Proteomics 2018, 175, 3-4.

6. Erba, E. B.; Signor, L.; Petosa, C., Exploring the structure and dynamics of macromolecular complexes by native mass spectrometry. Journal of Proteomics 2020, 222, 17.

7. Kaltashov, I. A.; Bobst, C. E.; Pawlowski, J.; Wang, G. B., Mass spectrometrybased methods in characterization of the higher order structure of protein therapeutics. Journal of Pharmaceutical and Biomedical Analysis 2020, 184, 11.

8. Hale, O. J.; Illes-Toth, E.; Mize, T. H.; Cooper, H. J., High-Field Asymmetric Waveform lon Mobility Spectrometry and Native Mass Spectrometry: Analysis of Intact Protein Assemblies and Protein Complexes. Analytical Chemistry 2020, 92 (10), 6811-6816.

9. Wu, H. M.; Zhang, R. K.; Zhang, W. J.; Hong, J.; Xiang, Y.; Xu, W., Rapid 3dimensional shape determination of globular proteins by mobility capillary electrophoresis and native mass spectrometry. Chemical Science 2020, 11 (18), 4758-4765.

10. Vimer, S.; Ben-Nissan, G.; Morgenstern, D.; Kumar-Deshmukh, F.; Polkinghorn, C.; Quintyn, R. S.; Vasil'ev, Y. V.; Beckman, J. S.; Elad, N.; Wysocki, V. H.; Sharon, M., Comparative Structural Analysis of 20S Proteasome Ortholog Protein Complexes by Native Mass Spectrometry. Acs Central Science 2020, 6 (4), 573588.

11. VanAernum, Z. L.; Busch, F.; Jones, B. J.; Jia, M. X.; Chen, Z. B.; Boyken, S. E.; Sahasrabuddhe, A.; Baker, D.; Wysocki, V. H., Rapid online buffer exchange for screening of proteins, protein complexes and cell lysates by native mass spectrometry. Nature Protocols 2020, 15 (3), 1132-1157.

12. Camerini, S.; Mauri, P., The role of protein and peptide separation before mass spectrometry analysis in clinical proteomics. Journal of Chromatography A 2015, 1381, 1-12. 
13. Gomes, F. P.; Yates, III, Recent trends of capillary electrophoresis-mass spectrometry in proteomics research. Mass Spectrometry Reviews 2019, 38 (6), 445-460.

14. Strnad, P.; McElvaney, N. G.; Lomas, D. A., Alpha(1)-Antitrypsin Deficiency. New England Journal of Medicine 2020, 382 (15), 1443-1455.

15. Iqbal, N. T.; Sadiq, K.; Syed, S.; Akhund, T.; Umrani, F.; Ahmed, S.; Yakoob, M. Y.; Rahman, N.; Qureshi, S.; Xin, W. J.; Ma, J. N. Z.; Hughes, M.; Ali, S. A., Promising Biomarkers of Environmental Enteric Dysfunction: A Prospective Cohort study in Pakistani Children. Scientific Reports 2018, 8, 10.

16. Ward, D. G.; Suggett, N.; Cheng, Y.; Wei, W.; Johnson, H.; Billingham, L. J.; Ismail, T.; Wakelam, M. J. O.; Johnson, P. J.; Martin, A., Identification of serum biomarkers for colon cancer by proteomic analysis. British Journal of Cancer 2006, 94 (12), 1898-1905.

17. Durney, B. C.; Lounsbury, J. A.; Poe, B. L.; Landers, J. P.; Holland, L. A., A Thermally Responsive Phospholipid Pseudogel: Tunable DNA Sieving with Capillary Electrophoresis. Analytical Chemistry 2013, 85 (14), 6617-6625.

18. Durney, B. C.; Bachert, B. A.; Sloane, H. S.; Lukomski, S.; Landers, J. P.; Holland, L. A., Reversible phospholipid nanogels for deoxyribonucleic acid fragment size determinations up to 1500 base pairs and integrated sample stacking. Analytica Chimica Acta 2015, 880, 136-144. 
Appendix 1 Supporting Experiments for Chapters 2 and 3

\begin{tabular}{|c|c|c|}
\hline \multicolumn{3}{|c|}{ Electrophoretic Mobility x $10-4 \mathrm{~cm} 2 \mathrm{~V}-1 \mathrm{~s}-1$} \\
\hline $\mathrm{C}_{16} \mathrm{TAB}$ & Phospholipid & $\mathrm{C}_{8} \mathrm{TAB}$ \\
\hline 3.12 & 0.22 & 0.23 \\
\hline
\end{tabular}




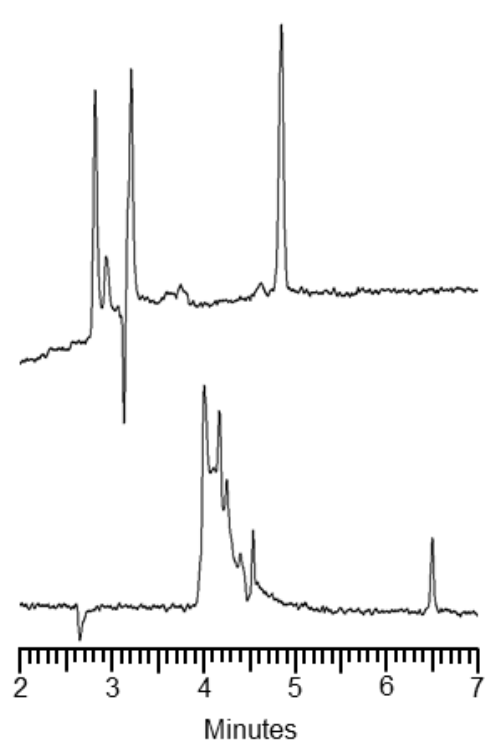

Figure A1-1. Separation of transferrin, enolase, and lysozyme using $100 \mathrm{mM}$ (top) and $50 \mathrm{mM}$ (bottom) ammonium acetate. 


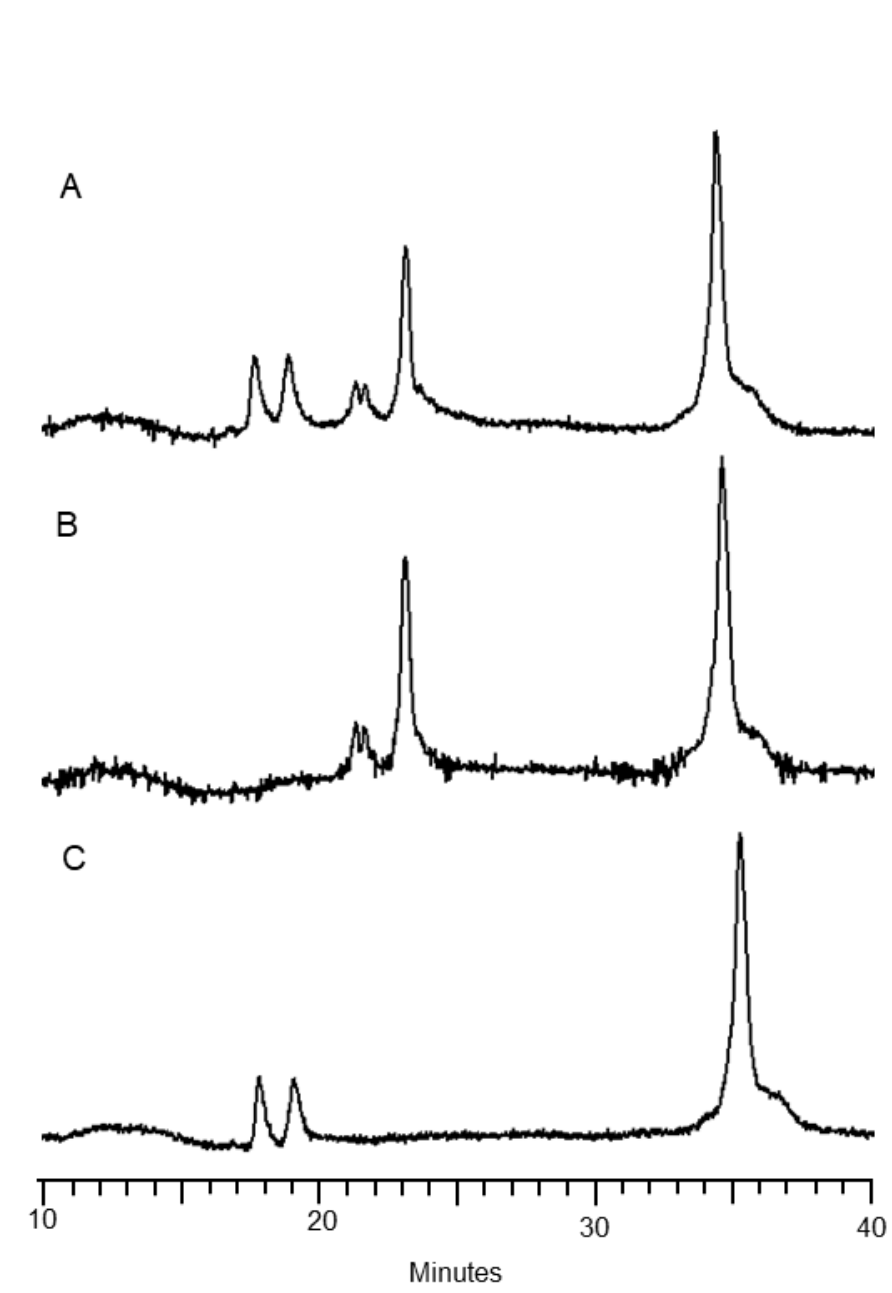

Figure A1-2. Identification of proteins in the separation of beta-lactoglobulin, alpha-1antitrypsin, and transferrin using $25 \%$ nanogel. Trace A contains all three proteins, trace B contains alpha-1-antitrypsin and transferrin, and trace $C$ contains beta-lactoglobulin and transferrin. 


\section{Appendix 2 Raw Data for Chapter 2}

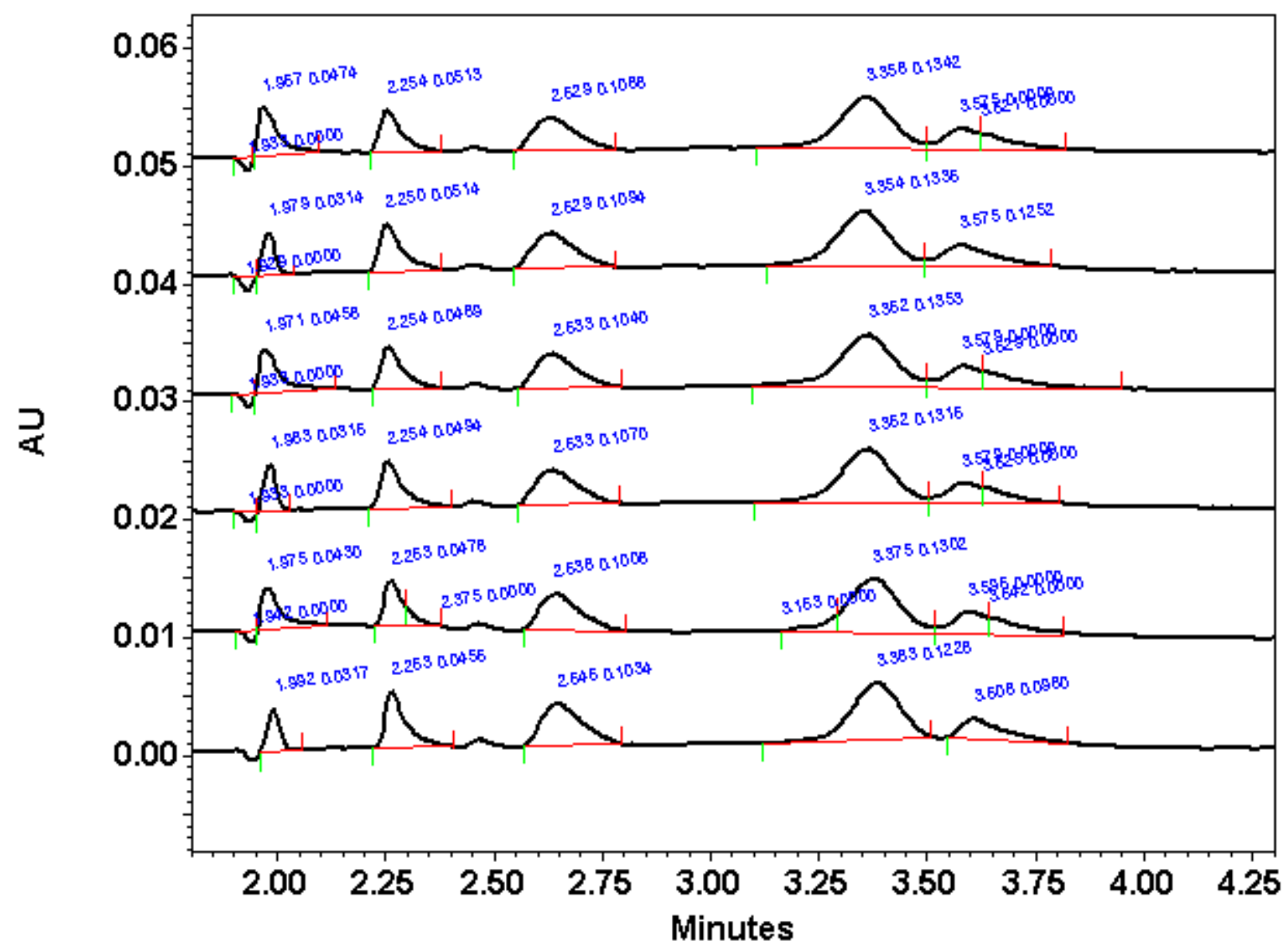

Figure A2-1. Bare fused silica separation of lysozyme, ribonuclease A, enolase, transferrin, and alpha-1-antitrypsin 


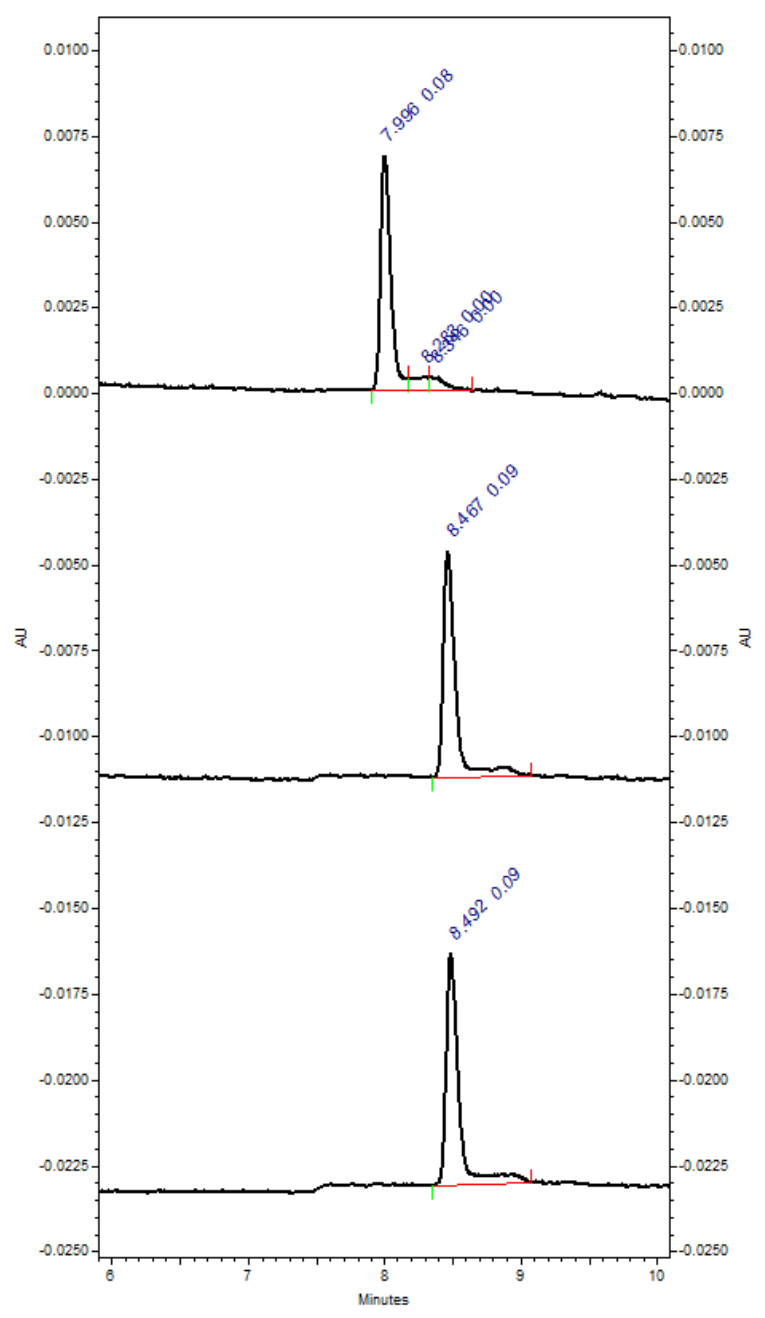

Figure A2-2. Separation of cations (lysozyme, ribonuclease A, and chymotrypsinogen) on phospholipid coated capillary. Only lysozyme has a high enough electrophoretic mobility to migrate within the given time frame with the suppressed electroosmotic flow. 


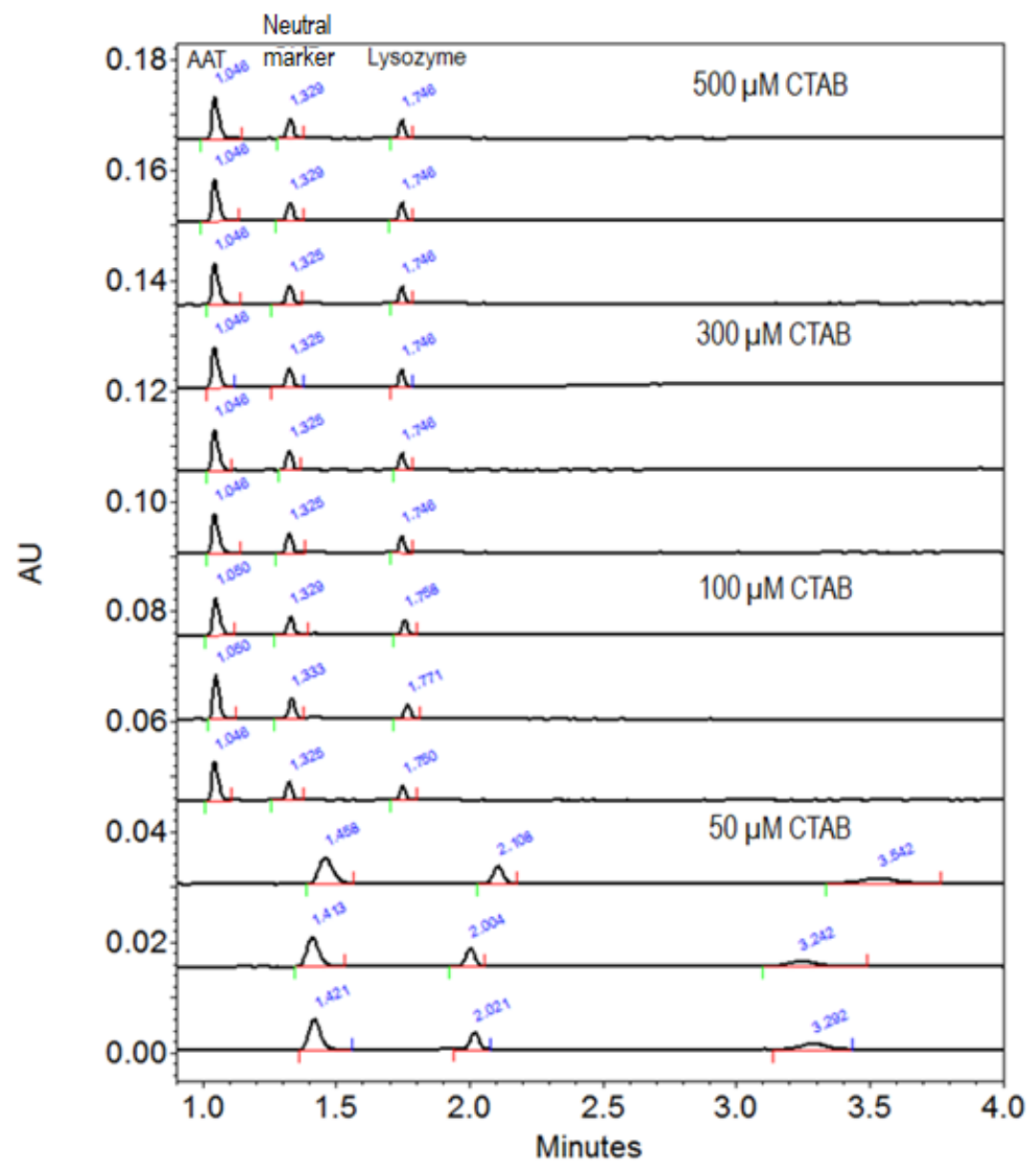

Figure A2-3. Labeled raw data for study of CTAB Concentration on EOF $500 \mu \mathrm{m}, 300$ $\mu \mathrm{m}, 100 \mu \mathrm{m}$ and $50 \mu \mathrm{m}$ at bottom 


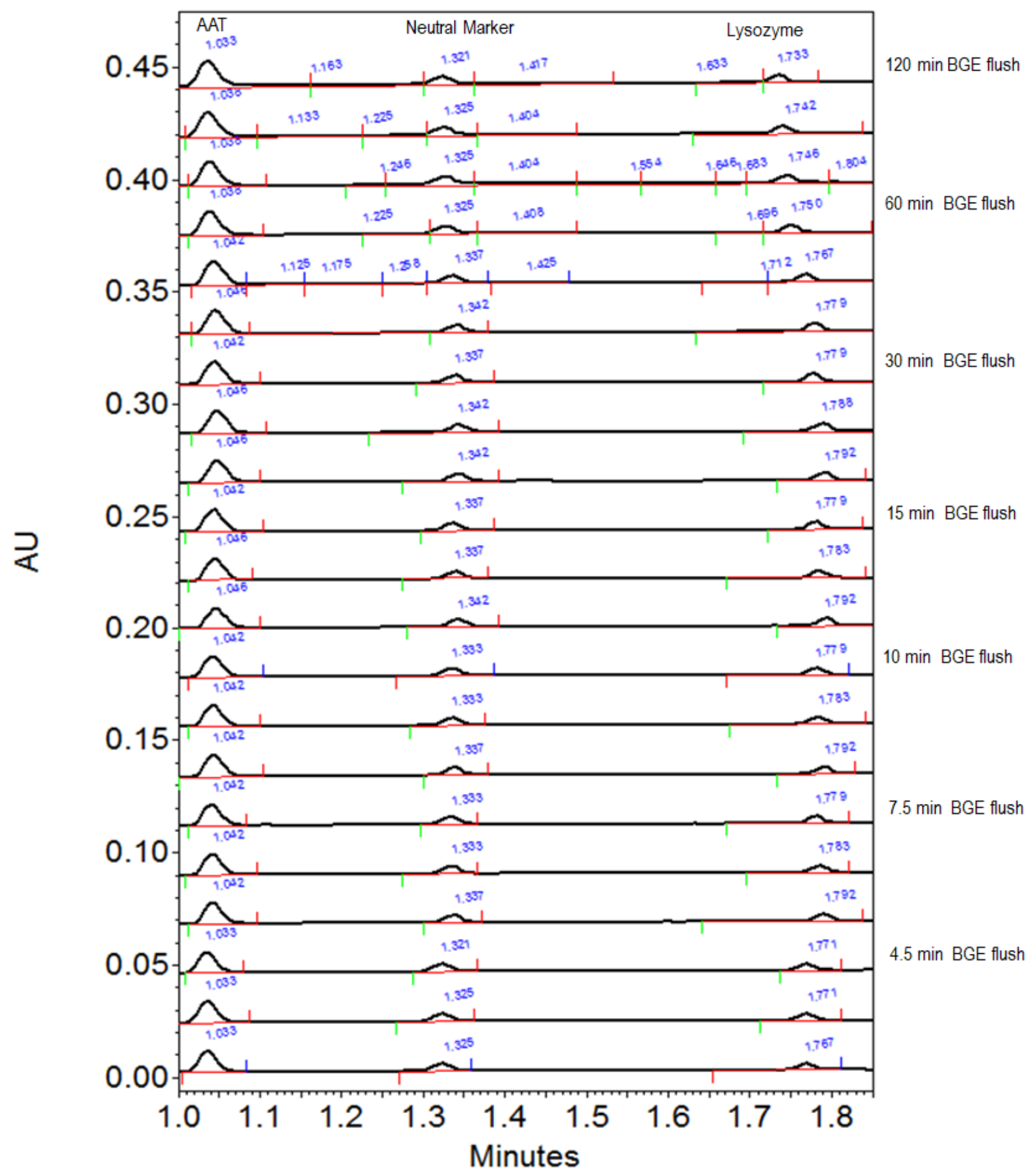

Figure A2-3. Raw data to show impact of increased background electrolyte flushing on phospholipid CTAB coating 


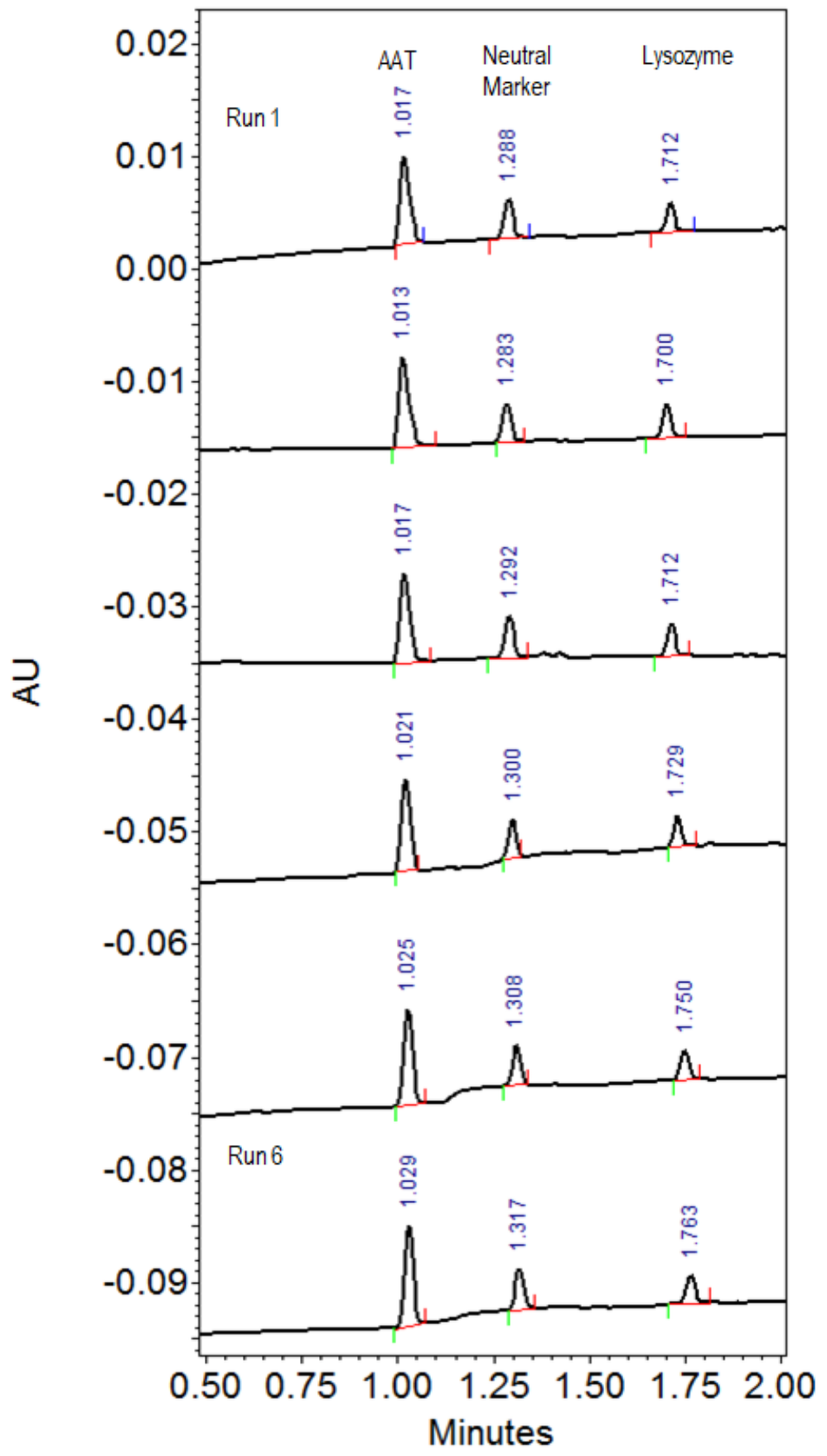

Figure A2-4. Consecutive injections of AAT, neutral marker, and lysozyme without flushing $n=6$ 


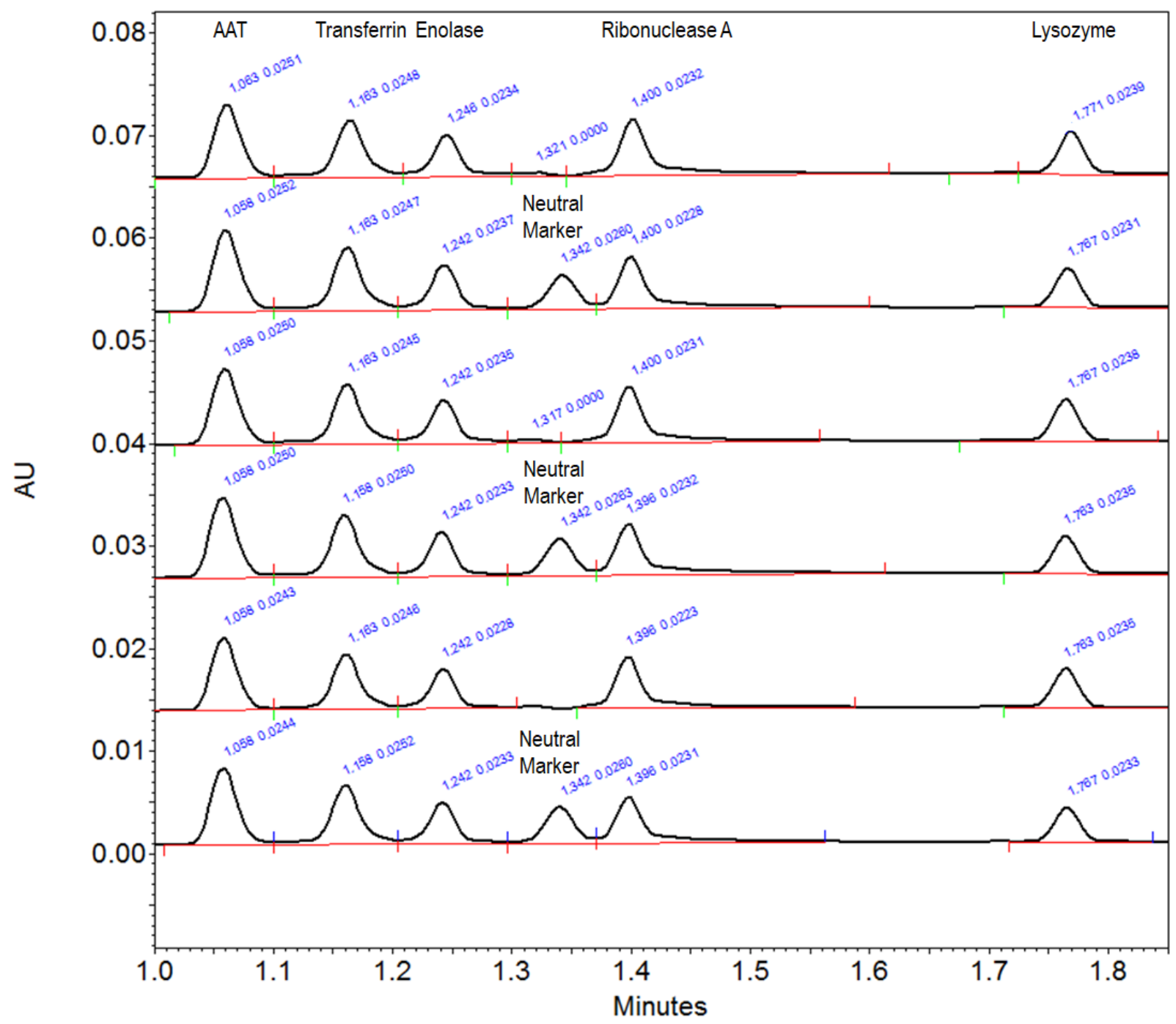

Figure A2-5. CTAB raw data for $10 \mathrm{~cm}$ efficiency study and comparison of short end CTAB to short end lipid tables 


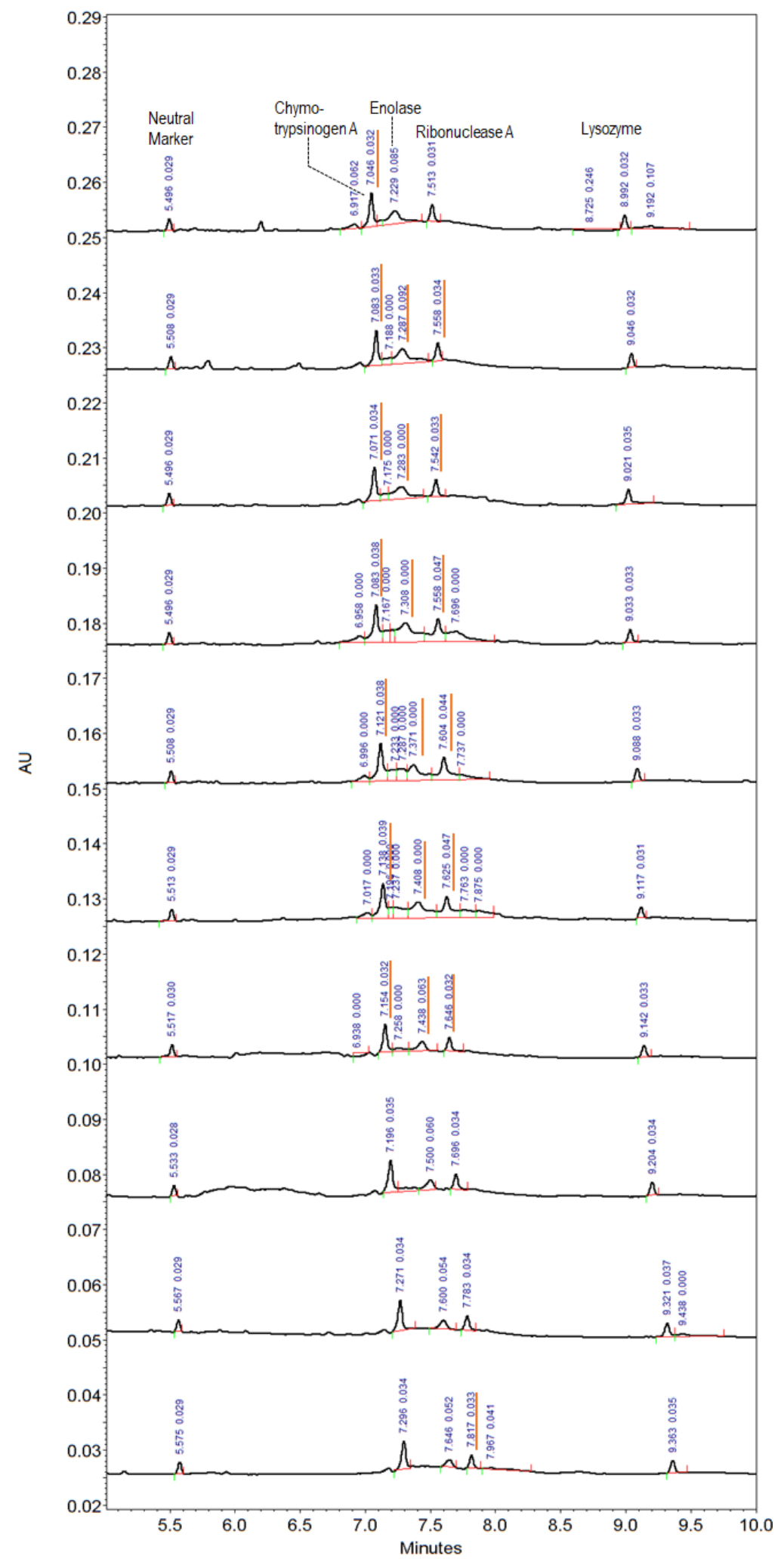

Figure A2-6. pH 4 Separation of protein standards and neutral marker on phospholipidCTAB coated capillary $n=10$ 


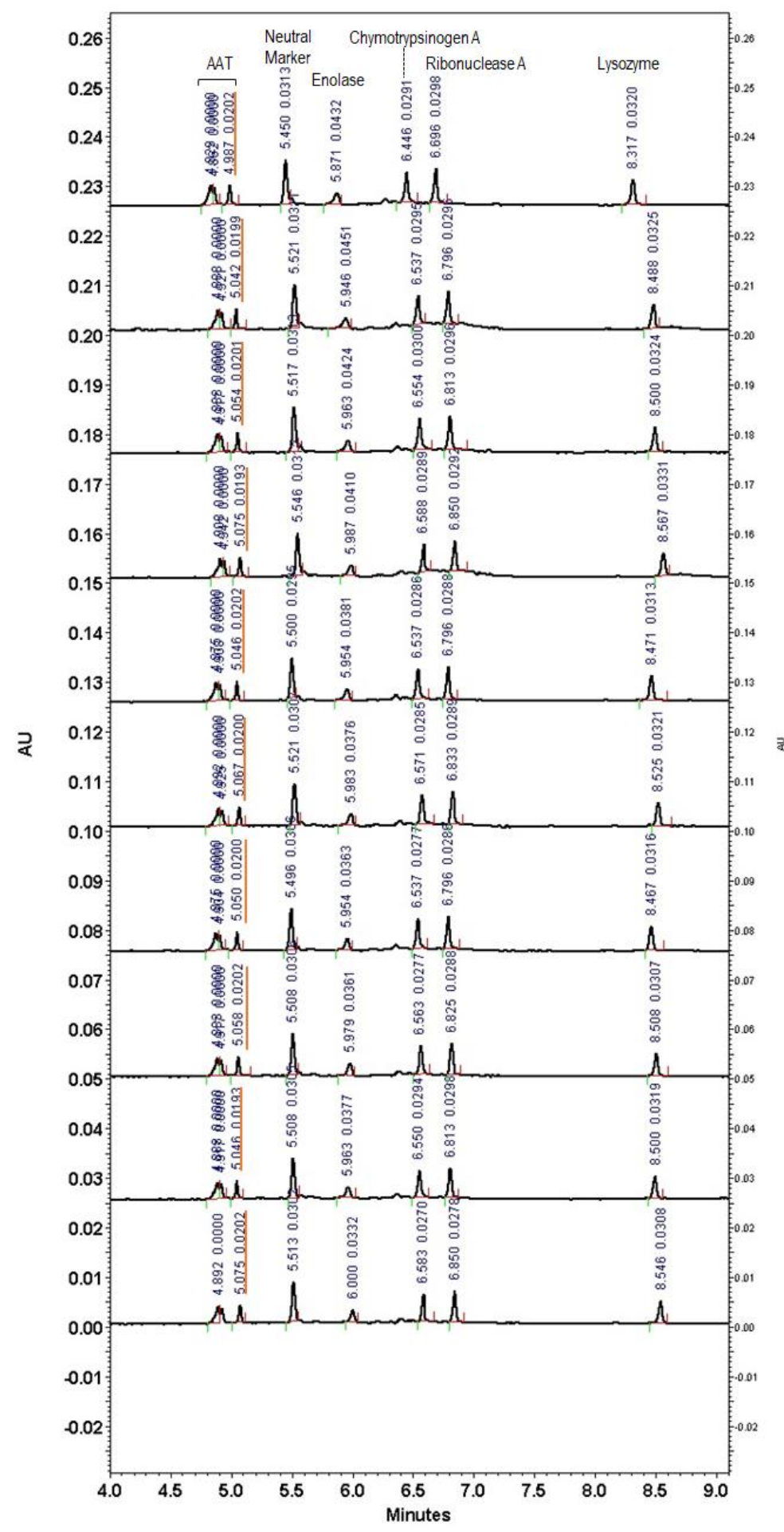

Figure A2-7. $\mathrm{pH} 5$ Separation of protein standards and neutral marker on phospholipidCTAB coated capillary $n=10$ 


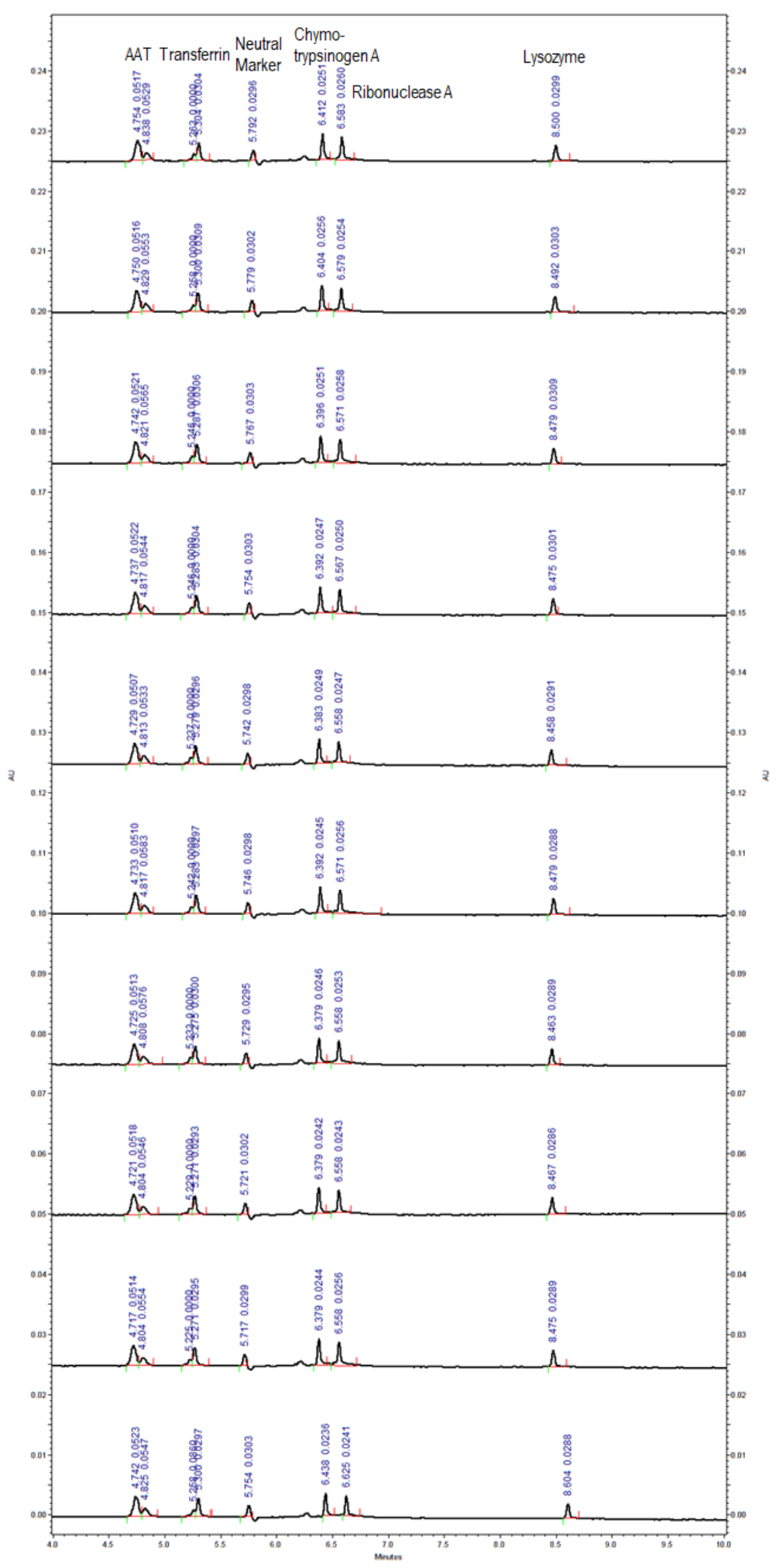

Figure A2-8. pH 6 Separation of protein standards and neutral marker on phospholipidCTAB coated capillary $n=10$ 


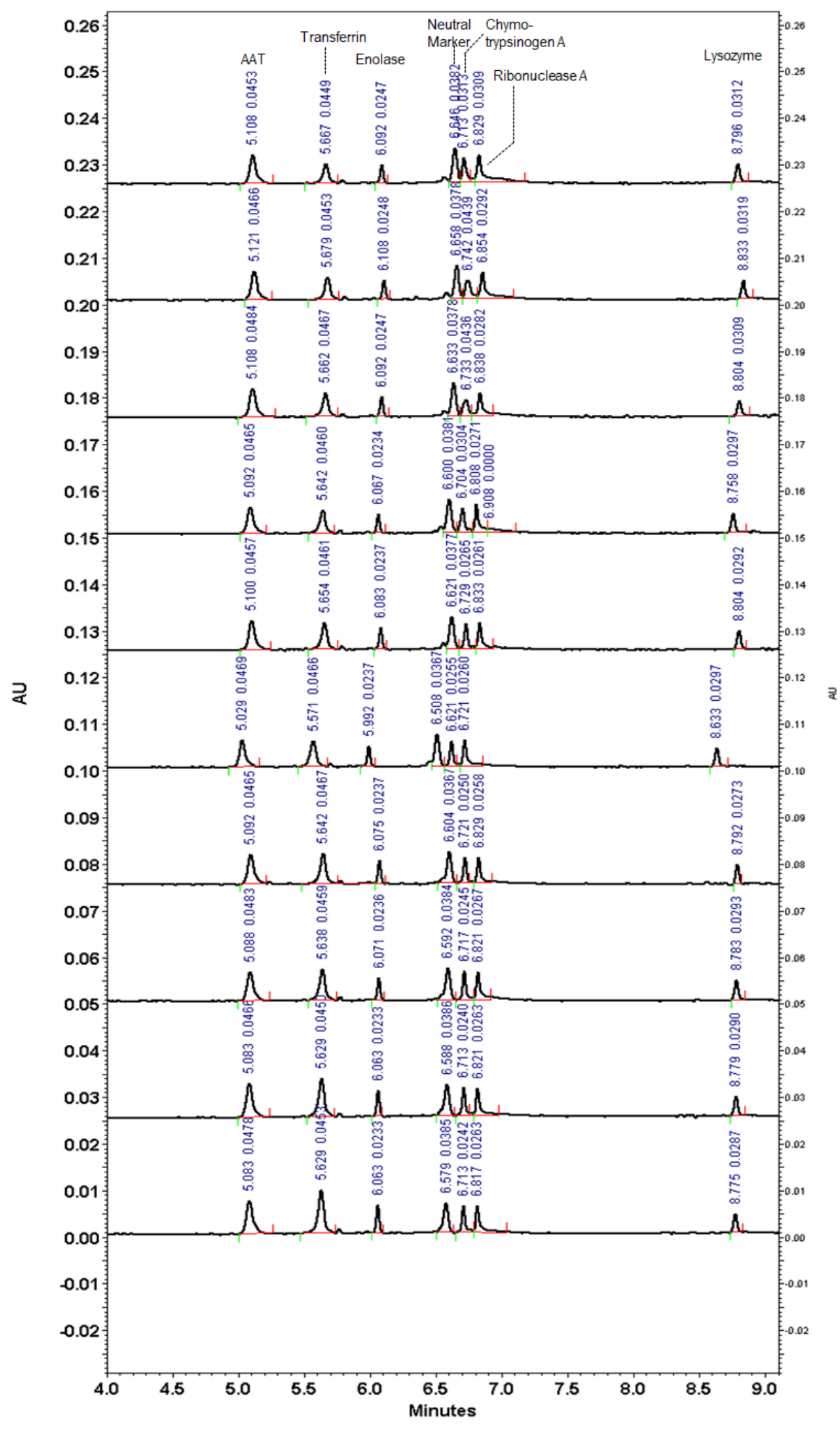

Figure A2-9. $\mathrm{pH} 7$ Separation of protein standards and neutral marker on phospholipidCTAB coated capillary $n=10$ 


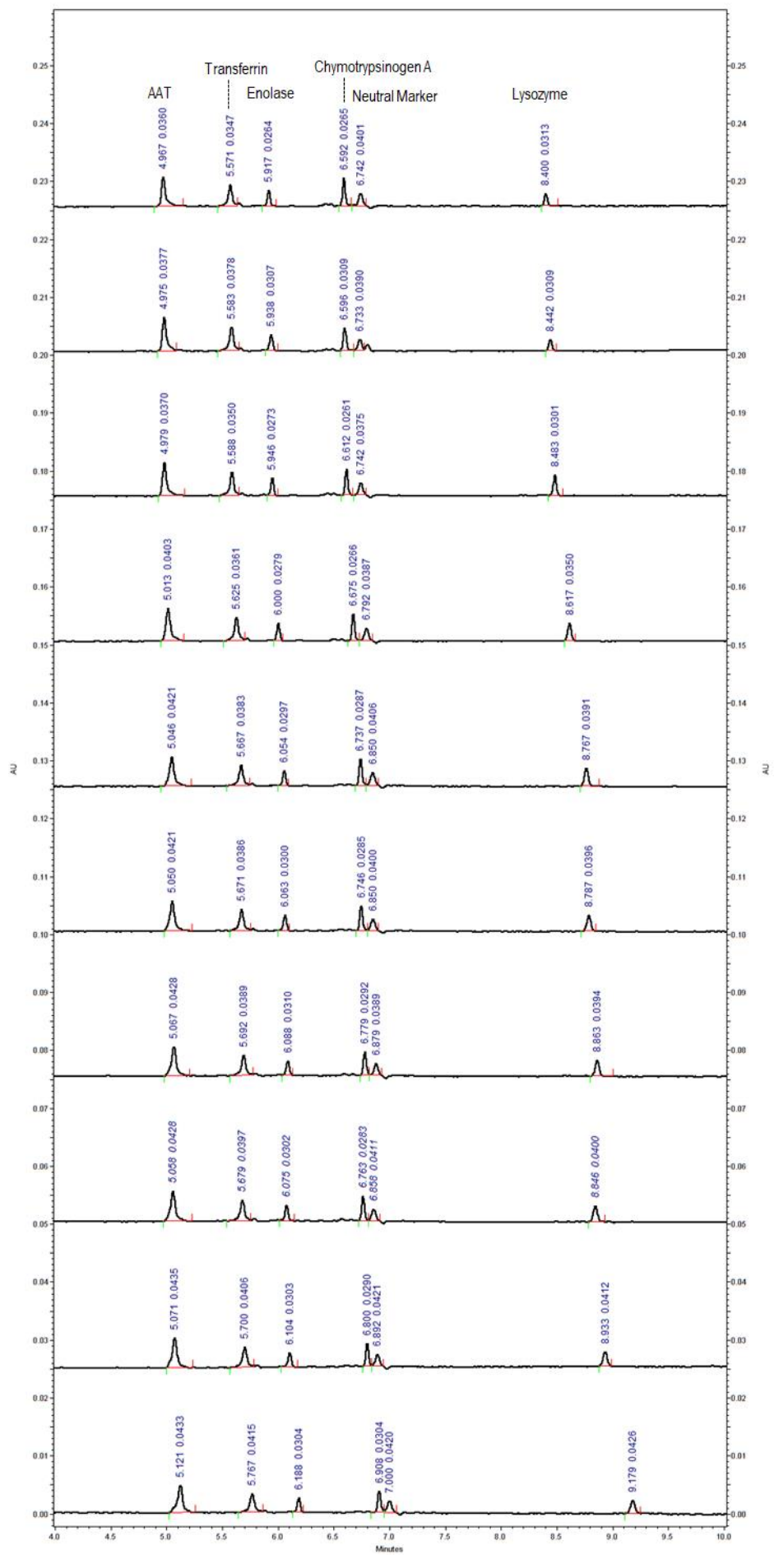

Figure A2-10. $\mathrm{pH} 8$ Separation of protein standards and neutral marker on phospholipid-CTAB coated capillary $n=10$ 


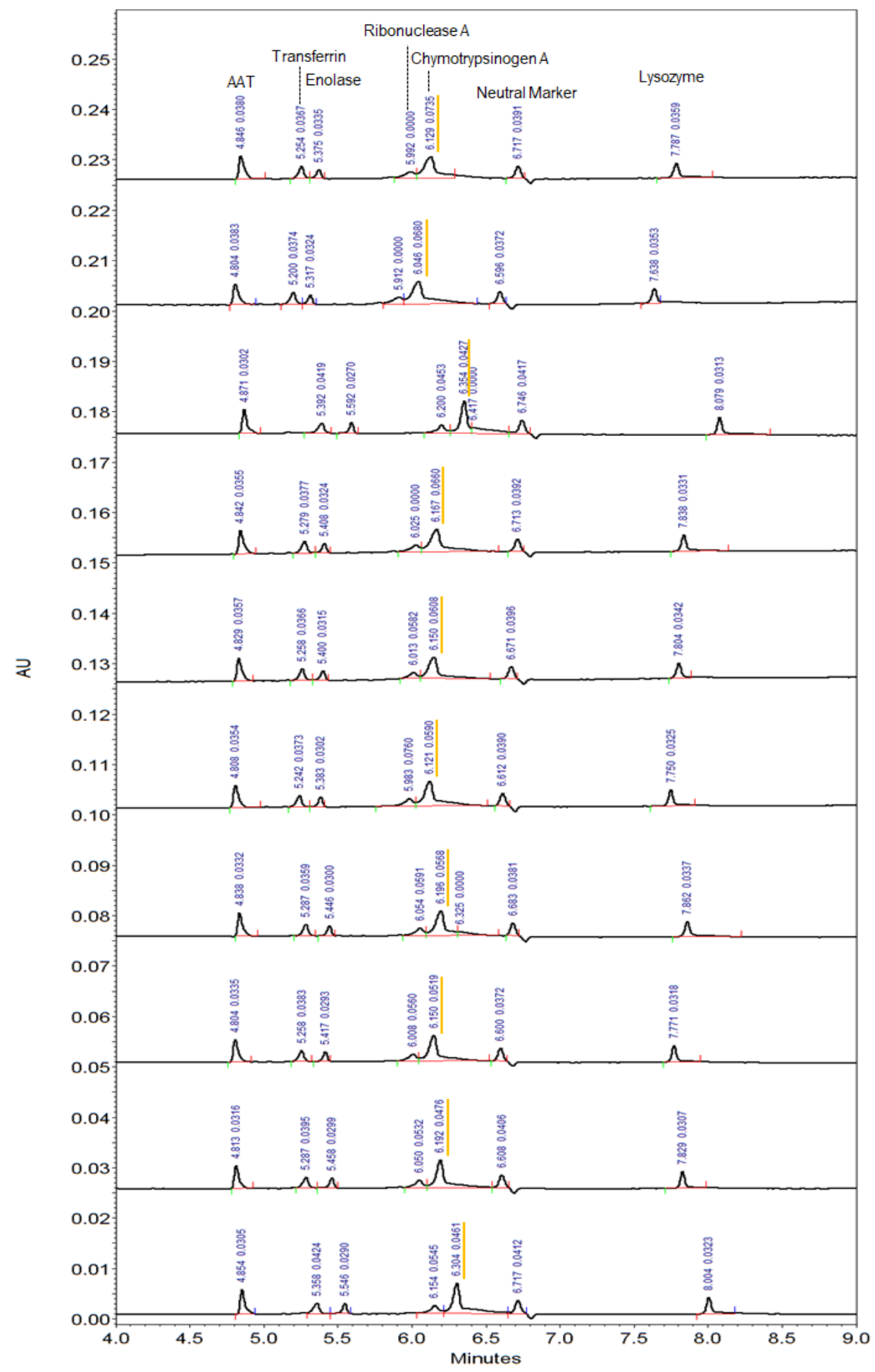

Figure A2-11. pH 9 CTAB raw data for plate count, eph mobility, and eof measurement 


\section{Appendix 3 Raw Data for Chapter 3}

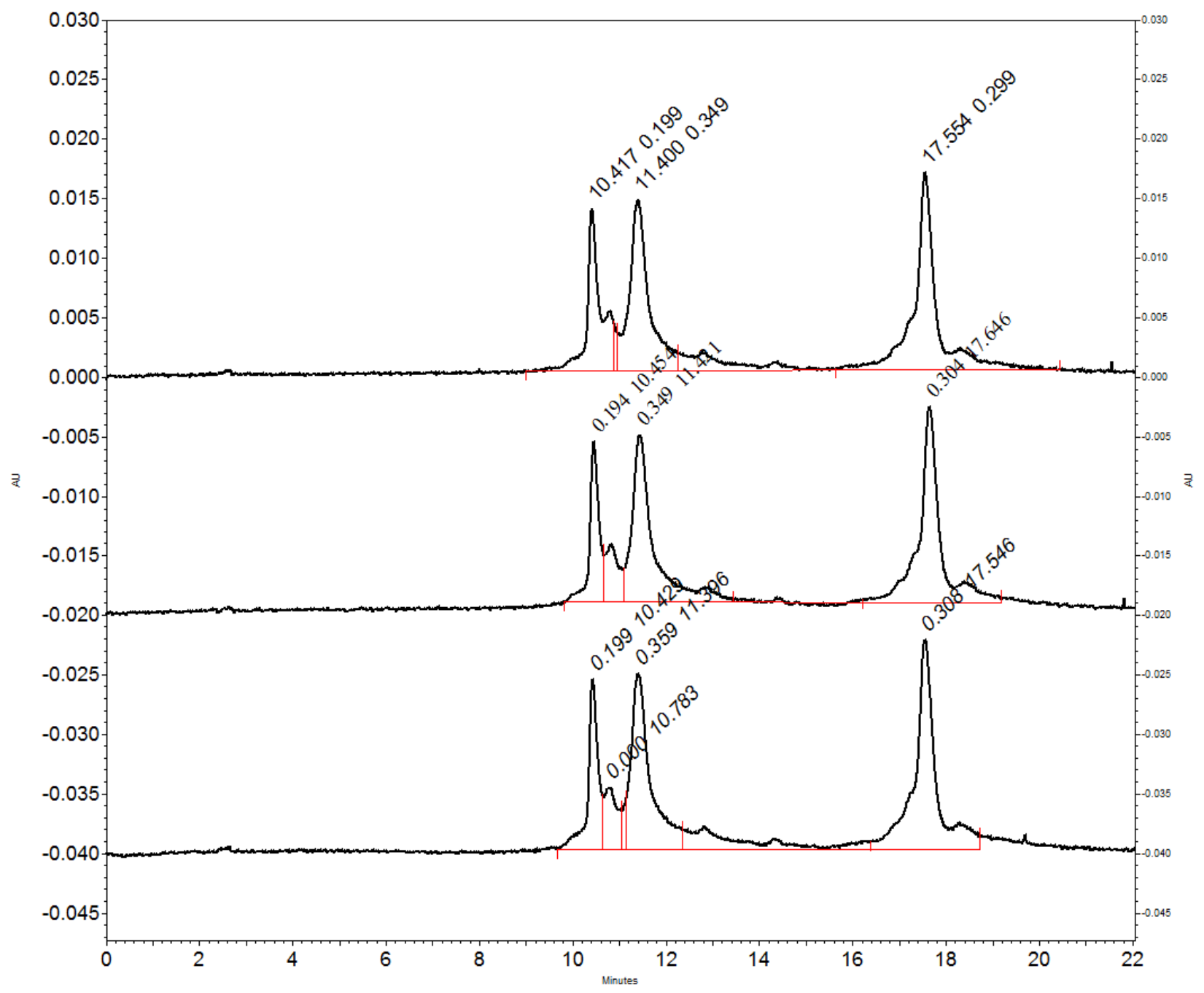

Figure A3-1. Non-sieving separation of trypsin inhibitior, alpha-1-antitrypsin, and transferring using a phospholipid coated capillary. 


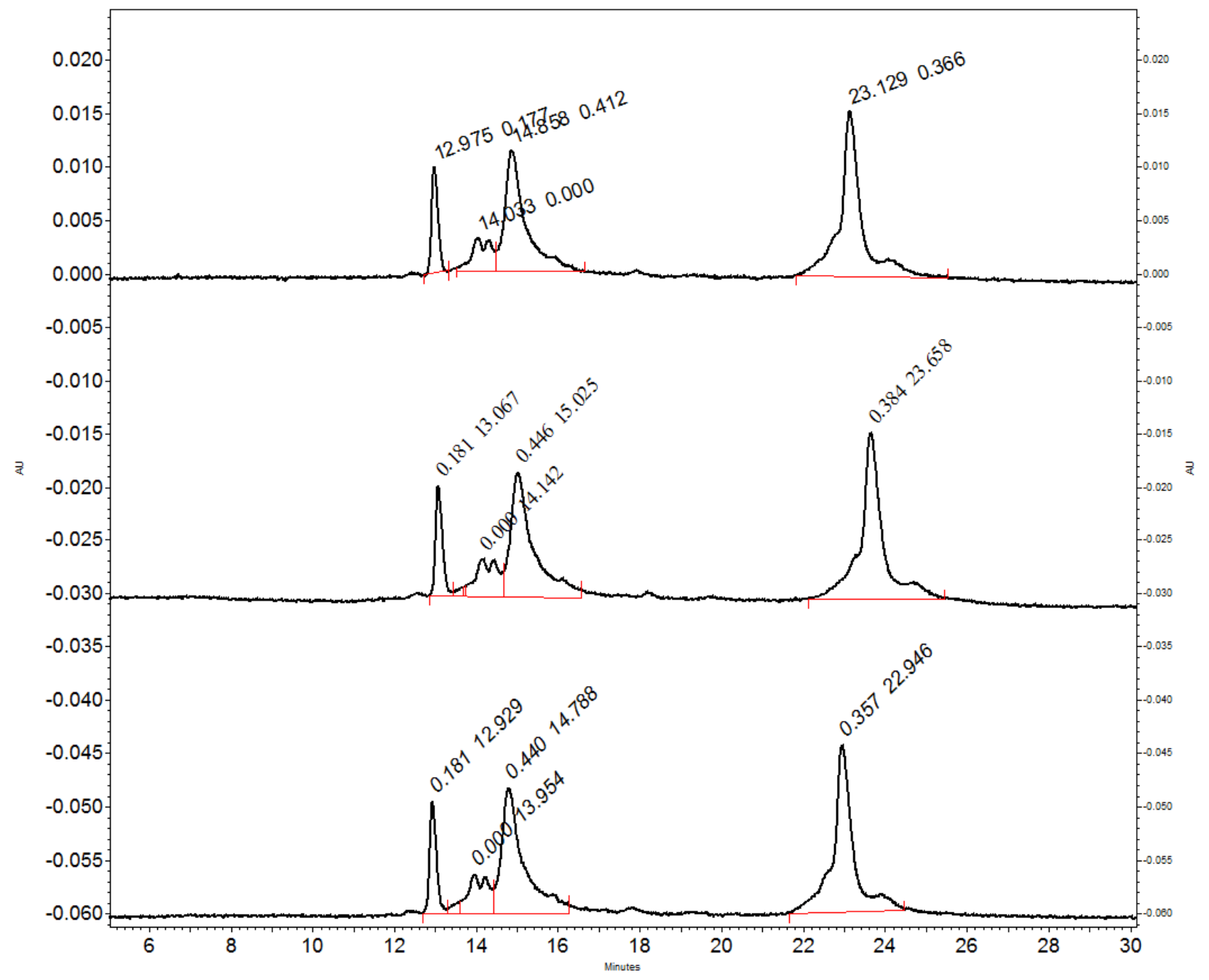

Figure A3-2. Separation of trypsin inhibitior, alpha-1-antitrypsin, and transferring using a phospholipid coated capillary and $10 \%$ nanogel. 


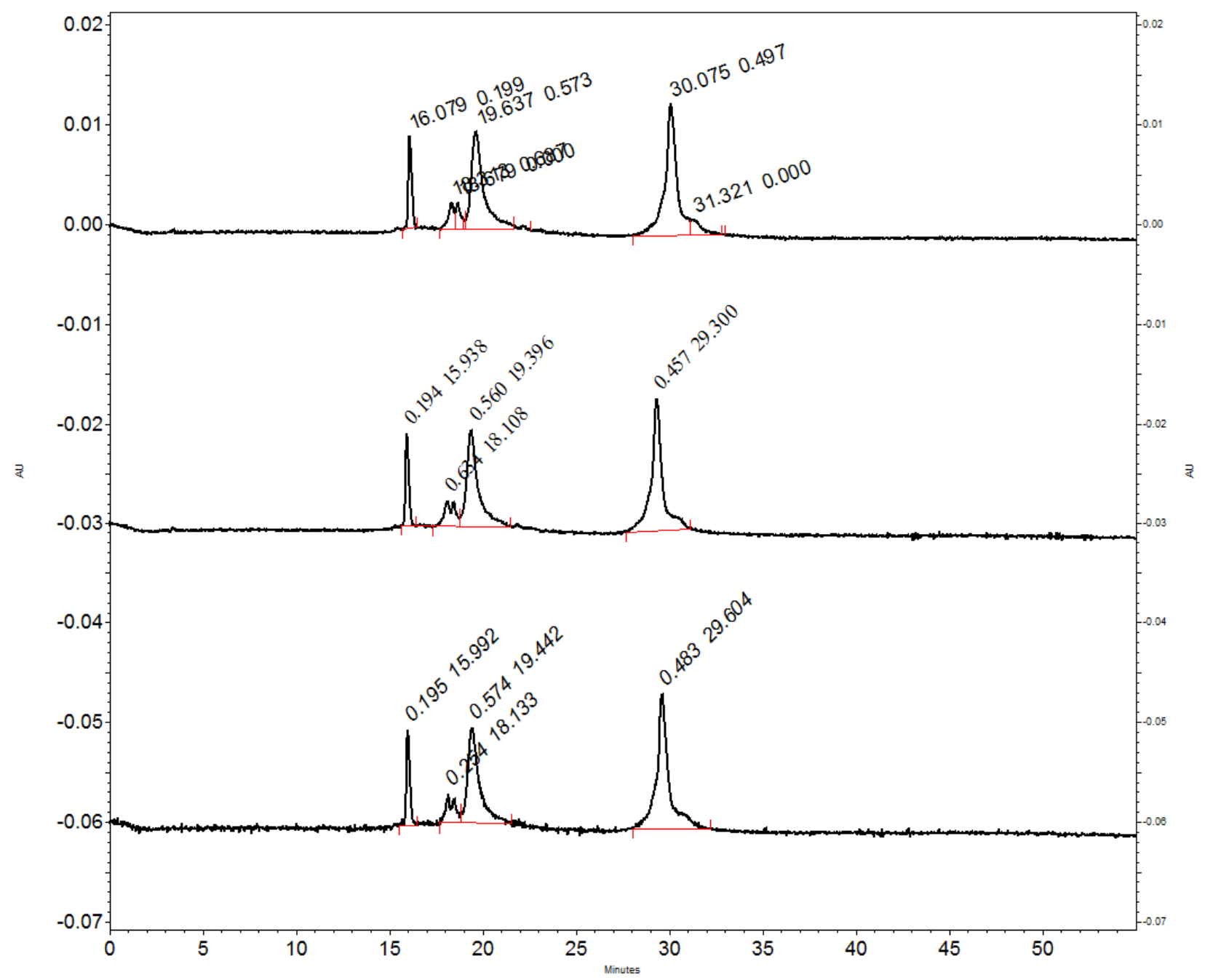

Figure A3-3. Separation of trypsin inhibitior, alpha-1-antitrypsin, and transferring using a phospholipid coated capillary and $20 \%$ nanogel. 


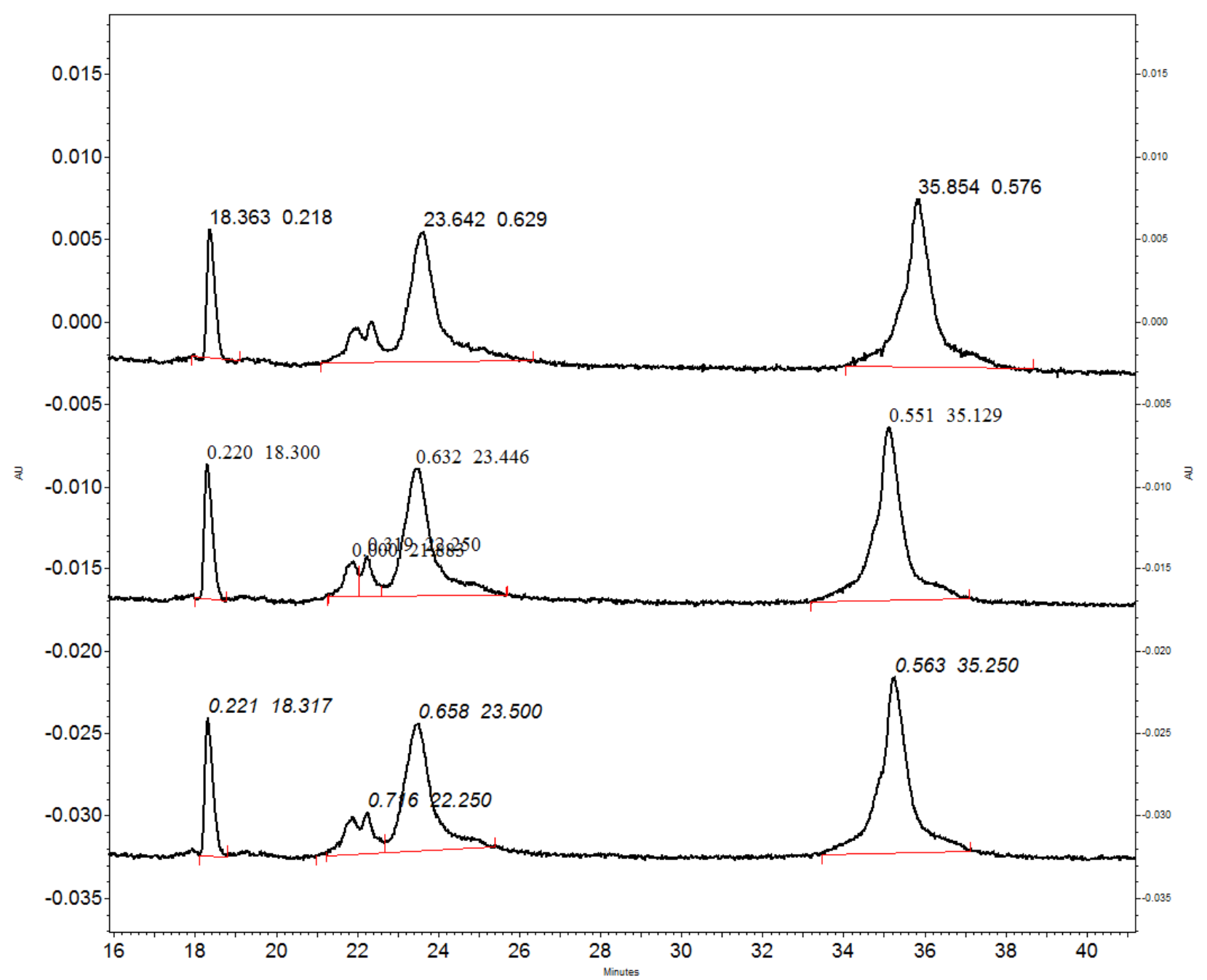

Figure A3-4. Separation of trypsin inhibitior, alpha-1-antitrypsin, and transferring using a phospholipid coated capillary and $25 \%$ nanogel. 


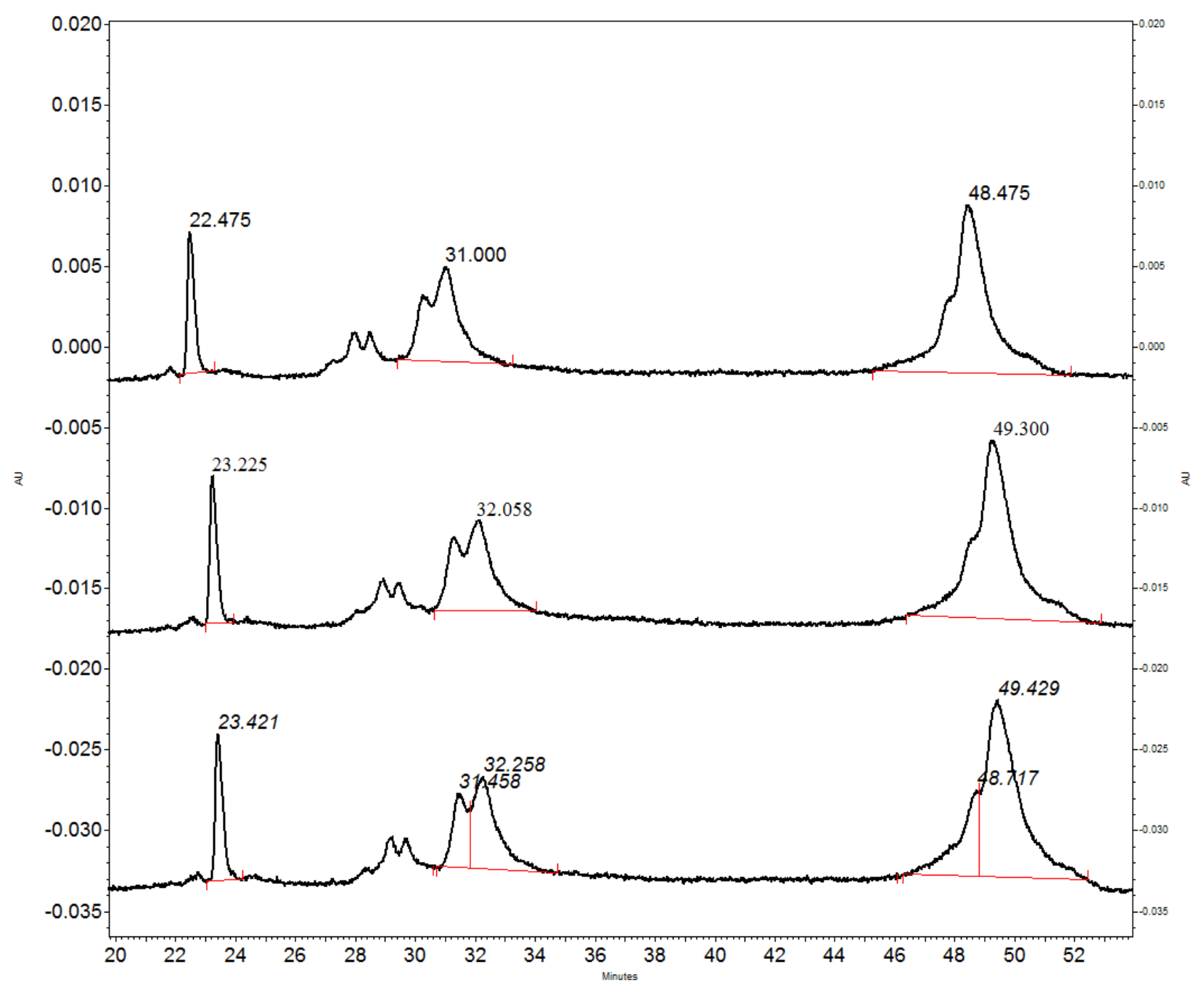

Figure A3-5. Separation of trypsin inhibitior, alpha-1-antitrypsin, and transferring using a phospholipid coated capillary and $30 \%$ nanogel. 


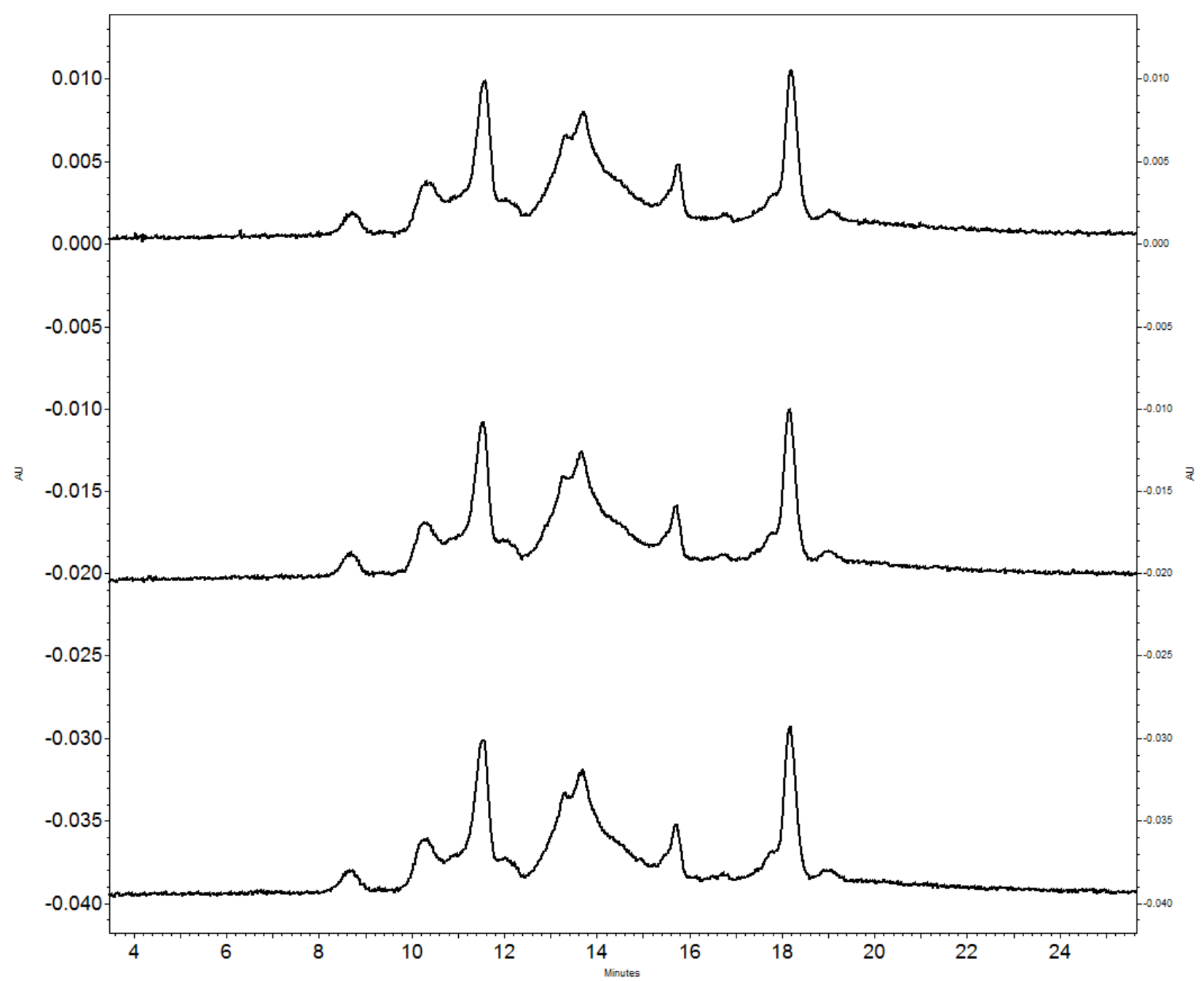

Figure A3-6. Separation of human serum proteins using a phospholipid coated capillary and no nanogel. 


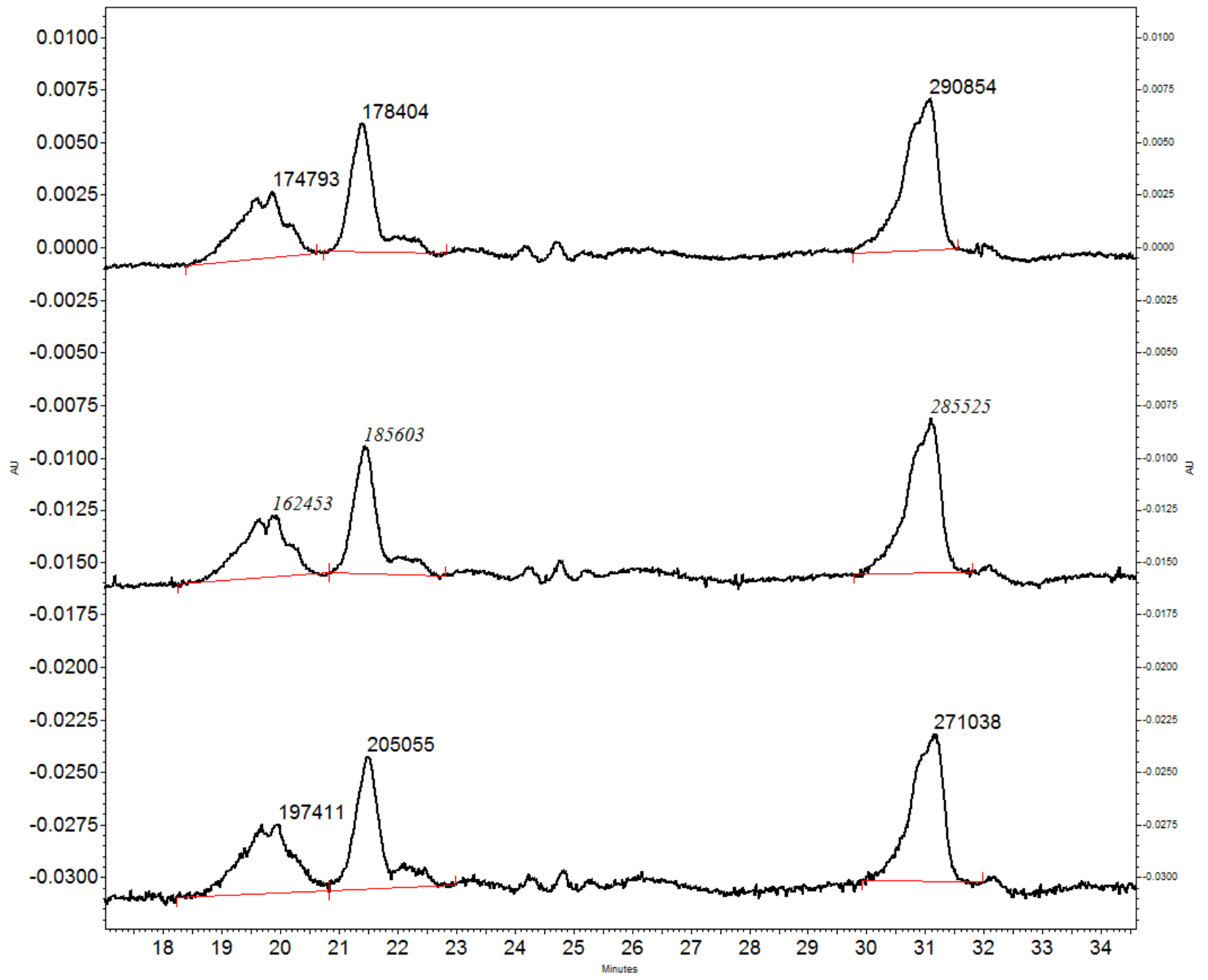

Figure A3-7. Separation of human serum proteins using a phospholipid coated capillary and $25 \%$ nanogel. 


\title{
Appendix 4 Curriculum Vitae
}

\author{
CASSANDRA CRIHFIELD \\ 304-215-8755 (Cell) | Cassandra.Crihfield@gmail.com
}

\section{EDUCATION}

West Virginia University, Morgantown, WV

2020

Ph.D. in Chemistry, Area of emphasis Analytical

Dissertation: Capillary Electrophoresis Analysis of Proteins

using Phospholipid Based Materials

Advisor: Dr. Lisa Holland

Wheeling Jesuit University, Wheeling, WV

2013

\section{B.S. in Chemistry}

Thesis: Slow scan investigation of cis-

dicarbonylbis(diorganodithiocarbamato) iron(II) complexes

Thesis passed "with Distinction"

\section{PUBLICATIONS}

Crihfield, C. L.; Kristoff, C. J.; Veltri, L. M.; Wilson, C. A.; Penny, W. M.; Holland, L.A., Data for Semi-permanent Cationic coating for protein separations. Data in Brief 2020, Volume 29.

Crihfield, C. L.; Kristoff, C. J.; Veltri, L. M.; Penny, W. M.; Holland, L.A., Semi-permanent Cationic coating for protein separations. Journal of Chromatography A 2019, 1407.

Gattu, S.; Crihfield, C. L.; Lu, G.; Bwanali, L.; Veltri, L. M.; Holland, L. A., Advances in enzyme substrate analysis with capillary electrophoresis. Methods 2018, 146 (15), 93-106.

Lu, G.; Crihfield, C. L.; Gattu, S.; Veltri, L. M.; Holland, L. A., Capillary electrophoresis separations of glycans. Chemical Reviews 2018, 118 (17), 7867-7885.

Holland, L. A.; Gattu, S.; Crihfield, C. L.; Bwanali, L., Capillary electrophoresis with stationary nanogel zones of galactosidase and Erythrina cristagalli lectin for the determination of beta(1,3)-linked galactose in glycans. Journal of Chromatography A 2017, 1523, 90-96.

Gattu, S.; Crihfield, C. L.; Holland, L. A., Microscale Measurements of Michaelis-Menten Constants of Neuraminidase with Nanogel Capillary Electrophoresis for the Determination of the Sialic Acid Linkage. Analytical Chemistry 2017, 89 (1), 929-936.

Durney, B. C.; Crihfield, C. L.; Holland, L. A., Capillary electrophoresis applied to DNA: determining and harnessing sequence and structure to advance bioanalyses (2009-2014). Analytical and Bioanalytical Chemistry 2015, 407 (23), 6923-6938.

Davis, T. A.; Athey, S. L.; Vandevender, M. L.; Crihfield, C. L.; Kolanko, C. C. E.; Shao, S.; Ellington, M. C. G.; Dicks, J. K.; Carver, J. S.; Holland, L. A., Electrolysis of Water in the 
Secondary School Science Laboratory with Inexpensive Microfluidics. Journal of Chemical Education 2015, 92 (1), 116-119.

Williams, R. M.; Crihfield, C. L.; Gattu, S.; Holland, L. A.; Sooter, L. J., In Vitro Selection of a Single-Stranded DNA Molecular Recognition Element against Atrazine. International Journal of Molecular Sciences 2014, 15 (8), 14332-14347.

Archer-Hartmann, S. A.; Crihfield, C. L.; Holland, L. A., Online enzymatic sequencing of glycans from Trastuzumab by phospholipid-assisted capillary electrophoresis.

Electrophoresis 2011, 32 (24), 3491-3498.

\section{PRESENTATIONS}

2020. Pittsburgh Conference on Analytical Chemistry and Applied Spectroscopy. Capillary Electrophoresis Separations of Cationic and Anionic Proteins Using A Cationic Coating. [oral presentation. Chicago, IL.

2019. CE in the Biotechnology and Pharmaceutical Industries. Capillary Electrophoresis Separations of Cationic and Anionic Proteins Using A Cationic Coating. [oral and poster presentation in Young Scientist award session] September 30. Washington D.C.

2019. Pittsburgh Conference on Analytical Chemistry and Applied Spectroscopy. Characterization of Protein Glycosylation with Capillary Nanogel Electrophoresis. [oral presentation] March 18. Philadelphia, PA.

2018. HPLC. Capillary Electrophoresis based Glycosylation Characterization with Phospholipid Nanogels. [poster presentation] July 30. Washington D.C.

2017. ACS National Conference. Nanogel assisted capillary electrophoresis separation of proteins. [oral presentation] August. Washington D.C.

2017. ACS National Conference. Electrolysis of water in the classroom using inexpensive microfluidics. [oral presentation] August. Washington D.C.

2016. Pittsburgh Conference on Analytical Chemistry and Applied Spectroscopy.

Microscale Separations of Proteins using a Phospholipid Nanogel. [poster presentation] March. Atlanta, GA.

2015. Pittsburgh Conference on Analytical Chemistry and Applied Spectroscopy. An Aptamer-Capillary Electrophoresis Method for the Detection of Atrazine. [oral presentation] March 12. New Orleans, LA.

2014. Pittsburgh Conference on AnalyticalChemistry and Applied Spectroscopy. Enzymatic characterization and enzymatic assay via phospholipid-assisted capillary electrophoresis. [oral presentation] March 6. Chicago, IL.

2013. Latin American Capillary Electrophoresis Conference. Phospholipid-assisted capillary electrophoresis for enzymatic characterization and assay. [poster presentation] December. 
Lima, Peru.

2013. ACS National Conference. Slow scan investication of cis-

dicarbanylbis(diorganodithiocarbamato)iron (II) complexes. [Poster Presentation] April 8.

New Orleans, LA.

\section{RESEARCH EXPERIENCE}

West Virginia University, Morgantown, WV

Graduate Research Assistant in the Chemistry Department

- Implementation and characterization of a stable cationic coating for high efficiency, low adsorption separations of cationic and anionic proteins in capillary electrophoresis

- Development and optimization of online enzyme and lectin reactions in capillary electrophoresis separations for sequencing the monomers and linkages in glycans relevant to biotherapeutics (Trastuzumab) and biomarkers

- Formulated fluorescent labeling protocols for protein and carbohydrate molecules

- Designed an aptamer-based detection assay for herbicide in river water

- Fabrication and implementation of PDMS and gelatin microfluidic devices as educational tools for personalized chemistry demonstrations

- Fluorospectrometer measurements of reactive oxygen species generation via copper oxide nanoparticles

- Fabricated glass microfluidic devices

- SEM analysis of fabricated nanopillar substrates working with an engineering research team

- Reviewed and aided in conceptualization of grants

- Mentored and trained 6 undergraduate students and 3 graduate students

Wheeling Jesuit University, Wheeling, WV

Undergraduate Researcher

- Synthesis and thermogravimetric analysis of iron dithiocarbamates to determine intermediates in thermal degradation and air stability

Kent State University, Morgantown, WV

REU researcher

- Fabricated microfluidic devices for the synthesis of porous silica spheres via double emulsion

- Developed protocols to synthesizes silica spheres to have desired pore density
June 2013 - Present
August 2010 - May 2013 
- Characterized silica spheres using scanning electron microscopy

West Virginia University, Morgantown, WV

NanoSAFE REU research

- Designed and executed experiments for electrophoresis separations of mannose ladders in microfluidic chips

- Manuscript preparation for research on sequencing Trastuzumab glycans

\section{SYNERGISTIC ACTIVITIES}

Executive Secretary for NASA grant proposal review panel

- Recorded minutes of grant proposals and summarized important points for the first reviewer

- Reviewed reviewer summaries to ensure completeness

Coordination of Science on Tap Series

- Invited scientists to present their research in a casual public setting, coordinated publicity for the events on social media and local newspapers and radio stations

Science Outreach for IGERT fellowship

- Presented IGERT sponsored workshops and activities focused on nanoscience demonstrations to support science literacy and excite next generation students at a wide range of venues including the WV state fair, Spark Imagination Center, Morgantown Children's Day, Expanding Your Horizons, and several others

WVU Summer Undergraduate Research Symposium Judge

- Judged posters in the nanoscience division of the symposium

\section{IGERT Innovation Challenge}

- Developed innovative products each summer and with the aid of the WVU Launch Lab and WVU library, carried the product through market research, patent searching, and prototyping

- Presented the product and a business plan to a panel of business executives

\section{TEACHING EXPERIENCE}

\section{Teaching Lab Assistant for Joseph Purpura and Mary Railing in Organic Chemistry Wheeling Jesuit University, Wheeling, WV}

- Prepared materials for labs, guided students through experiments, met with students on request, and graded written quizzes and homework for lecture

July 2018

Summer 2015-2017 


\section{AWARDS}

CEPharm Young Scientist Award

IGERT (Interdisciplinary Graduate Education and Research

Traineeship) Fellowship

NanoSAFE Fellowship

Haig Research Award Recipient
2019

August $2015-2019$

August $2013-2015$

May 2013

\section{SKILLS}

Capillary electrophoresis of small and large molecules, Capillary gel electrophoresis, Scanning electron microscopy (SEM), Microfluidic fabrication, Protein and purification, Glycan labeling and purification, Microsoft Powerpoint, Microsoft Word, Microsoft Publisher, ImageJ Processing, Leadership, Teamwork, Time management, Effective oral and written communication skills 